\title{
A Review on Biomass Densification \\ Technologies for Energy Application
}

Jaya Shankar Tumuluru

Christopher T. Wright

Kevin L. Kenny

J. Richard Hess

August 2010

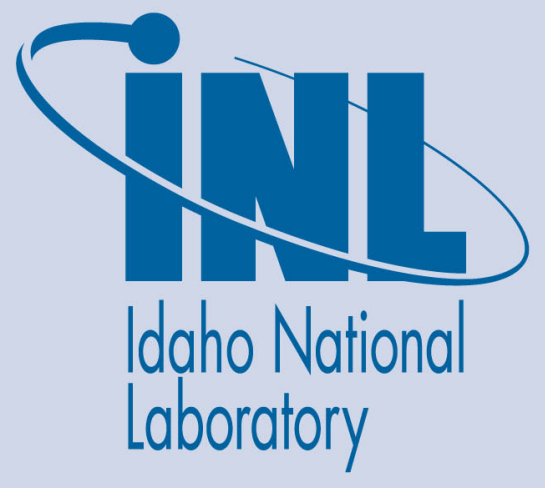

The INL is a U.S. Department of Energy National Laboratory operated by Battelle Energy Alliance 
INL/EXT-10-18420

\title{
A Review on Biomass Densification Technologies for Energy Application
}

\author{
Jaya Shankar Tumuluru \\ Christopher T. Wright \\ Kevin L. Kenny \\ J. Richard Hess
}

August 2010

\begin{abstract}
Idaho National Laboratory
Biofuels and Renewable Energy Technologies Department

Energy Systems and Technologies Division Idaho Falls, Idaho 83415

http://www.inl.qov
\end{abstract}

Prepared for the

U.S. Department of Energy

Assistant Secretary for Energy Efficiency and Renewable Energy

Under DOE Idaho Operations Office

Contract DE-AC07-05ID14517 


\section{DISCLAIMER}

This information was prepared as an account of work sponsored by an agency of the U.S. Government. Neither the U.S. Government nor any agency thereof, nor any of their employees, makes any warranty, expressed or implied, or assumes any legal liability or responsibility for the accuracy, completeness, or usefulness, of any information, apparatus, product, or process disclosed, or represents that its use would not infringe privately owned rights. References herein to any specific commercial product, process, or service by trade name, trademark, manufacturer, or otherwise, does not necessarily constitute or imply its endorsement, recommendation, or favoring by the U.S. Government or any agency thereof. The views and opinions of authors expressed herein do not necessarily state or reflect those of the U.S. Government or any agency thereof. 


\section{ABSTRACT}

It is generally acknowledged that burning fossil fuels and deforestation are major contributors to anthropogenic climate change. Biomass from plants can serve as an alternative renewable and carbon-neutral raw material for the production of energy. Low densities of $80-150 \mathrm{~kg} / \mathrm{m}^{3}$ for herbaceous and $150-200 \mathrm{~kg} / \mathrm{m}^{3}$ for woody biomass limit their application in energy production. Prior to cost-effective use in energy applications, these materials need to be densified to increase their bulk densities to help reduce technical limitations associated with storage, loading, and transportation. Pelleting, briquetting, or extrusion processing are methods commonly used to achieve densification. The aim of the present report is a comprehensive review of biomass processing, which includes densification technologies and specific energy consumption, biomass pretreatment methods, densification process modeling, and optimization. The specific objectives include:

1. Reviewing:

a. Mechanisms of particle bonding during densification

b. Densification technologies, including extrusion, briquetting, pelleting, and agglomeration

c. Specific energy requirements for densification

d. Effects of process and feedstock variables on quality attributes such as durability, bulk density, pellet density, and calorific value of densified biomass

e. Effects of preprocessing such as grinding, preheating, steam explosion, and torrefaction on biomass quality and binding characteristics

f. Some important physical quality attributes of densified biomass

g. Compaction models

h. Procedures for response surface modeling and optimization.

2. Existing International Solid Fuel Standards.

3. Identifying companies dealing with:

a. Densification equipment

b. Heat treatment technologies.

Some observations based on the present review are also made about the impact of particular technologies, such as a comparison between two widely used technologies for producing a densified biomass: the pellet mill and the briquette press. A briquette press is more flexible in terms of feedstock variables where higher moisture content and larger particles are acceptable for making good quality briquettes. Among the different densification systems, the screw press (involving both compression and pushing) consumes the most energy because it not only compresses but also shears and mixes the material, whereas a pellet mill or cubing machine consumes the least, depending on the material processed. Pretreatment technologies (i.e., preheating, grinding, steam explosion, torrefaction, and the AFEX process) can help to reduce specific energy consumption during densification and improve binding characteristics. Preheating biomass to temperatures of $100-130^{\circ} \mathrm{C}$, adjusting the moisture to $10-12 \%$, or a certain percentage of fine- to medium-size particles in the biomass mix also helps improve the degree of binding. Binding behavior can also be improved by adding natural or commercial binders, such as protein or lignosulphonates. Among the different 
densification models available on compaction, the Kawakita-Ludde model best describes the compression characteristics of agricultural biomass samples.

Experimental data analysis using both statistical methods like ANOVA and response surface methods and evolutionary algorithms like genetic algorithms or simulated annealing or particle swarm algorithms can help to better explain the complex densification process. Quality of the densified biomass for both domestic and international markets is evaluated using CEN (European Standard) or PFI (United States Standard). 


\section{CONTENTS}

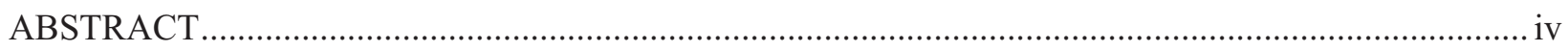

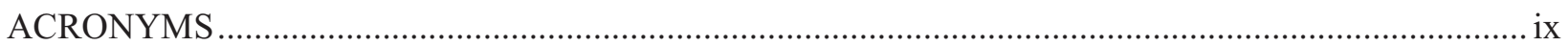

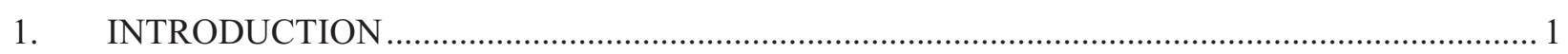

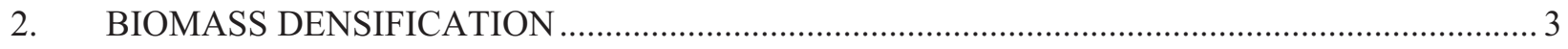

2.1 Mechanisms of Bonding of Particles ................................................................................. 3

2.1.1 Densification Technologies............................................................................... 5

2.1.2 Mechanical Densification Technologies................................................................. 10

2.1.3 Agglomeration ………………………………………………………. 15

2.2 Specific Energy Requirements.....................................................................................20

2.2.1 Densification .................................................................................................. 20

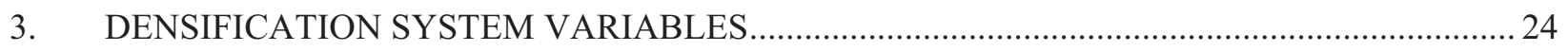

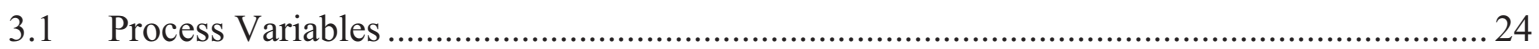

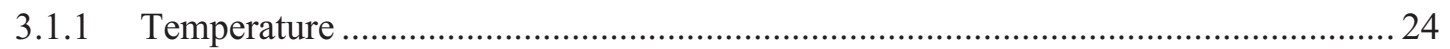

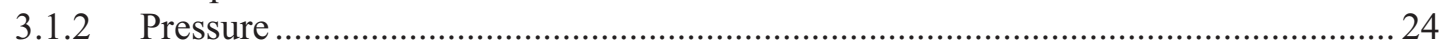

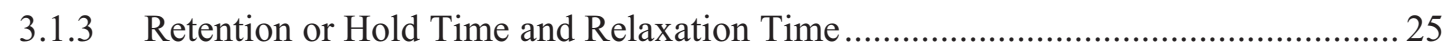

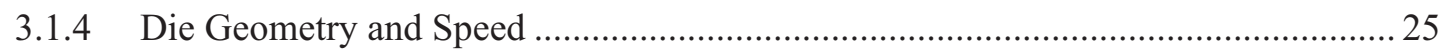

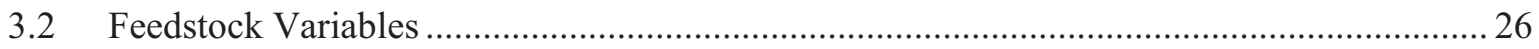

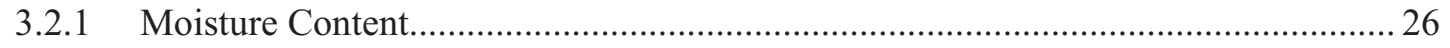

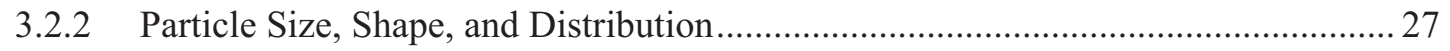

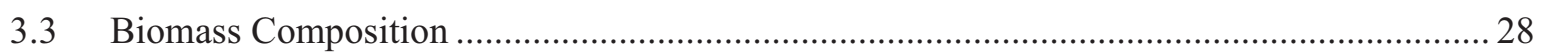

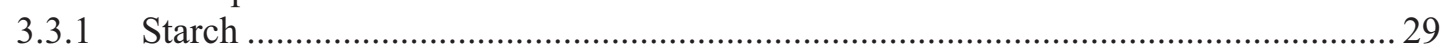

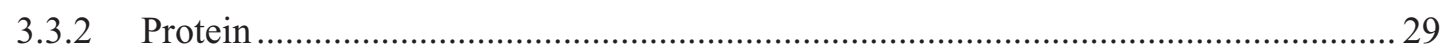

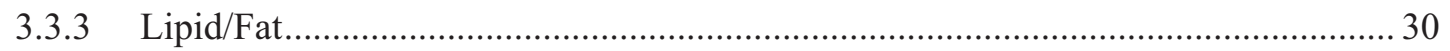

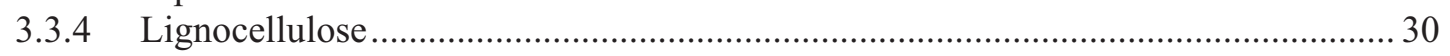

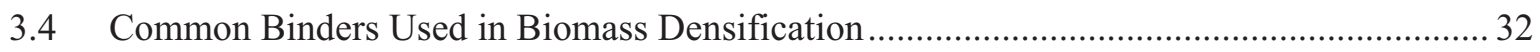

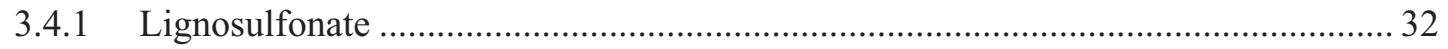

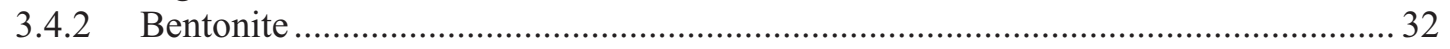

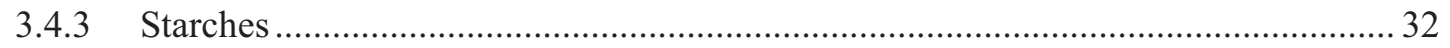

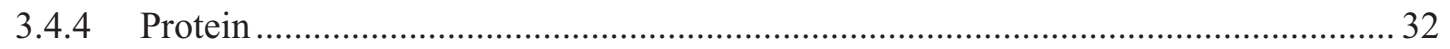

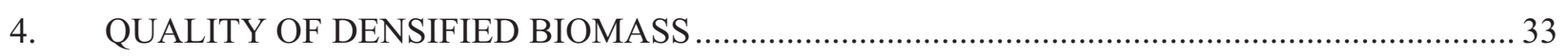

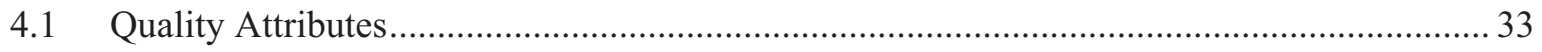

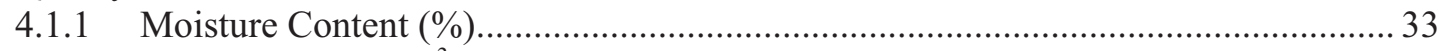

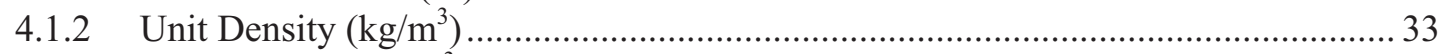

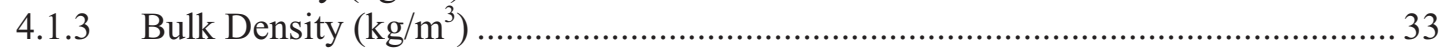

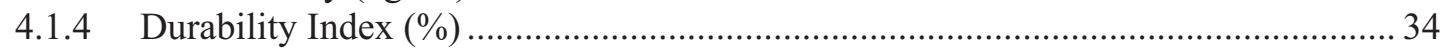

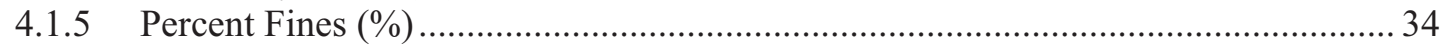

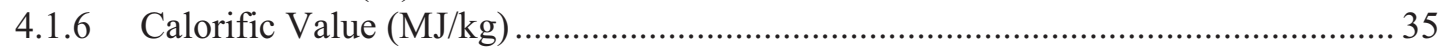

4.2 Pretreatment Technologies to Improve Quality Attributes ............................................... 35

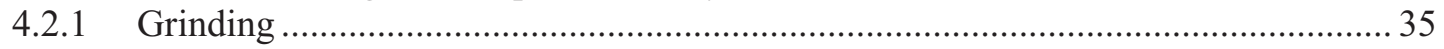

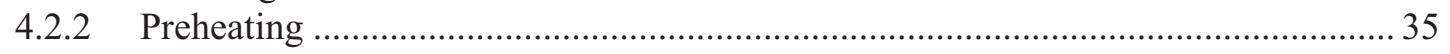

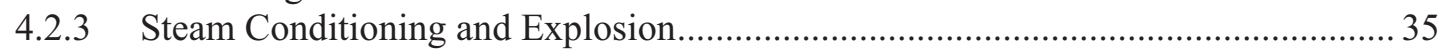

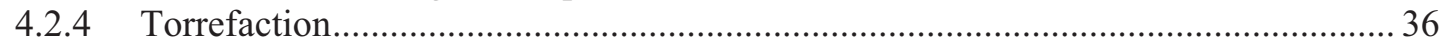

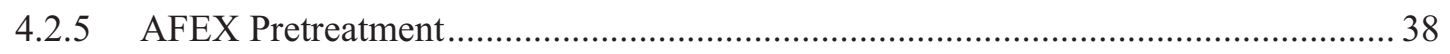




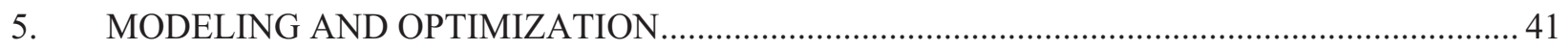

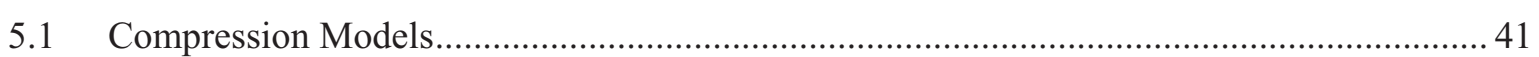

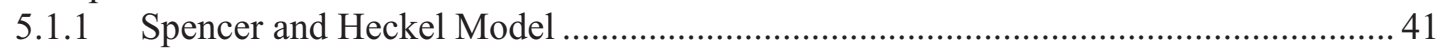

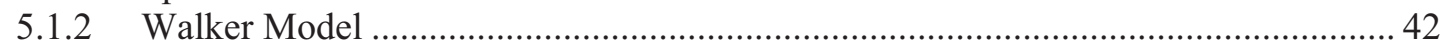

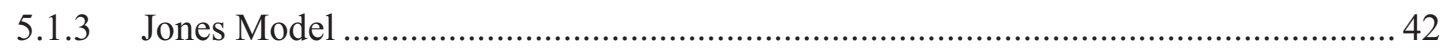

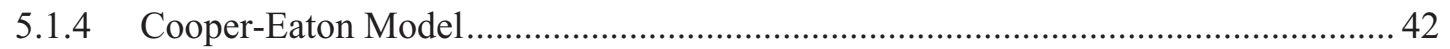

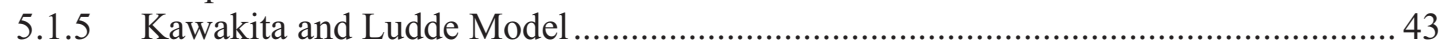

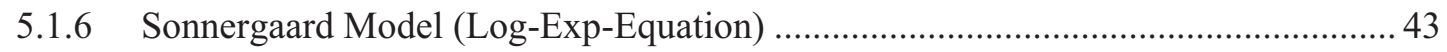

5.1.7 Panelli-Filho Model .......................................................................................... 44

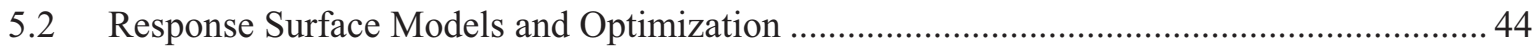

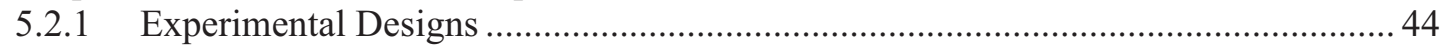

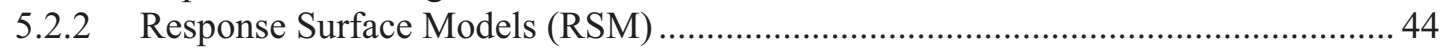

5.2.3 First-Order Models Analysis—Steepest Ascent or Descent Method ......................... 45

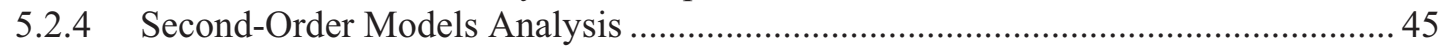

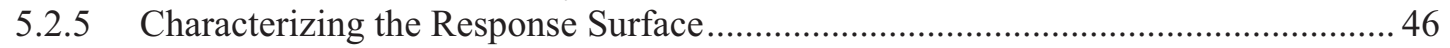

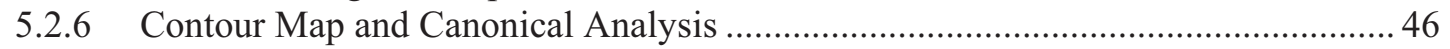

5.2.7 Optimization using Evolutionary Algorithms ....................................................... 47

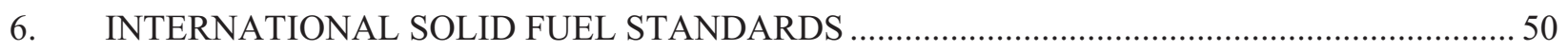

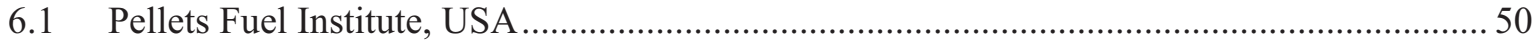

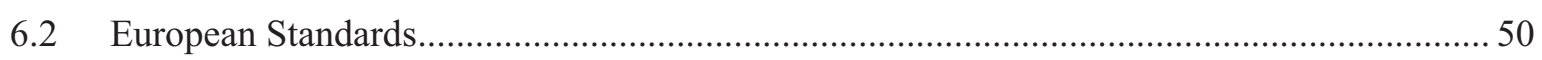

6.2.1 National Standards for Different Countries in Europe.......................................... 50

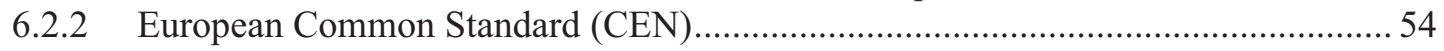

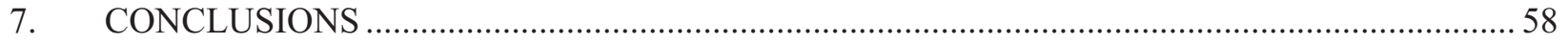

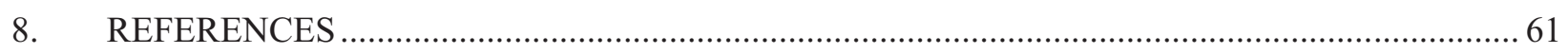

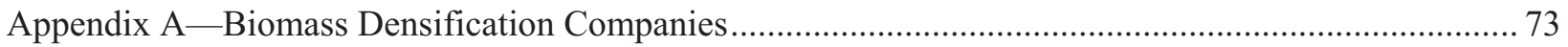

\section{FIGURES}

Figure 1. Deformation mechanisms of powder particles under compression ....................................... 5

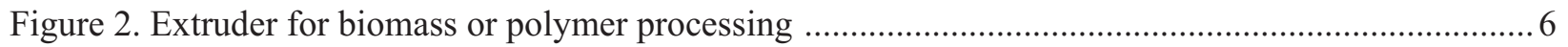

Figure 3. Heat logs produced using an extrusion press ........................................................................ 7

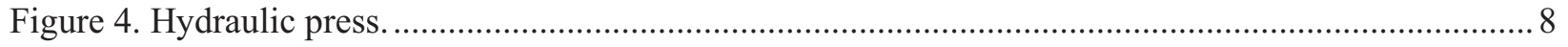

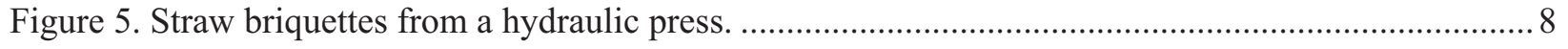

Figure 6. Energy tablet-making machine for biomass. ..................................................................... 9

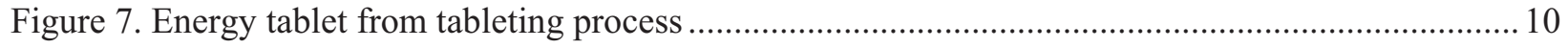

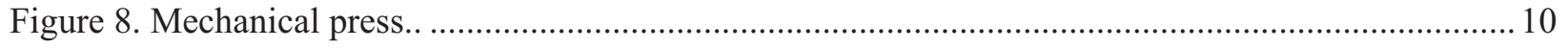

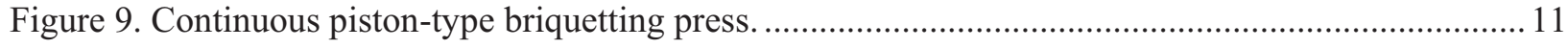

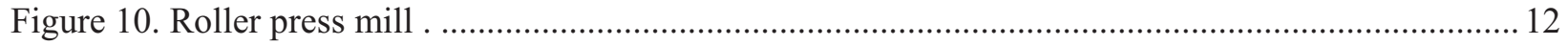

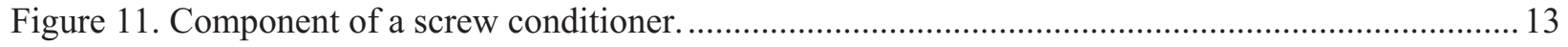

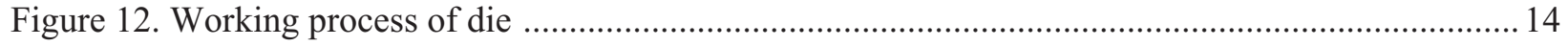

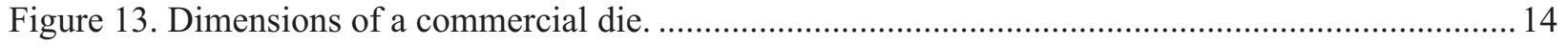




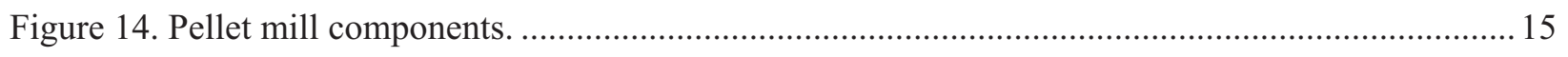

Figure 15. Position of granules or balls in a pan-shaped agglomerator. ................................................. 16

Figure 16. Agglomeration as a function of material properties and process parameters.......................... 17

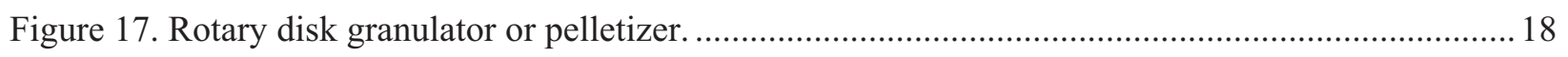

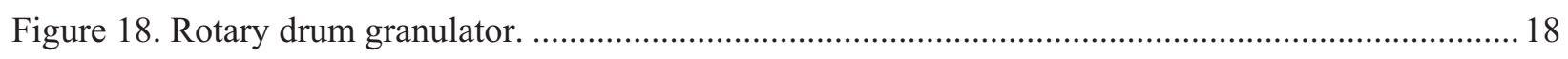

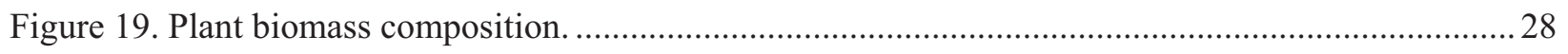

Figure 20. Arrangement of cellulose, hemicellulose, and lignin in biomass matrix................................. 31

Figure 21. Flow diagram for production of torrefied wood pellets......................................................... 37

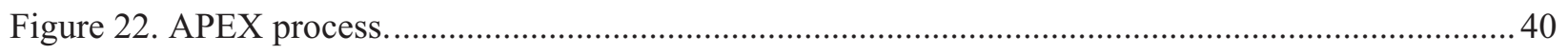

Figure 23. Flow diagram for GA-based algorithm for function optimization. ........................................ 48

Figure 24. Flow diagram for the densification data analysis using a combination of RSM and evolutionary algorithms.

\section{TABLES}

Table 1. General specification of extrudate produced by the Shimada SPMM 850 extrusion press........... 7

Table 2. Comparison of different densification equipments. .............................................................. 19

Table 3. Comparison of reported energy requirements for commercial densification apparatus

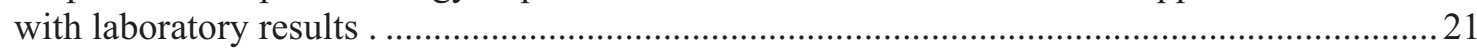

Table 4. Specific-energy consumption during extrusion of RDF. .......................................................2 22

Table 5. Specific energy consumption data for densification of different feedstocks ............................. 23

Table 6. Best particle size distribution for producing quality pellets from lignocellulosic biomass ......... 28

Table 7. Typical lignocellulosic content of some plant materials........................................................... 30

Table 8. Physical properties of wood chips, regular and torrefied pellets. ............................................... 38

Table 9. Ultimate analysis, HHV (dry ash free basis), and moisture content of untreated and

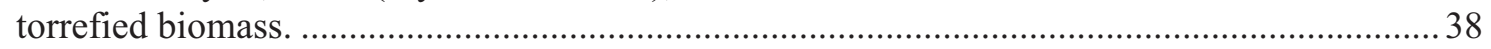

Table 10. Pellet Fuel Institute (PFI) standard specification for residential/commercial densified

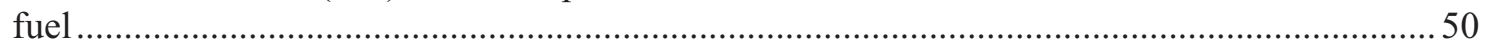

Table 11. General survey of limit values existing national standards for fuel pellets (Austria, Sweden, Germany and Italy) as well as national codes of good practice (UK) ........................ 52

Table 12. Classification of origin and sources of woody biomass according CEN ................................5 54

Table 13. Major traded forms of solid biofuels according to European Standard (CEN) ........................55

Table 14. Technical specifications for pellets according to European Standard (CEN) Table 15. Technical specifications of properties for briquettes according to European Standard $(\mathrm{CEN})$ 


\section{ACRONYMS}

ACO ant colony algorithm

ASTM American Society for Testing and Materials

CDM clean development mechanism

CEN Committee for European Standardization

DDGS distiller's dried grains with solubles

DTI Department of Trade and Industry

GA genetic algorithm

GHG greenhouse gas

HHV higher heating value

HTST high-temperature/short-time device

ITEBE International Association for Bioenergy Professionals

L/D length/diameter

LHV lower heating value

Mtoe million tons of oil equivalent

NSP non-starch polysaccharides

$\mathrm{O} / \mathrm{C} \quad$ oxygen to hydrogen ratio

$\mathrm{OH} \quad$ hydroxyl group

PDI Pellet Durability Index

PFI Pellet Fuel Institute

PSO particle swarm algorithm

QA Quality Assurance

QC Quality Control

RDF refuse-derived fuel

RSM response surface methodology

SA simulated annealing

SD standard deviation

TOP torrefaction and pelletization

tph tons per hour

TS tabu search

UK United Kingdom

w.b. wet basis 


\section{A Review on Biomass Densification for Energy Application}

\section{INTRODUCTION}

Behind coal and oil, biomass is the third largest energy resource in the world (Bapat et al. 1997). Until the mid-19th century, biomass dominated global energy consumption. Even though increased fossil-fuel use has prompted a reduction in biomass consumption for energy purposes over the past 50 years, biomass still provides about 1.25 billion tons of oil equivalent (Btoe) or about $14 \%$ of the world's annual energy consumption (Purohit et al. 2006; Werther et al. 2000; and Zeng et al. 2007). Out of the 230 exajoules of estimated global primary energy, 56 exajoules-nearly one-fourth of the global primary energy - are used for agricultural practices (WEC 1994). Wood fuels, agricultural straws, and grasses are the most prominent biomass energy sources. Biomass, if properly managed, offers many advantages, the most important being a renewable and sustainable energy feedstock. It can significantly reduce net carbon emissions when compared to fossil fuels. For this reason, renewable and sustainable fuel is considered a clean development mechanism (CDM) for reducing greenhouse gas (GHG) emissions ( $\mathrm{Li}$ and Hu 2003).

The least-expensive biomass resources are the waste products from wood or agro-processing operations, but their supply is limited. To overcome this limitation, countries around the world are considering biomass crops for energy purposes and have begun developing technologies to use biomass more efficiently. In the United States (U.S.) and most of Europe, biomass has already penetrated the energy market. The U.S. and Sweden obtain about $4 \%$ and $13 \%$ of their energy, respectively, from biomass (Hall et al. 1992), and Sweden is implementing initiatives to phase out nuclear plants, reduce fossil-fuel energy usage, and increase the use of biomass energy (Björheden 2006).

One of the major limitations of biomass for energy purposes is its low bulk density, typically ranging from $80-100 \mathrm{~kg} / \mathrm{m}^{3}$ for agricultural straws and grasses and $150-200 \mathrm{~kg} / \mathrm{m}^{3}$ for woody biomass, like wood chips (Sokhansanj and Fenton 2006; Mitchell et al. 2007). The low bulk densities of biomass often make the material difficult to store, transport, and use. Low bulk density also presents challenges for technologies such as coal cofiring, because the bulk density difference causes difficulties in feeding the fuel into the boiler and reduces burning efficiencies. Densification is one promising option for overcoming these limitations. During densification, biomass is mechanically compressed, increasing its density about ten fold. Commercially, densification of biomass is performed using pellet mills, other extrusion processes, briquetting presses, or roller presses in order to help overcome feeding, storing, handling, and transport problems.

Densification technologies available today have been developed for other enterprises and are not optimized for a biomass-to-energy industry's supply system logistics or a conversion facility's feedstock specifications requirements. This document provides a comprehensive review of the current state of technology in biomass densification research and development and provides parameters for optimization. Densification processes and technologies are described along with the impacts of process and feedstock variables and biochemical composition of the biomass on feedstock quality attributes like durability, bulk density, pellet density, and caloric value. This review includes compaction and response surface models and a discussion of optimization procedures. A review of international solid fuel standards and an introduction of companies dealing with densification equipment and heat treatment technologies are also included. 
The specific objectives of this review include:

- Technical reviews:

- Mechanisms of particle bonding during densification

- Densification technologies, including extrusion, briquetting, pelleting, and agglomeration

- Specific energy requirements of pellet mill, briquette press, and extruder

- Effects of process, feedstock variables, and biomass biochemical composition on the densification process

- Important quality attributes of densified biomass

- Effects of pretreatments such as grinding, preheating, steam explosion, torrefaction, and ammonia fiber expansion (AFEX) on biomass quality

- Compaction models

- $\quad$ Procedures for response surface modeling and optimization.

- International solid fuel standards.

- Equipment suppliers:

- Densification equipment

- Heat treatment technologies. 


\section{BIOMASS DENSIFICATION}

Biomass - in its original form - is difficult to successfully use as a fuel in large-scale applications because it is bulky, wet, and dispersed. Biomass densification represents technologies for converting plant residues into fuel. These technologies are also known as pelleting, briquetting, or agglomeration, which improves the handling characteristics of the materials for transport, storage, etc. Pelleting and briquetting have been applied for many years in several countries. William Smith was the first to be issued a United States patent (1880) for biomass densification. Using a steam hammer (at $66^{\circ} \mathrm{C}\left[150^{\circ} \mathrm{F}\right]$ ), Smith compacted waste from sawmills.

Conventional processes for biomass densification can be classified into baling, pelletization, extrusion, and briquetting, which are carried out using a bailer, pelletizer, screw press, piston or a roller press. Pelletization and briquetting are the most common processes used for biomass densification for solid fuel applications. These high-pressure compaction technologies, also called "binderless" technologies, are usually carried out using either a screw press or a piston press (Sokhansanj et al. 2005). In a screw press, the biomass is extruded continuously through a heated, tapered die. The briquette quality and production process of a screw press are superior to piston press technology. However, comparing wear of parts in a piston press, like a ram and die, to wear observed in a screw press shows that the screw press parts require more maintenance. The central hole incorporated into the densified logs produced by a screw press helps achieve uniform and efficient combustion, and the resulting logs can be carbonized more quickly due to better heat transfer.

Many researchers have worked on the densification of herbaceous and woody biomass using pellet mills and screw/piston presses. For instance, Tabil and Sokhansanj (1996) worked on understanding the compression characteristics of alfalfa pellets. Ndiema et al. (2002) examined the influence of die pressure on relaxation characteristics of briquetted biomass. Adapa et al. (2002b and 2003) studied pelleting fractionated alfalfa products. Li and Liu (2000) investigated high-pressure densification of wood residues to form an upgraded fuel. Mani et al. (2006) researched the compaction characteristics of lignocellulosic biomass using an Instron, and Tumuluru et al. (2010a) studied the effect of pelleting process variables on the quality attributes of a wheat distiller's dried grains with solubles.

\subsection{Mechanisms of Bonding of Particles}

The quality of the densified biomass depends on a number of process variables, like die diameter, die temperature, pressure, usage of binders, and preheating of the biomass mix. Tabil (1996) and Tabil and Sokhansanj (1996b and c) suggest that the compaction of the biomass during pelletization can be attributed to elastic and plastic deformation of the particles at higher pressures. According to their study, the two important aspects to be considered during pelletization are (1) the ability of the particles to form pellets with considerable mechanical strength; and (2) the ability of the process to increase density. The first is a fundamental behavior issue that details which type of bonding or interlocking mechanism results in better densified biomass.

The possible mechanism of binding during agglomeration could be due to the formation of solid bridges (Rumpf 1962; Sastry and Fuerstenau 1973). During compaction, solid bridges are developed by chemical reactions and sintering, hardening of the binder, solidification of the melted substances, or crystallization of the dissolved materials. The pressure applied during densification also reduces the melting point of the particles and causes them to move towards one another, thereby increasing the contact area and changing the melting point to a new equilibrium level (York and Pilpel 1972; Pietsch 1984). 
The presence of liquid-like water during pelletization results in interfacial forces and capillary pressures, thus increasing particle bonding. The models that are commonly used to describe the liquid distribution in moist agglomerates are pendular, funicular, capillary, and liquid-droplet states (Sastry and Fuerstenau 1973; Pietsch 1984; Ghebre-Sellassie 1989). The pendular state arises when the void spaces are filled with liquid to form lens-like rings at the point of contact; the air forms a continuous phase. The bond strength is due to negative capillary pressure and surface tension of the liquid. The funicular state occurs when the liquid content is increased, which results in lower pore volume and coalescence of the liquid rings, and in the formation of a continuous network and trapping of the air phase. In the capillary and droplet state, the agglomerate is completely enveloped by the liquid, and the primary particles are held only by the surface tension of the droplet.

The attraction between the particles is due to van der Waal's electrostatic or magnetic forces (Schineberger 1971). The attraction is inversely proportional to the distance between the particles, where larger distances have less attraction. Electrostatic forces' influence on particle bonding is negligible, and these are commonly encountered in dry fine powders where inter-particle friction can also contribute to particle bonding when magnetic forces exist (Sherrington and Oliver 1981). Closed bonds or interlocking occurs in fibers, platelets, and bulk particles, where particles interlock or fold about each other, thereby causing the bonding (Pietsch 1984). Interlocking of the particles can help provide sufficient mechanical strength to overcome the destructive forces caused by elastic recovery after compression (Rumpf 1962).

Mani et al. (2002) postulated that there are three stages during densification of biomass. In the first stage, particles rearrange themselves to form a closely packed mass where most of the particles retain their properties and the energy is dissipated due to inter-particle and particle-to-wall friction. In the second stage, the particles are forced against each other and undergo plastic and elastic deformation, which increases the inter-particle contact significantly; particles become bonded through van der Waal's electrostatic forces. In the third phase, a significant reduction in volume at higher pressures results in the density of the pellet reaching the true density of the component ingredients.

By the end of the third stage, the deformed and broken particles can no longer change positions due to a decreased number of cavities and a 70\% inter-particle conformity. It is important to understand the densification process and the variables that govern its performance, such as the combination of temperature, pressure, and equipment. If not optimized or at least carefully controlled, these variables can influence the intra-particle cavities of the biomass and have a serious negative effect on conversion processes like enzymatic hydrolysis. It is also important to understand that the yield point of the material governs the rate of approach to the true density of the product. Because the loading is hydrostatic in character, the application of pressure will fracture the brittle particles. These processes may result in mechanical interlocking. Figure 1 shows the deformation mechanism of the powder particles under compression (Comoglu 2007; Denny 2002). 


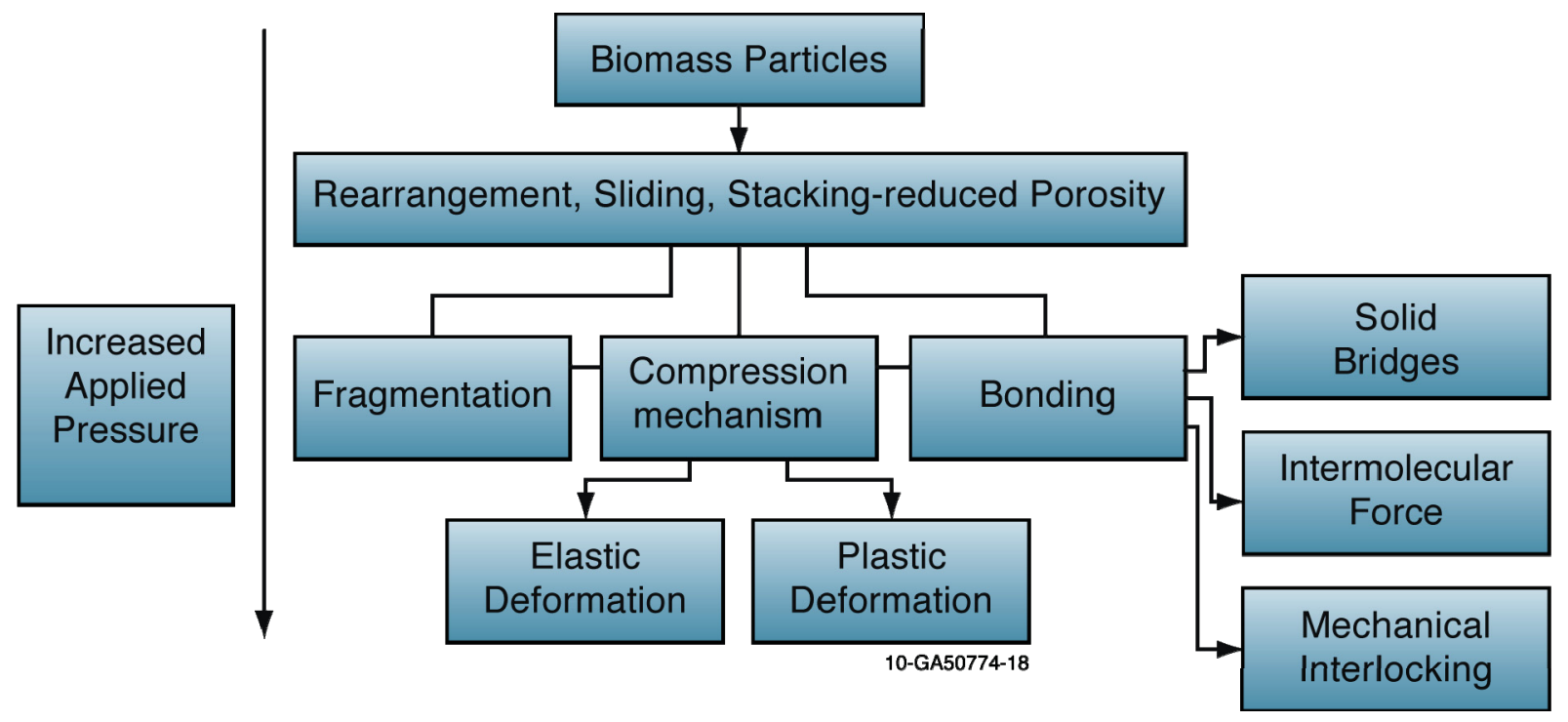

Figure 1. Deformation mechanisms of powder particles under compression (Comoglu 2007; Denny 2002).

The chemical composition of the biomass, which includes compounds like cellulose, hemicelluloses, protein, starch, lignin, crude fiber, fat, and ash, also affect the densification process. During compression at high temperatures, the protein and starch plasticizes and acts as a binder, which assists in increasing the strength of the pellet (Briggs et al. 1999). Starch present in the biomass acts as binder during densification. During densification of starch-rich biomass using an extrusion process like pelleting, the presence of heat and moisture gelatinizes the starch and results in better binding (Wood 1987; Thomas et al. 1998). High temperature and pressure, which are normally encountered during the densification process, results in softening of the lignin and improves the binding ability of the biomass. Low thermosetting properties and a low melting point $\left(140^{\circ} \mathrm{C}\right)$ help lignin take an active part in the binding phenomena (van Dam et al. 2004). Protein, starch, and lignin present in biomass takes an active part during pelleting of alfalfa, wheat, and barley grinds (Tabil and Sokhansanj 1996a and 1996b; Adapa et al. 2002b and 2009; Mani et al. 2004). Application of high compression pressures during biomass densification can result in crushing the biomass particles, thus opening up the cell structure and exposing the protein and pectin that act as natural binders (Bilanski and Graham 1984; O'Dogherty and Wheeler 1984). The major difference between biomass and other materials, like ceramic powders and pharmaceutical powders, is the presence of natural binding materials (Kaliyan and Morey 2006). The presence of components like bark, stems, leaves, etc., in the biomass further complicates understanding of the compaction behavior. Recently, Kaliyan and Morey (2010) used scanning electron microscope (SEM) studies for understanding the solid-type bridges formed during briquetting and pelleting of corn stover and switchgrass. More studies at a micro level using techniques like SEM and TEM will be useful in understanding the interaction of feedstock and process variables on the quality attributes of densified biomass.

\subsubsection{Densification Technologies}

\subsubsection{Screw Compaction or Extrusion}

The aim of compaction using an extruder is to bring the smaller particles closer so that the forces acting between them become stronger, providing more strength to the densified bulk material. During extrusion, the material moves from the feed port, with the help of a rotating screw, through the barrel and against a die, resulting in significant pressure gradient and friction due to biomass shearing. The 
combined effects of wall friction at the barrel, internal friction in the material, and high rotational speed $(\sim 600 \mathrm{rpm})$ of the screw, increase the temperature in the closed system and heat the biomass. This heated biomass is forced through the extrusion die to form the briquettes or pellets with the required shape. If the die is tapered, the biomass is further compacted. If the heat generated within the system is not sufficient for the material to reach a pseudo-plastic state for smooth extrusion, heat is provided to the extruders from outside either using band or tape heaters (Grover and Mishra 1996). Figure 2 shows the typical extruder, with different zones for processing of biomass.

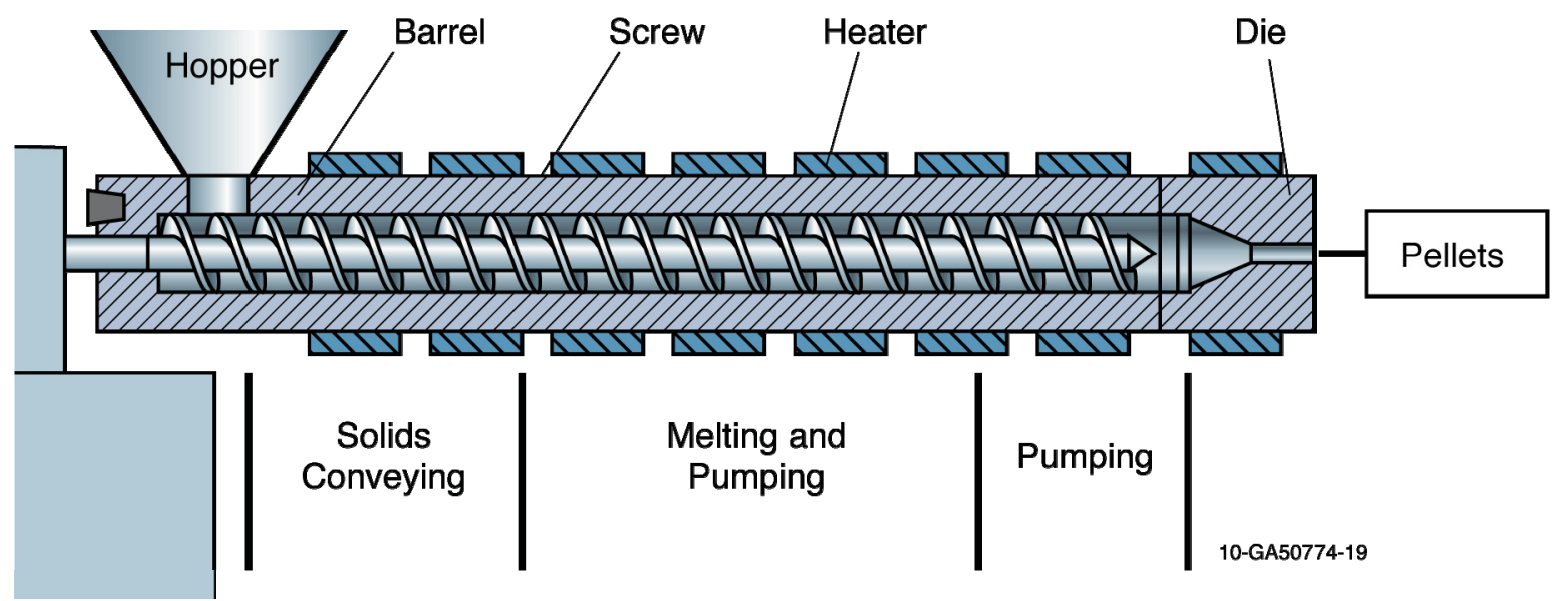

Figure 2. Extruder for biomass or polymer processing (Scientific Principles [http://matse1.mse.uiuc.edu/polymers/prin.html]).

Processing of biomass using screw compaction involves the following mechanisms (Grover and Mishra 1996):

1. Before reaching the compression zone (a zone usually formed by tapering of the barrel), the biomass is partially compressed to pack the ground biomass. It is during this first stage that the maximum energy is required to overcome particle friction.

2. Once the biomass is in the compression zone, the material becomes relatively soft due to high temperature $\left(200-250^{\circ} \mathrm{C}\right)$, and during this heating, the material loses its elastic nature, which results in an increased area of inter-particle contact. At this stage, local bridges are formed when the particles come closer, and the interlocking of particles may also result. During its passage through the compression zone, the biomass absorbs energy from friction so that it may be heated and mixed uniformly through its mass.

3. In the third stage, the biomass enters the tapered die, where the moisture is further evaporated due to the prevailing temperature of $280^{\circ} \mathrm{C}$, helping to better moisten the biomass and increase the compression on the material.

4. In the final stage, the removal of steam and compaction take place simultaneously and the pressure throughout the material normalizes, resulting in a uniform extruded log.

The following are the merits of screw compaction (Grover and Mishra 1996):

- The output from a screw press is continuous, and the briquettes are more uniform in size.

- The outer surface of the briquette is partially carbonized, which can help facilitate ignition and combustion. This also protects the briquettes from ambient moisture.

- A concentric hole formed in the briquettes helps for better combustion because of air circulation during burning. 
- The machine runs smoothly without any shock load.

- The machine parts and the oil used in the machine are free of dust or raw material contamination.

One demerit of screw compaction is that the power requirement of the machine is high compared to that of the piston press (Grover and Mishra 1996). Figure 3 illustrates the typical biomass heat logs prepared using an extrusion press. Specifications of typical biomass heat logs are given in Table 1.

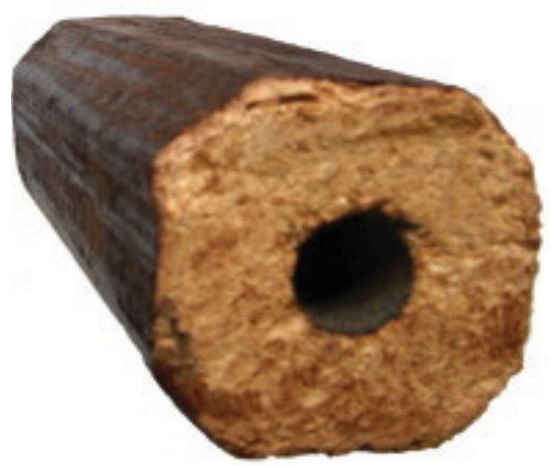

Figure 3. Heat logs produced using an extrusion press (Shimada systems, England, UK [http://www.shimada.co.uk/index.php]).

Table 1. General specification of extrudate produced by the Shimada SPMM 850 extrusion press. (Shimada systems, England, UK [http://www.shimada.co.uk/index.php]).

\begin{tabular}{ll}
\hline Raw Material prior to Extrusion (hard or soft wood) \\
\hline Moisture Content & $8 \%$ \\
Average Particle Size & $2-6 \mathrm{~mm}$ \\
Bulk Density & $200 \mathrm{~kg} / \mathrm{m}^{3}$ \\
\hline After Extrusion & \\
\hline Moisture Content & $4 \%$ \\
Bulk Density & $1400 \mathrm{~kg} / \mathrm{m}^{3}$ \\
Caloric Value & $4870 \mathrm{kcal}(8400 \mathrm{btu} / \mathrm{lb})$ \\
Ash Content & $0.35-0.5 \%$ \\
\hline
\end{tabular}

\section{Extruders}

\section{High-shear Extruders}

These extruders are designed to produce a large variety of precooked, gelatinized, or heat-treated products. High-shear extruders are classified as high-temperature/short-time (HTST) devices, wherein the biomass is usually preheated with steam or hot water and then processed through the high-shear cooking extruder to further work the product and rapidly increase its temperature (Harper 1981).

\section{Low-shear Extruders}

Low-shear extruders have moderate shear, high compression, and grooved barrels to enhance mixing. These extruders are used to extrude low-viscosity materials. Heat can be applied to the barrel or screw to heat the product since little viscous dissipation to shear occurs due to the relatively low viscosity of the materials being extruded (Harper 1981). 


\subsubsection{Briquetting}

Densification of loose and smaller biomass waste using a briquette press is a viable and attractive solution to utilize biomass for fuel applications. Briquetting is usually performed using hydraulic, mechanical, or roller presses. The briquettes' densities generally range from 900 to $1300 \mathrm{~kg} / \mathrm{m}^{3}$. The biofuel briquette is a clean and green fuel that can ideally be used in furnaces, boilers, or open fires.

Unlike pellet mills, briquetting machines can handle larger-sized particles and wider moisture contents without the addition of binders. Advantages of briquettes are the ease of charging the furnace, increased calorific value, improved combustion characteristics, reduced entrained particulate emissions, and uniform size and shape. In addition, furnaces that use other solid fuels can use briquettes also. The main disadvantage of using biomass briquettes or pellets in industrial furnaces is ash slagging due to the alkali content in briquettes made from biomass (Ndiema et al. 2002).

In the biomass briquetting process, the material is compressed under high pressure and temperature. During briquetting the biomass particles self-bond to form a briquette due to thermoplastic flow. Lignin, which is a natural binder, is made available from high temperatures and pressures resulting in the formation of high-density briquettes.

\section{Hydraulic Piston Pump}

Hydraulic piston presses are commonly used as briquetting machines for densification of biomass. The energy to the piston is transmitted from an electric motor via a high-pressure hydraulic system. The output of a hydraulic press is lower, since the movement of the cylinder is slower compared to mechanical processes. The briquettes have a bulk density lower than $1000 \mathrm{~kg} / \mathrm{m}^{3}$ because pressure is limited to 40 $135 \mathrm{~kg} / \mathrm{h}$. However, these machines can tolerate higher moisture contents than the usually accepted $15 \%$ for mechanical piston presses (www.cfnielsen.com). To improve the production capacity, some continuous briquetting presses are available commercially. Figure 4 and Figure 5 show a hydraulic press and the briquettes produced from straw using a hydraulic press.

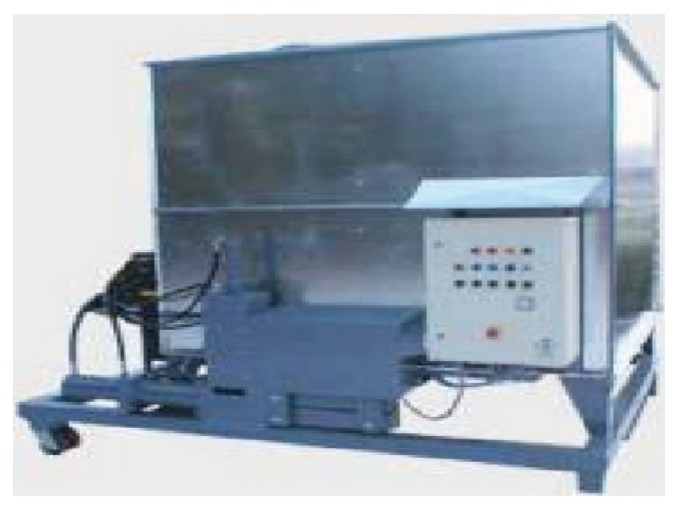

Figure 4. Hydraulic press.

(C. F. Nielsen A/S, Solbjergvej 19, DK-9574 Baelum)

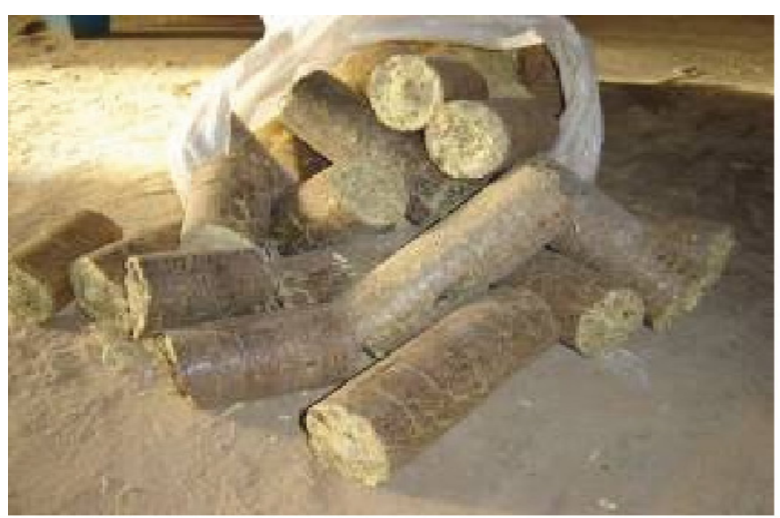

Figure 5. Straw briquettes from a hydraulic press.

\subsubsection{The Tabletizing Process}

The tabletizer works by a hopper with a hydraulic motor turning the auger and feeding the 4- to 6-inch-diameter cylindrical mold with biomass (Figure 6). Following that, a ram compresses the biomass tightly into the mold, reducing the material from about 10 inches to 2 (smaller than most biomass briquettes). The application of high pressure of about 20,000 psi in the mold is sufficient to force the material to adhere together without additional binders. Long, coarse-cut feedstocks are favorable in the process, as they stick together more easily. Tablet density averages $55 \mathrm{lb} / \mathrm{ft}^{3}$ compared to bale density of 
$15 \mathrm{lb} / \mathrm{ft}^{3}$ and pellet density of $45 \mathrm{lb} / \mathrm{ft}^{3}$. However, the drawback is that the tabletizing process uses more energy. Each tablet weighs about $1.2 \mathrm{lb}$, and the time necessary to produce it depends on how much material is being compacted and how fluffy it is (Figure 7). In general, corn stover, corn stalks, and switchgrass have low density and are considered fluffy. Therefore, a large volume of material may be required to add up to $1.2 \mathrm{lb}$. The tablets have not been tested extensively for energy density. The experiments have been geared toward using tablets in power plants. Tablets have not been evaluated to determine whether they make good feedstock for gasification processes. Research is ongoing to determine the energy requirements for making the tables and scale-up process to be followed in the case of largescale production (Gibson 2010).

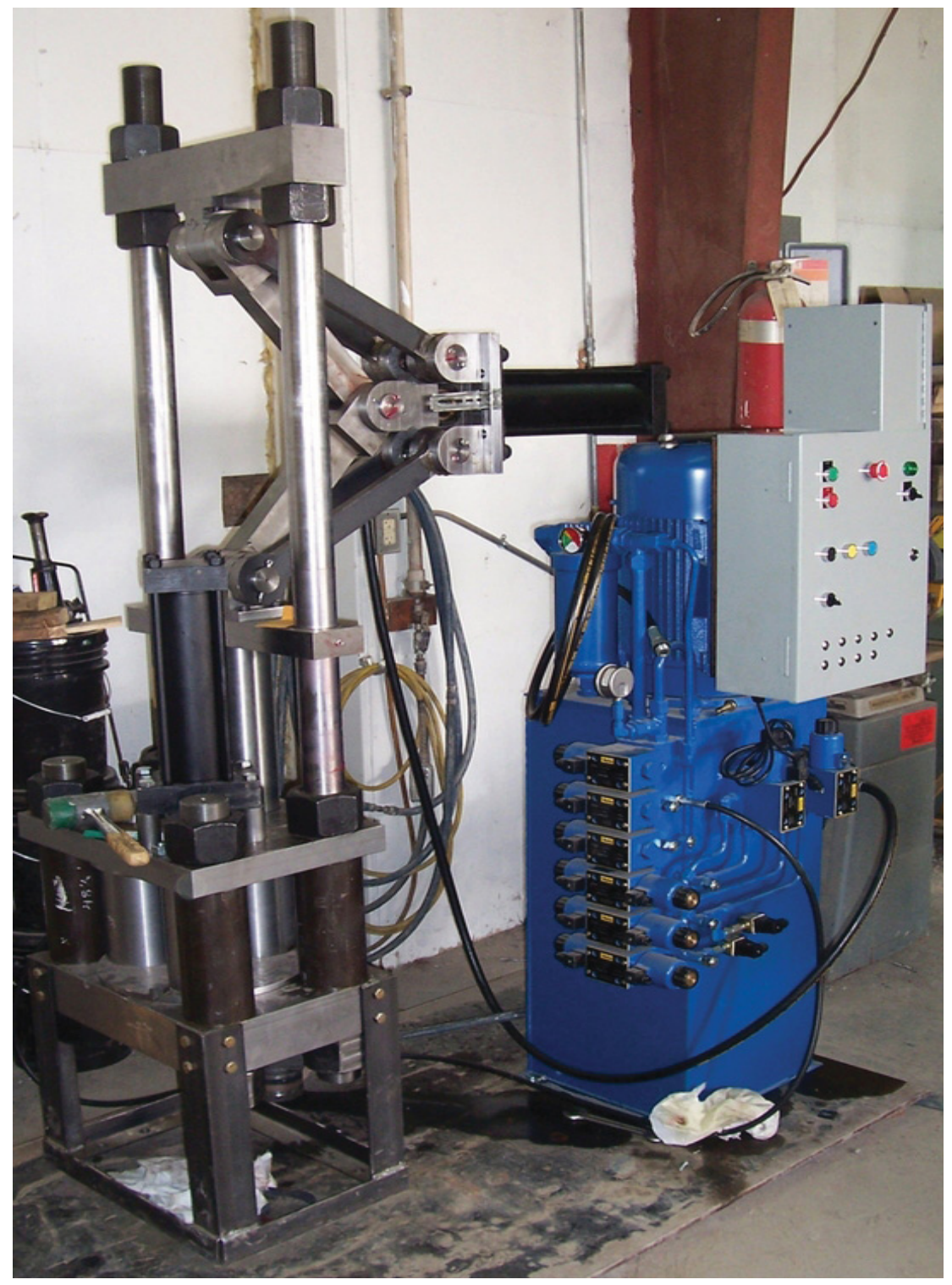

Figure 6. Energy tablet-making machine for biomass (Photo: Bradford Research and Extension Center, University of Missouri). 


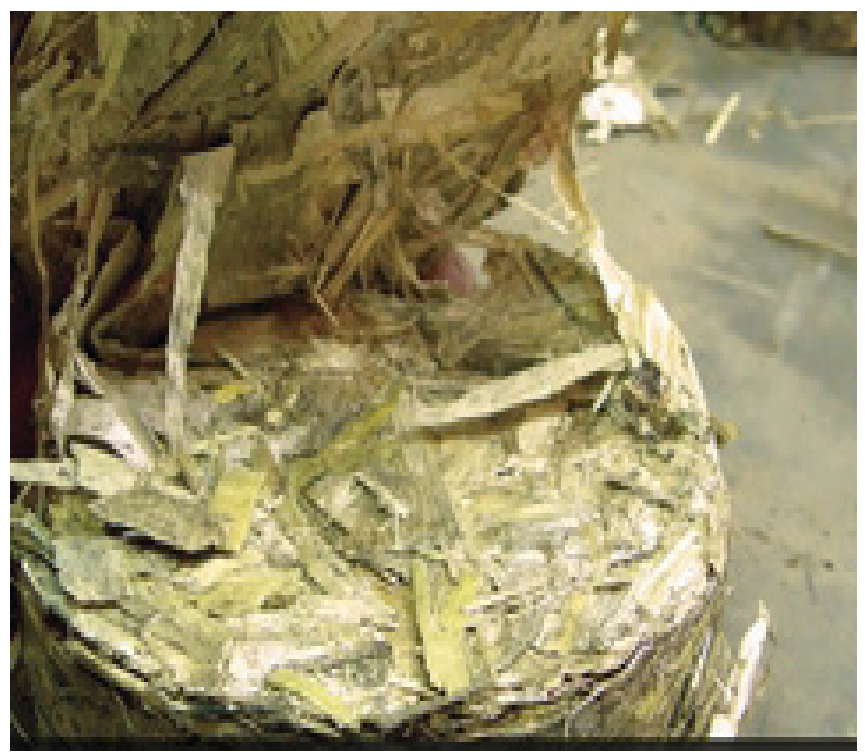

Figure 7. Energy tablet from tableting process (Photo: Bradford Research and Extension Center, University of Missouri).

\subsubsection{Mechanical Densification Technologies}

\subsubsection{Mechanical Piston Press}

Mechanical piston presses are typically used for large-scale production, ranging from 200 to $2,500 \mathrm{~kg} / \mathrm{hr}$ (Figure 8). The mechanical press is designed as an eccentric press. A continuously rotating eccentric, connected to a plunger, presses the raw material through a conic die. In mechanical presses, the counter pressure required can only be adjusted by mounting a die with a different conicity (www.cfnielsen.com). The mechanical press is driven by electric motors instead of a hydraulic motor. Energy loss in the machine is limited, and the output in relation to power consumption is optimal. The operating life of a mechanical press is considerably longer than hydraulic presses. Generally, a mechanical press gives a better return on investment than a hydraulic press (www.cfnielsen.com). The process flow for continuous briquetting using a mechanical piston-type press is given in Figure 9 . Table 2 compares the working conditions of a screw extruder and a piston press.

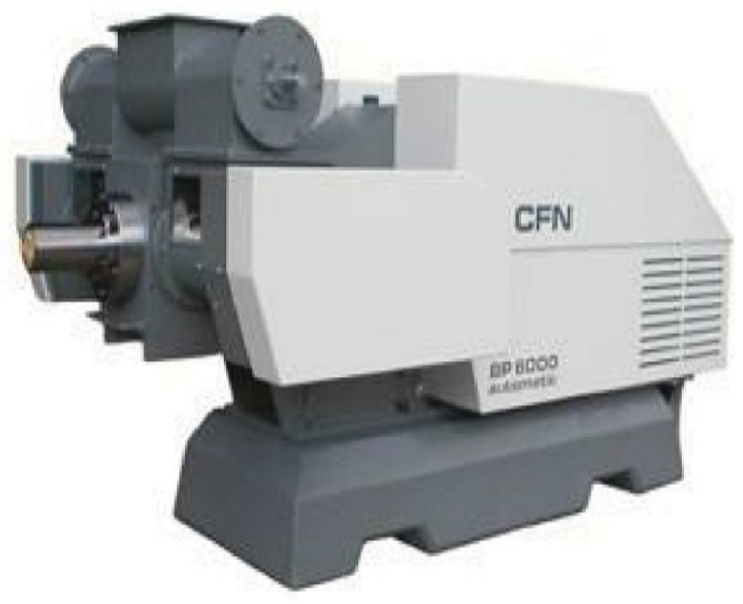

Figure 8. Mechanical press. (C. F. Nielsen A/S, Solbjergvej 19, DK-9574 Baelum). 


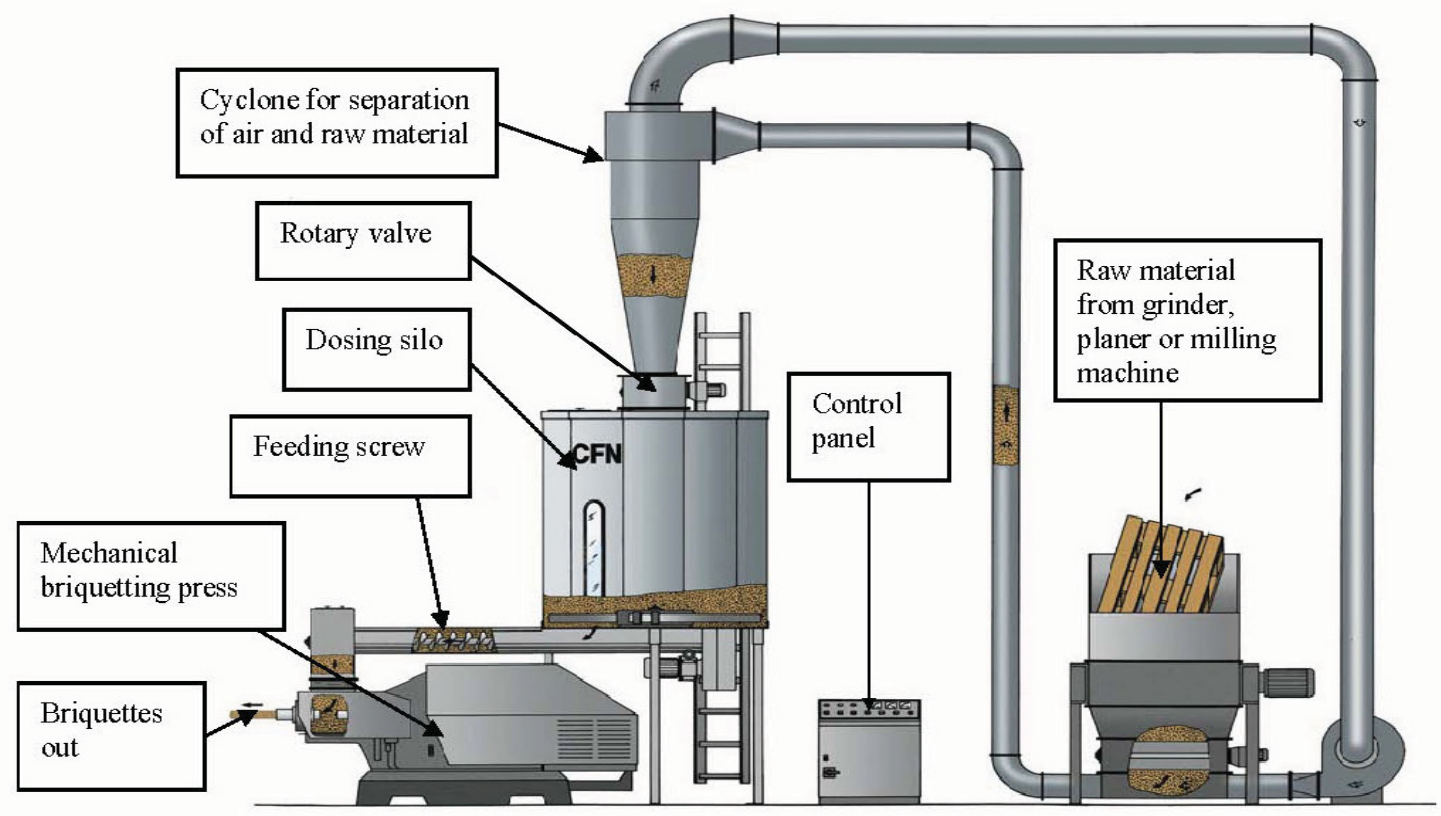

Figure 9. Continuous piston-type briquetting press. (C. F. Nielsen A/S, Solbjergvej 19, DK 9574 Baelum, www.cfnielsen.com).

\subsubsection{Roller Press}

Densification of biomass using roller presses works on the principle of pressure and agglomeration, where pressure is applied between two counter-rotating rolls. Ground biomass, when forced through the gap between the two rollers, is pressed into a die, or small pockets, forming the densified product (Yehia 2007). Design parameters that play a major role on the quality of the densified product are the diameter of the rollers, the gap width, the roller force, and the shape of the die (Yehia 2007).

Roller-press machines have been in use since 1870. Johanson (1965) and Pietsch (1991) first proposed the theoretical analysis and operation of roll pressing machines. Johanson's (1965) analysis was based on understanding the behavior of granular solids within a roller press, which involves the interaction between the particles of the material itself as well as the interaction between the material and the machine (roller surface). The typical working principle of a roller press is shown in Figure 10. Roller presses consist of two cylindrical rollers of the same diameter, rotating horizontally in opposite directions on parallel axes, allowing feed to be drawn in one side and densified product to be discharged out the opposite. The two rollers are arranged in such a way that a small gap exists between them. The distance between the two rollers, which is normally referred to as "the gap," depends on many factors such as the type of biomass, the particle size, the moisture content, and the addition of binders. Shape of the densified biomass depends upon the type of die used (Yehia 2007).

In the case of agglomerate production, by using smooth rolls, the machine output can be a sheet having a specific thickness based on the gap provided between the rollers. The sheet produced is used to produce the agglomerates, as shown in Figure 10, and the fines are again recycled back to the feeder. (In the case of briquettes, the material passes directly to the screener instead of a crusher and the fines are recycled back to the production process). 


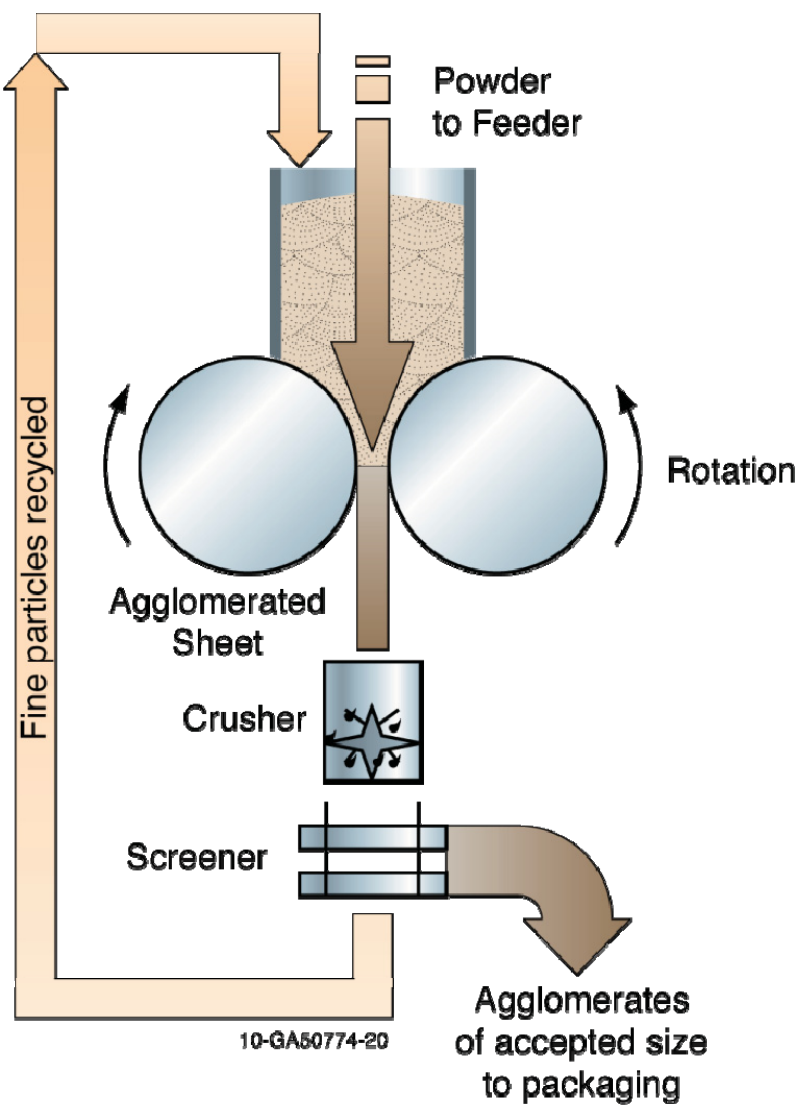

Figure 10. Roller press mill (adapted from Yehia 2007).

\subsubsection{Pelletization}

Pelletization is similar to briquetting, except that it uses smaller dies (approximately $30 \mathrm{~mm}$ ) to produce smaller densified products called pellets. Pellet presses consist of two types: the ring die and the flat die. In both the ring- and flat-die machines, the die remains stationary, and the rollers rotate. Some rotating die pellet mills are available in which the rollers remain stationary during the production process.

In principle, the incoming feed is delivered uniformly into the conditioner for the controlled addition of steam and/or molasses. This unit operation helps improve binding of the material during pelletization. Most pellet mills now have, mounted above the main unit, one or more conditioning units where liquids such as water and molasses can be added to improve pelletability. Various components of a screw conditioner normally used in the pellet mill are shown in Figure 11. 


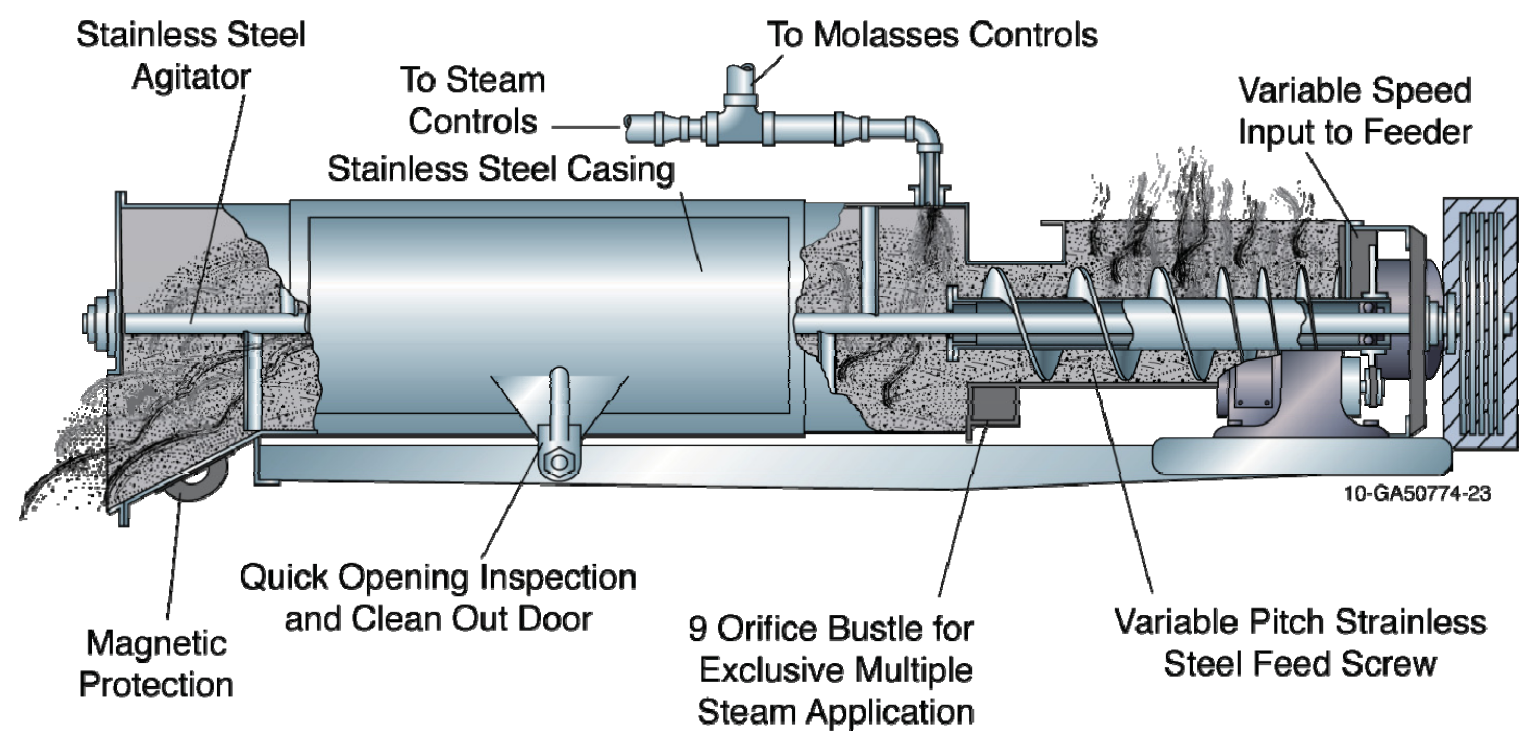

Figure 11. Component of a screw conditioner. (Adapted from Richard H. Leaver, Andritz Sprout, A division of Andritz Inc, Pennsylvania).

The feed from the conditioner is discharged over a permanent magnet and into a feed spout leading to the pelleting die. The added steam softens the feed and partially gelatinizes the starch content to create more durable pellets. Inter-elevator flights in the die cover feed the mash evenly to each roller, and the feed distributor flights distribute the material across the face of the die. Cut-off knives mounted on the swing cover cut the pellets as they are extruded from the die, allowing the pellets to fall through the discharge opening in the swing door.

\section{Pellet Mill}

A pellet mill consists of a perforated hard steel die with one or two rollers. By rotating the die or the rollers, the feedstock is forced through the perforations to form densified pellets (see Figure 12). Different dimensions of a commercial pellet die are shown in Figure 13. Figure 14 shows the various pellet mill components used for continuous production of pellets. Commercial pelletizers are available with production capacities ranging from $200 \mathrm{~kg} / \mathrm{hr}$ to $8 \mathrm{ton} / \mathrm{hr}$, indicating that the pelletizer capacity is not restricted by the density of the raw material (as in the case of piston or screw presses). Power consumption of the pellet mills ranges from 15-40 kWh/ton (Grover and Mishra 1996). 


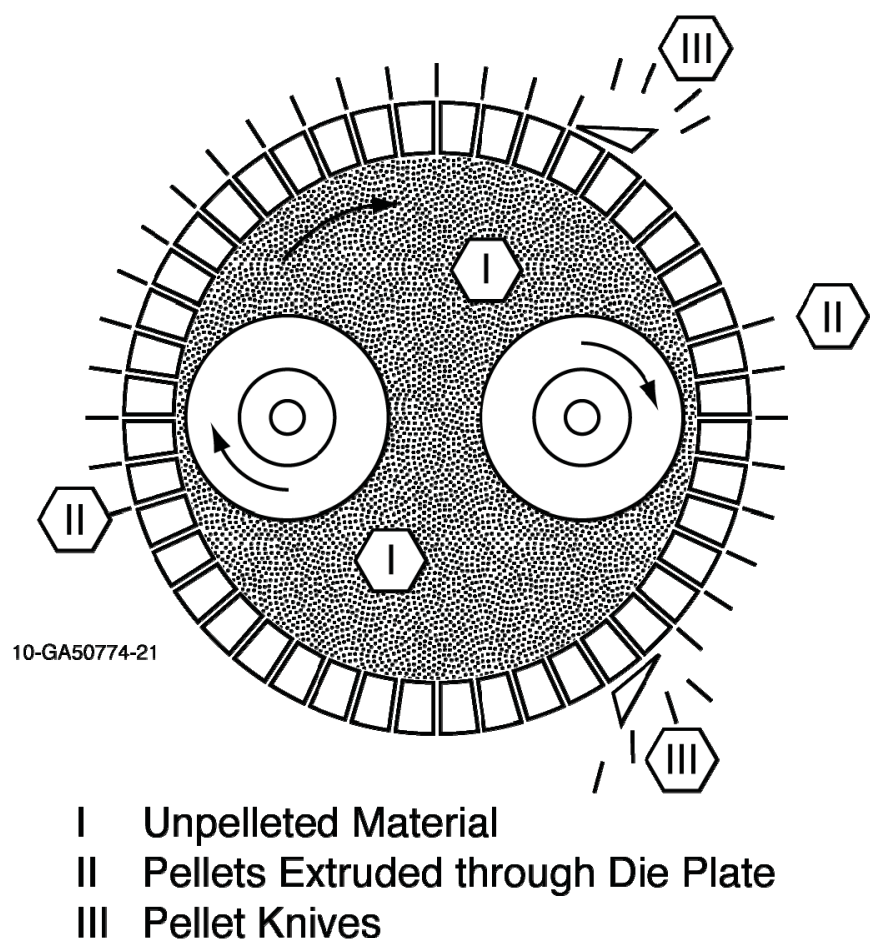

Figure 12. Working process of die (www.feedmachinery.com).

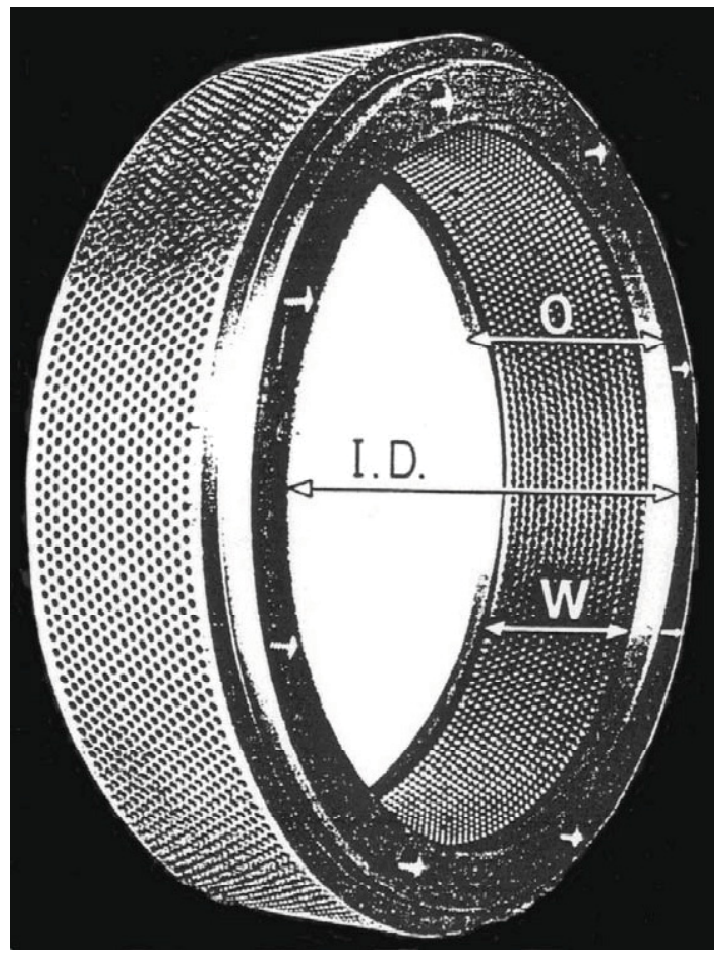

I.D. - Inside diameter of the die. This is the most common identifying factor for a die size.

$\mathbf{O}$ - Overall width of the die. There are normally two die widths for each die diameter.

W - Working width, measured between the two inside edges of the die grooves.

Grooves - Cut on the inside circumference of the die, into which the outside edges of the roll extend. This provides relief for the ends of the rolls so that the roll can be adjusted downward as the die wears away.

Die Working Area - Defined as the area between the two inside die grooves. This area is what is available for drilling the holes through which the pellets extrude.

(Source: Richard H. Leaver, Andritz Sprout, A division of Andritz Inc, Pennsylvania)

Figure 13. Dimensions of a commercial die. 


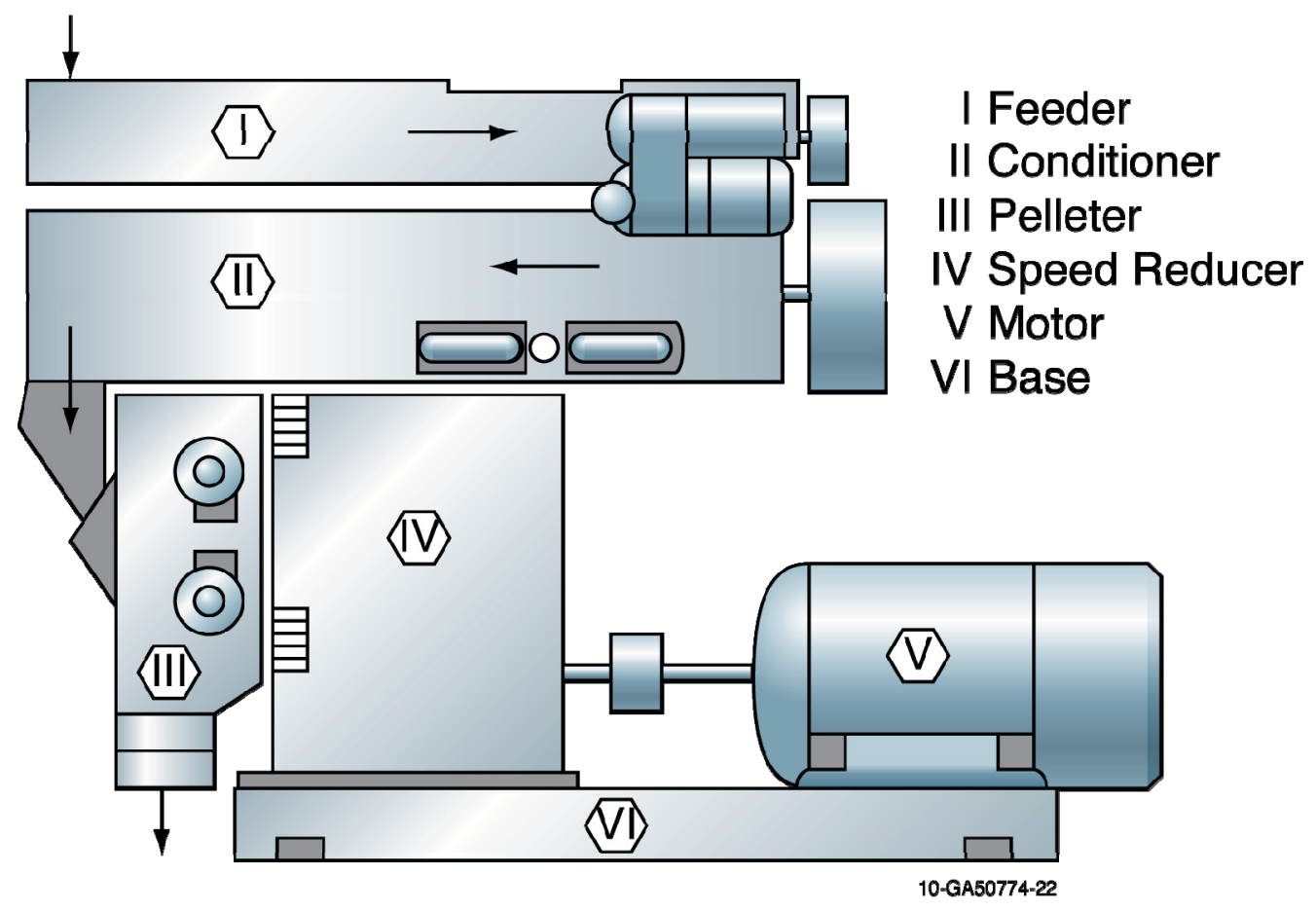

Figure 14. Pellet mill components (adapted from www.feedmachinery.com).

\subsubsection{Comparison Between Pelleting and Briquetting}

Briquette processing is more efficient than pelleting because the biomass materials do not necessarily have to be preprocessed or uniformly ground up, which results in less preparation. Another advantage of briquetting is it can be set onsite. Briquetting waste byproducts and reusing them onsite for energy rather than transporting them to another location or to a landfill can save on disposal costs. Briquetting generally use less horsepower. From the investment point of view, the purchase capital and maintenance costs to make briquettes are less than for pellets. Pellets have been considered more of a residential fuel even though they are used in some larger, commercial applications. If transportation is one of the main criteria, pellets are more advantageous because there are more pounds per foot than briquettes. This is especially true if the briquettes are larger because it allows for more air between them when they are stacked (Austin 2010).

\subsubsection{Agglomeration}

Agglomeration is a method of increasing particle size by gluing powder particles together. This technology is used for a variety of powders, such as hydrated lime, pulverized coal, iron ores, fly ash, cement, and many others. The application of agglomeration for biomass is limited (Beaudequin et al. 1985; Reynieix 1987).

The most commonly used method is called "tumbling agglomeration." The equipment consists of a rotating volume that is filled with balls of varying sizes and fed with powder and often a binder. The rotation of the agglomerator results in centrifugal, gravitational, and frictional forces from the smooth rolling balls. These forces, together with inertial forces, press the balls against the powder, helping them to stick together and grow (Siemons et al. 1989). 
Segregation of the balls takes place as their diameter starts growing. Large balls tend to "float" on the surface, whereas small balls are mainly located at the bottom of the vessel. With an increased number of balls during the process, larger balls are pushed outside as the bulk volume size of the agglomerator is limited (Siemons et al. 1989). Typical position of granules or balls in a pan-shaped agglomerator is shown in Figure 15; the agglomerator can also be drum, conical, or plate shaped. The following are important parameters for a rotating agglomerator:

- Pan-tilt angle

- Rotation speed

- Powder-to-binder feed ratio

- Absolute powder feed rate

- Number and location of feeder points

- Rim height

- Scraper position.

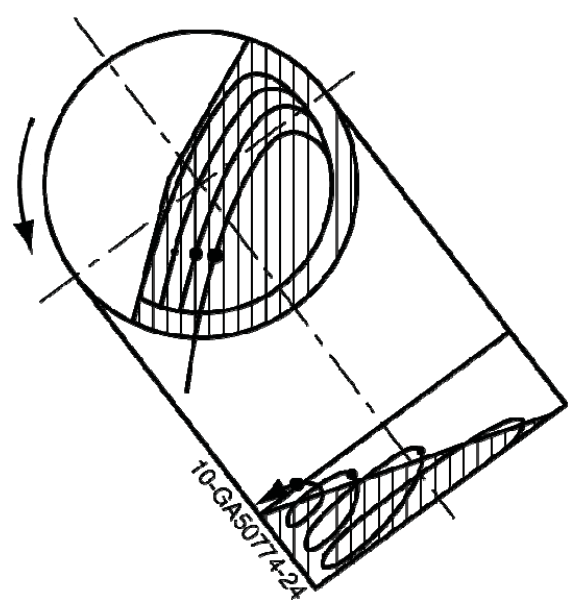

Figure 15. Position of granules or balls in a pan-shaped agglomerator (adapted from Siemons et al. 1989).

No specific rules exist to design agglormeration equipment. The final choice of a balling device rests on a careful consideration of the particular application by individuals experienced in the field (Snow 1984). For any particular agglomerator, the main process parameters are the ball residence time (depending on powder feed rate, acting volume, and pan-tilt angle) and proper rolling action (depending on scraper position, binder premixing, and pan-tilt angle). These parameters are interrelated, and process settings depend very much on the powder characteristics (Seimons et al. 1989). An agglomerator using granulation involves the following steps:

- Fine raw material is continually added to the pan and wetted by a liquid binder spray.

- The disc's rotation causes the wetted fines to form small, seed-type particles (nucleation).

- The seed particles "snowball" by coalescing into larger particles until they discharge from the pan. While pellets can be formed in batches, almost all tonnage pelletizing is accomplished through continuous processes using a disc pelletizer with a comparatively simple design.

The fundamental problem in an agglomerator is maintaining a uniform ball-size distribution during the operation. This problem grows out of the fact that large balls not only grow by powder layering, but also by consuming considerably smaller balls. This is because the largest balls in an agglomerator producing $30-\mathrm{mm}$ balls are 1,000 times heavier than the $3-\mathrm{mm}$ balls present in the same machine. This difference in diameters is the main reason for the operation instabilities. In order to overcome this problem, automatic agglomeration machines are designed for step-wise diameter increase-the product 
balls from one agglomeration step serve as the nuclei for the next one, and so on, until the desired ball diameter is reached (Siemons et al. 1989).

Literature on agglomeration of agricultural or woody biomass is scarce. In principle, the biomass agglomeration process may consist of the following steps: biomass grinding, agglomeration of the powder with a binder, and briquette drying. The efficiency of agglomeration can be improved by mixing biomass powder separately and feeding it into the agglomerator.

Mani (2008) proposed the following mechanism for pellet/granules formation:

1. Attraction forces between solid particles

2. Interfacial forces and capillary pressure in movable liquid surfaces

3. Adhesion and cohesion forces in non freely movable binder bridges

4. Mechanical interlocking

5. Solid bridges.

Agglomeration is a function of material properties and process parameters (Mort 2009). Figure 16 shows the process of agglomeration as a function of various material properties and process parameters (Mort 2009). Figure 17 and Figure 18 show the rotary drum and disk agglomerator.

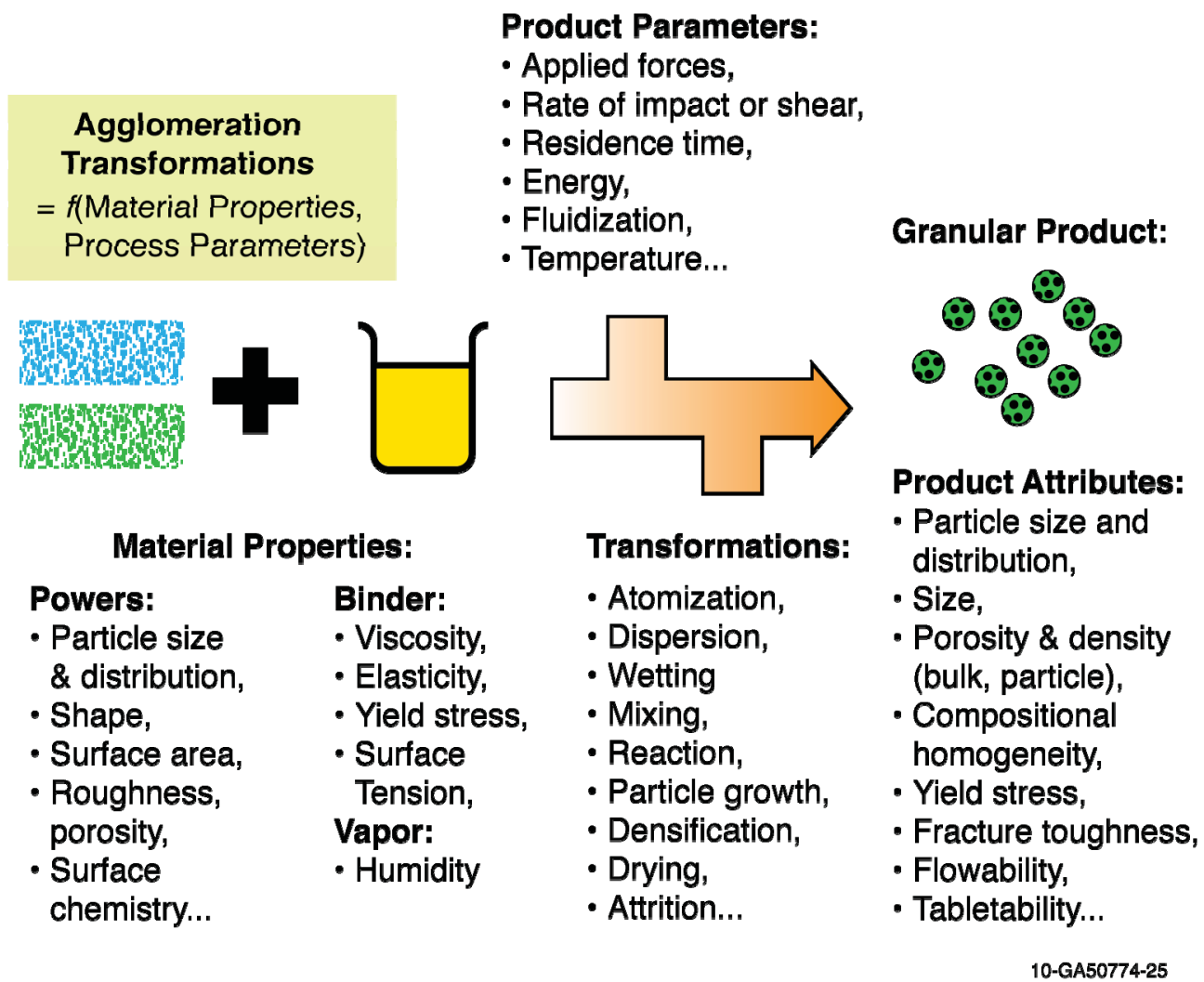

Figure 16. Agglomeration as a function of material properties and process parameters. 


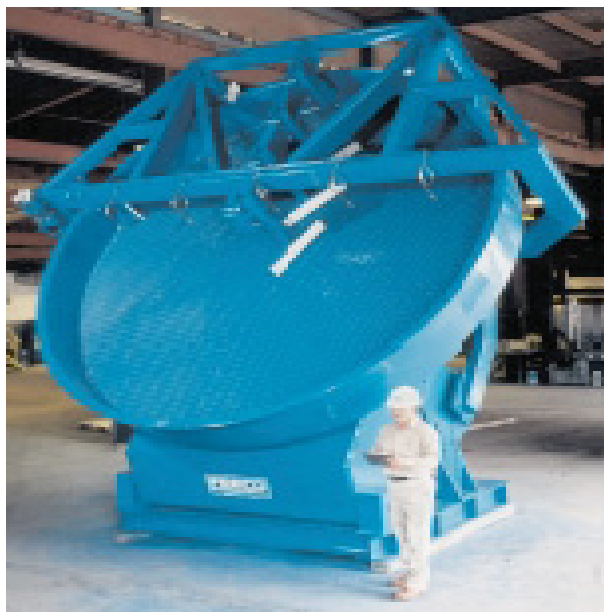

Figure 17. Rotary disk granulator or pelletizer.

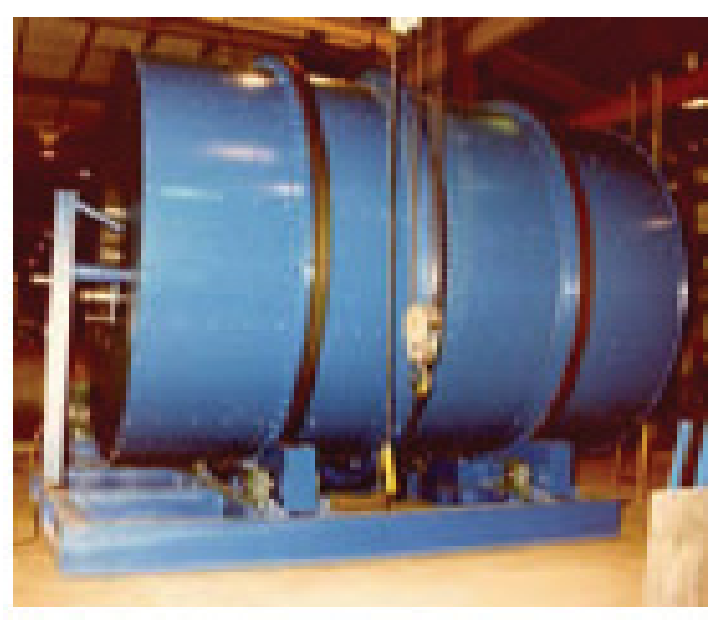

Figure 18. Rotary drum granulator.

Table 2 compares various densification equipment in terms of feedstock material properties, specific energy consumption, and suitability of the densified material for different end-use applications. From the table it is clear that screw pressed material is more suitable for cofiring and combustion as it leads to carbonization of the biomass during densification. The pellet roller and piston-pressed material are more suitable for biochemical and thermochemical conversion processes. Even though there is no specific information on the properties of agglomerates made from biomass, their suitability mentioned in Table 2 (Tumuluru et al., 2011) takes into account the physical properties like size, shape, and bulk density of the agglomerates made for the pharmaceutical industry. 
Table 2. Comparison of different densification equipments (FAO (1996), Tumuluru et al. (2011), Kaliyan et al. (2009) and (Grover and Mishra 1996)).

\begin{tabular}{|c|c|c|c|c|c|}
\hline & Screw press & Piston Press & Roller press & Pellet mill & Agglomerator \\
\hline $\begin{array}{l}\text { Optimum moisture content of } \\
\text { the raw material }\end{array}$ & $8-9 \%$ & $10-15 \%$ & $10-15 \%$ & $10-15 \%$ & No information \\
\hline Particle size & Smaller & Larger & Larger & Smaller & Smaller \\
\hline Wear of contact parts & High & Low & High & High & Low \\
\hline Output from machine & Continuous & In strokes & Continuous & Continuous & Continuous \\
\hline $\begin{array}{l}\text { Specific energy consumption } \\
(\mathrm{kWh} / \text { ton) }\end{array}$ & $36.8-150$ & $37.4-77$ & $29.91-83.1$ & $16.4-74.5$ & No information \\
\hline Through puts (ton $/ \mathrm{hr}$ ) & 0.5 & 2.5 & $5-10$ & 5 & No information \\
\hline Density of briquette & $1-1.4 \mathrm{~g} / \mathrm{cm}^{3}$ & $1-1.2 \mathrm{~g} / \mathrm{cm}^{3}$ & $0.6-0.7 \mathrm{~g} / \mathrm{cm}^{3}$ & $0.7-0.8 \mathrm{~g} / \mathrm{cm}^{3}$ & $0.4-0.5 \mathrm{~g} / \mathrm{cm}^{3}$ \\
\hline Maintenance & Low & High & Low & Low & Low \\
\hline $\begin{array}{l}\text { Combustion performance of } \\
\text { briquettes }\end{array}$ & Very good & Moderate & Moderate & Very good & No information \\
\hline Carbonization of charcoal & Makes good charcoal & Not possible & Not possible & Not possible & Not possible \\
\hline Suitability in gasifiers & Suitable & Suitable & Suitable & Suitable & Suitable \\
\hline Suitability for cofiring & Suitable & Suitable & Suitable & Suitable & Suitable \\
\hline $\begin{array}{l}\text { Suitability for biochemical } \\
\text { conversion }\end{array}$ & Not suitable & Suitable & Suitable & Suitable & No information \\
\hline $\begin{array}{l}\text { Homogeneity of densified } \\
\text { biomass }\end{array}$ & Homogenous & Not homogenous & Not homogeneous & Homogeneous & Homogenous \\
\hline
\end{tabular}




\subsection{Specific Energy Requirements}

\subsubsection{Densification}

The specific energy requirements for biomass densification depend on the system used and process variables (e.g., temperature and pressure), feedstock variables (e.g., moisture content and particle size/distribution), and biochemical composition variables (e.g., presence of starch, protein, fat, and lignocellulosic composition) (Reed et al. 1980).

Most densification processes involve both compression and pushing/extrusion work. The energy required for compression and pushing is more than what is required for compression alone, as it is independent of the dimension of the pressing channel. Extrusion through the channels requires more energy as the material has to overcome friction during compression and pushing. The work done during densification is given for both processes by:

$w=A \int_{0}^{x} P d x=A \int_{0}^{x} P d x$

where

$\mathrm{P}=$ the applied pressure

$\mathrm{x}=$ the sample thickness

$\mathrm{A}=$ the cross sectional area of the die and piston.

In the compression apparatus, the density at each point is calculated from:

$P=m / x A$

where

$\mathrm{m}=$ the sample mass.

Three types of pressure applications exist in commercial densification processes: (1) straight compression in the die, (2) extrusion through a constriction, and (3) shear of precompacted material to produce heat and flow under pressure (Reed et al. 1980). Table 3 shows a comparison of energy requirements for commercial densification systems with the laboratory results. 
Table 3. Comparison of reported energy requirements for commercial densification apparatus with laboratory results (Reed et al. 1980).

\begin{tabular}{|c|c|c|c|c|}
\hline & Material & Density & $\begin{array}{r}\text { Energy } \\
\text { kWh/tonne }\end{array}$ & $\mathrm{kWh} /$ ton \\
\hline \multicolumn{5}{|l|}{ Compression } \\
\hline \multirow[t]{2}{*}{ In laboratory ${ }^{\mathrm{a}}$} & Sawdust & 1.0 & 4.0 & 3.6 \\
\hline & Sawdust & 1.2 & 6.6 & 6.0 \\
\hline Commercial $^{\mathrm{b}}$ & Sawdust & $\sim 1.2$ & 37.4 & 34.0 \\
\hline \multicolumn{5}{|l|}{ Extrusion } \\
\hline In laboratory $^{\mathrm{c}}$ & Municipal Solid Waste & 1.0 & 7.76 & 7.06 \\
\hline \multirow[t]{2}{*}{ Commercial $^{\mathrm{d}}$} & Municipal Solid Waste & 1.0 & 16.4 & 14.9 \\
\hline & Sawdust & 1.0 & 36.8 & 33.5 \\
\hline \multicolumn{5}{|l|}{ a. $2.5-\mathrm{cm}$ pellet } \\
\hline \multirow{2}{*}{\multicolumn{5}{|c|}{$\begin{array}{l}\text { b. From specifications of } 150 \text {-hp Hausmann briquettor no. } \mathrm{FH} 2 / 90 / 200 \text { for } 8 \text {-cm diameter log } \\
\text { c. } 1.2 \text {-cm pellet made at } 25^{\circ} \mathrm{C}\end{array}$}} \\
\hline & & & \multicolumn{2}{|c|}{ c. $1.2-\mathrm{cm}$ pellet made at $25^{\circ} \mathrm{C}$} \\
\hline
\end{tabular}

As shown in Table 3, the compression-specific energy required is lower by a factor of 2-10 as compared to commercial compression machines because the measurement does not include motor and bearing losses associated with commercial equipment. Given this fact, the laboratory results likely represent lower specific-energy requirements for densification. The specific-energy consumption for both compression and extrusion can be reduced by a factor of about 2 by preheating the biomass to $200-225^{\circ} \mathrm{C}$ before densification (Reed et al., 1980). This extra heating of the biomass before densification may require about $1.8 \mathrm{~J} / \mathrm{g}-\mathrm{C}$. However, electrical power costs and equipment costs may be reduced due to lower pressure requirements and reduced wear of the die from improved lubricity. Also, preheating the biomass not only reduces the specific energy consumption, but also increases the energy content of the biomass (Reed et al., 1980). The pellet made at $225^{\circ} \mathrm{C}$ had an energy content of $20.2 \mathrm{~J}$, which may be due to better densification of the sawdust. This may also be due to a prepyrolysis reaction for biomass similar to what occurs for lignite when $\mathrm{CO}_{2}$ and $\mathrm{H}_{2} \mathrm{O}$ are driven off with little or no energy loss.

Winter (1981) postulates a power law or exponential relation to describe the specific energy with respect to throughput through a densification systems like pelletizer:

$E_{n}=a M_{0}^{b}$

where $a$ and $b$ are constants that varied with density. He concludes that constants $a$ and $b$ depend on die and feed characteristics. Over a throughput range of 0.05-1.3 metric tons per hour (MTPH), the specific energy requirements decreased from 180 to $8 \mathrm{kWh}$ /metric ton. Winter (1981) also indicated that during pelletization the specific energy is required to accomplish the following processes: (1) precompression of the loose feed, (2) deformation of the feed as it enters the die, and (3) balancing the die frictional force as the pellet passes through the die. The frictional force is related to die length and diameter and is given by the following equation:

$F=F_{0} \exp \frac{4 \mu L}{D}$ 
The initial static friction that the pellet must overcome is greater than that which must be overcome when the pellet begins to flow. Stopping and starting the flows significantly increases the specific energy requirements.

Table 4. Specific-energy consumption during extrusion of RDF.

\begin{tabular}{ccc}
\hline & & \\
\hline Temperature & & \\
$\left({ }^{\circ} \mathrm{C}\right)$ & & $\mathrm{kWh} /$ ton \\
\hline 25 & $\mathrm{kWh} /$ tonne & 7.06 \\
93 & 7.76 & 5.54 \\
149 & 6.09 & 5.67 \\
204 & 6.23 & 4.05 \\
\hline Extrusion Rate ${ }^{\mathrm{b}}$ & 4.45 & \\
$\left(\mathrm{~cm} /\right.$ min $^{\mathrm{a}}$ & & \\
5 & & 7.06 \\
10 & 7.76 & 9.95 \\
20 & 10.93 & 9.92 \\
\hline a. Extrusion rate $5 \mathrm{~cm}(2$ in. $) / \mathrm{min}$ & 10.90 & \\
b. At $25^{\circ} \mathrm{C}$ & & \\
\hline
\end{tabular}

Table 4 shows the effect of temperature and extrusion rate on refuse-derived fuel (RDF). Regarding energy consumption during densification using compression technologies, only $37-40 \%$ of the input energy was required to compress the material; the remaining energy was required to overcome friction during compression (Mewes 1959). The increase in moisture content reduced the energy required to reach a specific density (Mohsenin and Zaske 1975). For the moist and woody biomass like bark, less energy was required for compaction to reach a certain density compared to lower moisture contents. O'Dogherty and Wheeler (1984), in their studies on compressing barley straw in a circular die, noted an energy requirement of 5-25 MJ/t, depending on wafer density. Faborode and O'Callagham (1987) observed that chopped barley straw at 8.3\% moisture (w.b.) consumed $28-31 \mathrm{MJ} / \mathrm{t}$, whereas unchopped material consumed 18-27 MJ/t. Aqa and Bhattacharya (1992) observed that the densification process variables, like die temperature and preheating of the sawdust, significantly impacted the specific energy consumption. They found that the energy inputs to a briquetting machine motor, die heaters, and overall system were reduced by $54,30.6$, and $40.2 \%$, respectively, for sawdust preheated to $115^{\circ} \mathrm{C}$. They also found that operating the briquetting machine at higher throughputs further reduced the electrical energy requirements per kg of sawdust. Various researchers observed that pellet mills require less energy compared to screw or piston presses. Table 5 indicates specific energy consumption data for different biomass material densified using different densification systems. 
Table 5. Specific energy consumption data for densification of different feedstocks (Sudhagar 2005).

\begin{tabular}{llcl}
\hline \multicolumn{1}{c}{ Materials } & \multicolumn{1}{c}{$\begin{array}{c}\text { Type of } \\
\text { densification unit }\end{array}$} & $\begin{array}{c}\text { Specific energy } \\
\text { consumption }(\mathrm{kWh} / \mathrm{t})\end{array}$ & \multicolumn{1}{c}{ Source } \\
\hline Sawdust & Pellet mill & 36.8 & Reed \& Bryant (1978) \\
Municipal Solid & Pellet mill & 16.4 & Reed \& Bryant (1978) \\
Bark + wood & Pellet mill & $30-45$ & Miles \& Miles (1980) \\
Straws + binders & Pellet mill & $37-64$ & Miles \& Miles (1980) \\
Straws & Pellet mill & $22-55$ & Neale (1986) \\
Grass & Pellet mill & $33-61$ & Shepperson \& Marchant (1978) \\
Switchgrass & Pellet mill & 74.5 & Jannasch et al. (2001) \\
Alfalfa & Pellet mill & 30 & Tabil and Sokhansanj (1996) \\
Straws + binders & Cubing machine & 75 & Miles and Miles (1980) \\
Grass & Cubing machine & $28-36$ & Balk (1964) \\
Cotton trash & Cubing machine & 60 & Miles and Miles (1980) \\
Hay & Cubing machine & 37 & Miles and Miles (1980) \\
Sawdust & Piston press & 37.4 & Reed et al. (1980) \\
Straws & Screw press & $150-220$ & Carre et al. (1987) \\
Grass & Piston press & 77 & Shepperson \& Marchant (1978) \\
Straws + binder & Ram extruder & $60-95$ & Miles \& Miles (1980) \\
\hline
\end{tabular}




\section{DENSIFICATION SYSTEM VARIABLES}

Controlling densification system variables can be important to achieving the desired density, durability, and quality. The quality of pellets or briquettes can be managed by proper control of manufacturing conditions, such as control of the manufacturing process, change of formulation, and the use of additives (MacMahon 1984). Shaw (2008), in his studies on densification of biomass, demonstrates how process variables (die temperature, pressure, and die geometry), feedstock variables (moisture content, particle size, and shape) and biomass composition (protein, fat, cellulose, hemicellulose, and lignin) play a major role in the quality of the densified biomass.

\subsection{Process Variables}

Process variables such as temperature, pressure, retention time, and die geometry and speed play an important role in reaching the desired product quality of densified biomass in terms of durability, density, and calorific value.

\subsubsection{Temperature}

Quality attributes like durability and bulk density are significantly influenced by barrel temperature. Hall and Hall (1968) found that for given moisture content, the pressure required to obtain a certain wafer density is reduced by the addition of heat in the die, and addition of heat increases the upper limits of the moisture content at which a certain pressure is able to produce a specific wafer density. Hill and Pulkinen (1988) found that high-temperature conditioning of the raw materials will increase pellet durability. They reported that pellet durability of alfalfa increases by about 30-35\% when pelleting temperature increases from 60 to $104^{\circ} \mathrm{C}$. Mani et al. (2003) and Sokhansanj et al. (2005) observed a similar effect in terms of temperature, where higher temperatures resulted in reduced resistance of the material against an applied load for densification and resulted in better quality of pellets. Smith et al. (1977), in their article on briquetting of wheat straw, found that for a given pressure at temperatures between $60-140^{\circ} \mathrm{C}$, the degree of compaction and dimensional stability were higher. They also concluded that the expansion of the briquettes was less when the die temperature was between 90 and $140^{\circ} \mathrm{C}$. The same authors observed that briquettes were surface charred and slightly discolored at temperatures above $110^{\circ} \mathrm{C}$ due to chemical degradation. Tabil and Sokhansanj (1996) observed that pelleting temperatures $>90^{\circ} \mathrm{C}$ significantly improved durability values of alfalfa pellets. They concluded that to obtain durable pellets, it is necessary to precondition the grinds at $90^{\circ} \mathrm{C}$ or above, which can result in high pelleting temperature and promote better bonding of particles. Kaliyan and Morey (2006) used the glass transition temperature behavior of the biomass to understand the densification behavior. Glass transition temperature was found to be inversely related to moisture content. Their studies included three different temperatures: two within the glass transition temperature $\left(75\right.$ and $\left.100^{\circ} \mathrm{C}\right)$ and one outside $\left(150^{\circ} \mathrm{C}\right)$. The durability values of the densified biomass outside the glass transition temperature were lower compared to ones within the range.

\subsubsection{Pressure}

Pressure plays an important role in the quality of pellets made from agricultural biomass. Butler and McColly (1959) observe that the density of chopped alfalfa-hay pellets is proportional to the natural logarithm of the applied pressure and that an increase in pressure significantly increases density. Yaman et al. (2000) recommended that briquetting pressure should be selected at an optimum value that influences the mechanical strength by increasing plastic deformation. However, above an optimum briquetting pressure, fractures may occur in the briquette due to a sudden dilation. For a given die size and storage condition, there is a maximum die pressure beyond which no significant gain in cohesion (bonding) of the briquette can be achieved (Ndiema et al. 2002). Application of high pressures and temperatures during densification may develop solid bridges by a diffusion of molecules from one particle 
to another at the points of contact, which increases the density. Li and Liu (2000) observed that compression of oak sawdust at pressure application rates varying from 0.24 to $5.0 \mathrm{MPa} / \mathrm{s}$ has a significant effect on the dry density of the compacts at moisture content of $10.3 \%$. They also observed that when the compaction speed was lower than $3 \mathrm{MPa} / \mathrm{s}$, the density of the logs decreased, whereas the effect was negligible with the increase in compaction speeds to $>3 \mathrm{MPa} / \mathrm{s}$. Demirbas et al. (2004), in their article on compaction of biomass waste materials like waste paper, observed that increasing the pressure from 300 to $800 \mathrm{MPa}$, with about $7 \%$ moisture (w.b.), increases the density sharply from 0.182 to $0.325 \mathrm{~g} / \mathrm{Ml}$, and then the densities slightly rise to $0.405 \mathrm{~g} / \mathrm{mL}$. They also observe that for a sample with $18 \%$ moisture content at the same pressures, the briquettes' densities increase sharply to 0.278 and $0.836 \mathrm{~g} / \mathrm{mL}$, respectively. During continuous pelletization of agricultural biomass, a backup pressure is needed to initiate the process of pelletization. The backup pressure is created by the buildup of material in the press channel, which sets the requirement for a pressure (prestressing pressure) to overcome the friction within the channels. The initial pelletization pressure depends on die dimensions such as die hole, die length, friction coefficient, and prestressing pressure (Holm et al. 2006).

\subsubsection{Retention or Hold Time and Relaxation Time}

The quality of the briquettes is significantly influenced by the retention or hold times of the materials in the die (Tabil and Sokhansanj 1996). Al-Widyan et al. (2002) found that retention times between 5 and 20 seconds did not have a significant effect on olive cake briquette durability and stability. Li and Liu (2000) found that the hold time for oak sawdust had more effect at lower pressures than at higher pressures. At the highest pressure (138 MPa), the effect of hold time became negligible. They also observed that the holding time had little effect on the expansion rate, and that holding time had more effect at lower pressure than at high pressure. It appeared that hold times greater than 40 seconds had a negligible effect on density. A 10 -second hold time could result in a 5\% increase in log density whereas at holding times longer than 20 seconds, the effect diminished significantly. In general, relaxation time has a great affect on the density of the materials. Final relaxed density of briquetted fuel and the relaxation behavior following removal from the die depend on many factors related to die geometry, the magnitude and mode of compression, the type and properties of the feed material, and storage conditions. Many studies on high-pressure compaction of biomass materials have indicated that, on removal of densified material from the die, the density of the compacted material decreases with time to a final relaxed density. For most feed materials, the rate of expansion is highest just after the removal of pressure and decreases with time until the particle attains constant volume (Carre et al. 1987; Miles 1980). The relaxation characteristics, which are mainly measured by the percentage elongation and increase in voidance, depend on many factors related to feed material and storage conditions, such as relative humidity (Wamukonya and Jenkins 1995). Shrivastava et al. (1990) used statistical analysis of rice husks to establish a multiple correlation equation in the following form:

$Y=\alpha_{0}+\alpha_{1} P+\alpha_{2} T$

where

$\mathrm{Y}=$ percent volume expansion

$\mathrm{T}\left({ }^{\circ} \mathrm{C}\right)$ and $\mathrm{P}\left(\mathrm{kg} / \mathrm{m}^{2}\right) \quad=$ die temperature and pressure, respectively

$\alpha_{0}, \alpha_{1}$ and $\alpha_{2}=$ constants.

\subsubsection{Die Geometry and Speed}

Die geometry normally refers to the size and shape of the die. These die dimensions significantly affect both the amount of material that can be pelleted and the energy required for compression and influence the product properties like moisture content, bulk density, and durability. The L/D (length to diameter) ratio can be a good measure for degree of compression during pelletization. The increase in 
pelletizing pressure increases the length of the pellet, whereas the increase in diameter of the pellet decreases the pelleting pressure. Hence, the dimensions of the die and the press channels in the matrix have a strong influence on deciding the pressure needed to press the pellets through the matrix.

Butler and McColly (1959) found that for a constant mass of material, pellet density is greater for smaller diameter chambers at a given pressure, and longer pellets were produced in smaller chambers, which resulted in a lesser expansion. Tabil and Sokhansanj (1996) studied the effect of process parameters like steam conditioning, die geometry, L/D ratio, die speed, and particle sizes of the biomass and found that at a higher conditioning temperature of $>95^{\circ} \mathrm{C}$, the durability of the pellets increases. They also concluded that durability of the pellets significantly improves when a smaller die with higher L/D ratios is used. Also, they found that the hammer mill screen size does not have much effect on pellet durability, but the speed of rotation of the die (at about $250 \mathrm{rpm}$ ) significantly increases durability. Shankar et al. (2005) found that die barrel temperature and screw speed significantly affect quality attributes like bulk density and hardness of the biomass feed mix during extrusion processing. Shankar et al. (2008a), in their studies on volumetric flow rate through a single screw extruder, found that L/D ratio and screw speed significantly affect the flow rate of the biomass feed mix in a single screw extruder, and this flow behavior affects the final quality of the pelleted biomass.

Hill and Pulkinen (1988) report that pellet durability of alfalfa increases by about $30-35 \%$ when pelleting temperature increases from 60 to $104^{\circ} \mathrm{C}$. They also indicate that an $\mathrm{L} / \mathrm{D}$ ratio between 8 and 10 is ideal for making high quality pellets. Heffiner and Pfost (1973) evaluated the effect of three die sizes, $4.8 \times 44.5,6.4 \times 57.2$, and $9.5 \times 76.2 \mathrm{~mm}$, on durability, finding that the pellets produced on the smallest die have the best durability values. Tumuluru et al. (2010a), in their article on pelleting of distiller's dried grains with solubles (DDGS), report that larger die diameters of $7.2 \mathrm{~mm}$ produce less-durable DDGS pellets as compared to a smaller one (of $6.4 \mathrm{~mm}$ ), both with and without steam addition.

\subsection{Feedstock Variables}

Feedstock variables include moisture content and particle size, shape, and distribution. These variables are feedstock dependent and have a great effect on pellet quality and in selecting proper process conditions.

\subsubsection{Moisture Content}

Moisture present in the biomass facilitates starch gelatinization, protein denaturation, and fiber solubilization processes during extrusion, pelleting, or briquetting. Steam-treated biomass is superior, as the additional heat modifies physiochemical properties (gelatinization of starch, denaturation of protein) to such an extent that binding between the particles is significantly enhanced, resulting in improved densification quality (Thomas et al. 1997). Mani et al. (2003) observed that moisture in the biomass during the densification process acts as a binder and increases the bonding via van der Waal's forces, thereby increasing the contact area of the particle. Tabil and Sokhansanj (1996), in their article on pelletization of alfalfa grinds, found that larger die $($ of $7.8 \mathrm{~mm})$ can handle conditioned grind moisture contents above $10 \%$, but the durability after cooling of the pellets was low. They also found that the smaller die became plugged when the moisture content of the conditioned grinds exceeded $10 \%$. Tumuluru et al. (2010a), in their article on pelleting of DDGS grinds using a pilot scale pellet mill, found that steam conditioning before pelletization and using a smaller die of $6.4 \mathrm{~mm}$ size produced more highly durable pellets compared to $7.4 \mathrm{~mm}$. Demirbas (2004) found that increasing the moisture content from 7 to $15 \%$ of spruce wood sawdust significantly increased the strength of the pellets. Mani et al. (2006), in their article on densification of corn stover, found that low moisture $(5-10 \%)$ resulted in denser, more stable, and more durable briquettes. 
Li and Liu (2000) researched the compaction of tree bark, sawmill waste, wood shavings, alfalfa hay, fresh alfalfa, and grass in a punch and die assembly and found that an optimum moisture content of approximately $8 \%$ was recommended to produce high-density briquettes. They also recommended that a moisture content of 5-12\% is necessary to produce good quality (in terms of good density and long-term storage properties) logs from hardwood, softwood, and bark in the forms of sawdust, mulches, and chips. They also remarked that pellets or briquettes tend to become fragile in just a few days if the moisture content is less than $4 \%$ (w.b.) due to absorption of moisture from the environment ( $\mathrm{Li}$ and Liu 2000).

Moshenin and Zaske (1976), in their study on densification, report that materials having lower moisture content and fewer long fibers (more fines) gave more stable wafers due to limited expansion. Tabil and Sokhansanj (1996) observed that during compression, the protoplasm present in fresh alfalfa of about 19\% moisture content acted as a binder, and pellets with highest durability were produced.

Sokhansanj et al. (2005) identified that feed material that contains higher proportions of starch and protein will produce more durable and higher quality pellets than the materials with only cellulosic material. They also identified that the optimum moisture content for pelleting cellulosic materials is $8-12 \%$, whereas that for starch and protein materials (mostly animal feeds) can reach up to 20\% (w.b). Ollett et al. (1993), in their article on understanding the compaction behavior of food powders, concluded that the effect of moisture on the compaction behavior of the food powders was a complex phenomenon. Heckel (1961) found that increasing the water content of food powders decreased the deformation stresses. Peleg and Moreyra (1979) demonstrated that wet powders were more deformable than dry powders and require a longer time to reach the preset load. Many researchers have found that the optimum moisture content for densification of biomass is different for each individual feedstock and operating condition.

\subsubsection{Particle Size, Shape, and Distribution}

In general, density and durability of pellets is inversely proportional to particle size since smaller particles have greater surface area during densification. MacBain (1966) and Payne (1978), in their studies on alfalfa, concluded that medium or fine-ground materials are desirable in pelleting because, at these sizes, they have greater surface area for moisture addition during steam conditioning, which results in increased starch gelatinization and better binding. Payne (1978) reports that a certain percentage of fine to medium particles are required to improve pelleting efficiency and reduce costs. Absence of coarse particles in the feed or biomass mix will significantly affect the production efficiency of commercial pellet mills. There is a critical particle size below which the pelletization is not commercially feasible in terms of technical ability and economics of pellet production. Very small particles can also jam the pellet mills and significantly affect production capacity. Table 6 indicates the particle size distribution spectrum for producing good quality pellets. Payne (1996) found that the effect of the particle-size distribution was listed as an important material property for forage wafering. He found that higher leaf content in the forage produces a superior density product, both in terms of physical and nutritional point of view. Smith et al. (1977) mention that the compaction and stabilization of straw may have a different mechanism than that of grass, because straw is dead material and has a significantly smaller leaf content. Many researchers have worked on identifying the optimum particle sizes for different biomass materials to produce the best quality of pellets in terms of density and durability. Dobie (1959) indicates that fine grinding of the feed material produces pellets with higher density and increases the capacity of the machine as the material passes through the die more easily. MacBain (1966), in his document on feed pelleting, mentioned that medium- or fine-ground feed constituents are desirable in pelleting because, at these sizes, the material provides greater surface area for moisture addition during steam conditioning. High starch content in biomass can result in an increase of starch gelatinization during pelletization and helps in better binding, whereas the coarsely ground materials will tend to create a natural fissure in the pellet and yield less durable pellets, which are susceptible to breakage. Hill and Pulkinen (1988), in their report on alfalfa pellets, indicate that an increase in screen size from 2.8 to $6.4 \mathrm{~mm}$ reduced the durability of the alfalfa pellet by more than $15 \%$ and that the particle size of ground material and pellet durability must be 
weighed with respect to energy requirement to accomplish size reduction. Robinson (1984), in his research on fiber-rich feed, reports that lower conditioning time enhances pellet quality. Coarsely ground materials tend to yield less-durable pellets because they may create natural fissures in the pellets, which are then susceptible to breakage (MacBain 1996).

Table 6. Best particle size distribution for producing quality pellets from lignocellulosic biomass (Payne 1996).

\begin{tabular}{cc}
\hline Sieve size $(\mathrm{mm})$ & Material retained on sieve \\
\hline 3.0 & $\leq 1 \%$ \\
2.0 & $\leq 5 \%$ \\
1.0 & $\approx 20 \%$ \\
0.5 & $\approx 30 \%$ \\
0.25 & $\approx 24 \%$ \\
$<0.25$ & $\geq 20 \%$ \\
\hline
\end{tabular}

\subsection{Biomass Composition}

Feedstock composition is one of the major variables that contribute significantly to the quality of the densified materials. Plant biomass has both low molecular weight and macromolecular compositions. Low-molecular-weight substances include organic matter and inorganic matter, while macromolecular substances include cellulose, hemi-cellulose, and lignin (Mohan et al. 2006) (Figure 19).

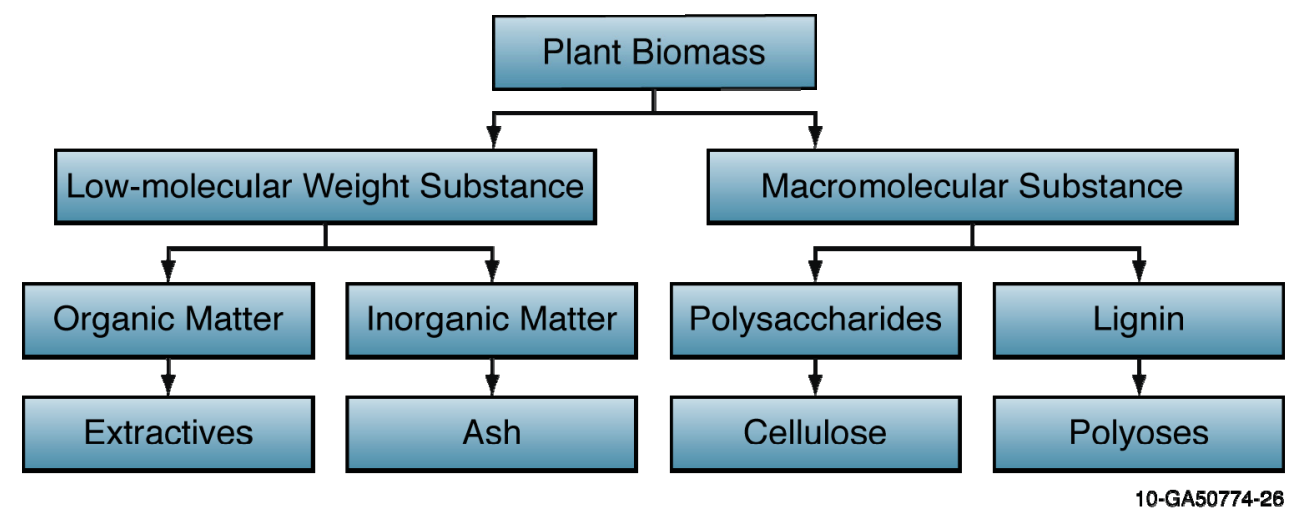

Figure 19. Plant biomass composition (adapted from Mohan et al. 2006).

Understanding some of the major chemical compositional changes that take place during processing of biomass can be useful in understanding their compaction behavior. As the densification of the biomass is coupled with process variables like temperature, pressure, die geometry, and mechanisms of densification, changes in these variables will bring about significant changes in the chemical compositions of the biomass by the mechanisms known as interaction reactions. Understanding the effects of densification process variables on some common chemical constituents like starch, cellulose, hemicellulose, fat, and lipid will help clarify quality parameters, such as moisture content, bulk density, and durability of densified biomass. Thomas et al. (1998), in their article on the pelleting of animal feeds, identify starch, protein, sugar and non-starch polysaccharides (NSP), fat, fiber, inorganic matter, and water as some of the important ingredients that influence pellet quality. Shankar and Bandyopadhyay (2004 and 2005) and Shankar et al. (2008a) found that the protein and fat in the feed material significantly affect the quality of the extruded feed and also impact flow behavior. 


\subsubsection{Starch}

Starch is as abundant and available as cellulose in plants. Starch is a D-glucose polymer with branched (amylopectin) or un-branched (amylose) chains (Collado and Corke 2003). It occurs as semi-crystalline granules in the chloroplasts of green leaves and in the amyloplasts of storage organs such as seeds and tubers. Ellis et al. (1998) mention that starch granules may also contain non-starch components such as lipids, proteins, and phosphate groups. Its behavior is mainly controlled by the gelatinization process it undergoes at high processing temperatures. Starch granules at higher temperature and moisture contents gelatinize and significantly influence the textural properties of many foods and feeds (Shankar and Bandyopadhyay 2006). Collado and Corke (2003) state that starch undergoes mainly the reactions of gelatinization, pasting, and retrogradation, and, among all these reactions, gelatinization plays a major role in the pelletization process. Gelatinization of starch is an irreversible process and is mainly influenced by densification process variables like heat, water, shear, and residence time (Thomas et al. 1999).

Binding/adhesion characteristics of starch are mainly based on the amylase-to-amylopectin ratio. During gelatinization of the starch granule, amylase immediately forms double helices that may aggregate (hydrogen bonds) to each other, creating semi-crystalline regions and helping in binding. The underlying principles of why and how starch contributes to the binding properties in pellets are yet to be explored (Thomas et al. 1998). Starch in food and feed processing is mainly used as a thickener, colloidal stabilizer, gelling agent, bulking agent, water retention agent, and adhesive (Singh et al. 2002). The non-food applications of starches include adhesives for board, paper, or labels in the paper industry (Thomas et al. 1999). In the pharmaceutical industry, starch is widely used as a binder or filler in tablet formulations (Alebiowu and Itiola 2002). During the pelleting process, starch not only acts as a binder, but also as a lubricating agent, helping to ease the flow of materials through the die.

\subsubsection{Protein}

Protein that is heated during the densification process undergoes denaturization leading to the formation of new bonds and structures with other proteins, lipids and starch available in the biomass and improves the binding capacity (Thomas et al., 1998 and Nyanzi and Maga, 1992).According to Briggs et al. (1999) and Wood (1987), increasing the protein content increases pelleted feed durability. Raw protein improves the physical quality of the pellets better than denatured proteins. Feed pellets formed using extrusion of protein result in the modification of the protein structures where non-covalent and covalent bonds stabilizing secondary structures are destroyed, resulting in new intermolecular bonds (LampartSzczapa et al. 2006). Extrusion processing of proteins results in texturization mainly because of aggregation, fragmentation, and covalent cross-linking between protein and starch (Schaich and Rebello 1999; Shankar and Bandyopadhyay 2006). Tabil (1996) reported an improvement in the binding properties of the material if sufficient natural proteins are present during pelletization. Sokhansanj et al. (2005) report that feed material with larger fractions of starch and protein composition produces denser and more stable pellets than biomass with a larger composition of cellulose. Shankar and Bandyopadhyay (2004 and 2005) found that fish in the feed, barrel temperature, and feed moisture play an important role in the hardness of the extrudates. They observe that, at higher processing temperatures of $100-200^{\circ} \mathrm{C}$, proteins crosslink with starches and lipids, which results in more durable and stable pellets. Other studies by these authors using scanning electron microscopy have corroborated the occurrence of protein crosslinking with the other constituents like starch and lipids. Wood (1987), in his article on the functional properties of protein and starch fractions, concludes that protein plays a great part in feed quality attributes like hardness and durability, which shows that pellet durability is protein-dependent and emphasizes that protein in raw form and starch in a gelatinized state, when added, generate more durable pellets. He could obtain a maximum pellet durability (93\%) when mixtures contain raw soya protein and 
pregelatinized tapioca starch, and minimum durability with mixtures containing denatured soya protein and native tapioca starch.

\subsubsection{Lipid/Fat}

In general, the fat added to the biomass acts as a lubricant during pelletization, increasing throughput and reducing pelleting pressure (Thomas et al. 1998). But an increase of fat decreases the binding capacity of the biomass and may require additional binders to improve its durability and hardness. Rout (1997) in his article on extrusion of aquafeed with high lipids of about $8-10 \%$, found that a commercial binder is required to improve density and water-stability values. Briggs et al. (1999), in their article on pelletization, found that increased oil content produces lower quality pellets since fat is hydrophobic and tends to interfere with particle binding during pelletization. York and Pilpel (1973), in their article on manufacture of pharmaceutical tablets, found that decreasing the fatty-acid-to-lactose ratio by the addition of fatty acid results in poor tablet strength due to weak bonds formed between fatty acids.

\subsubsection{Lignocellulose}

Lignocellulose is a typical characteristic of non-food-related biomass, such as trees, grasses, and waste materials. Wood-based polymers comprise cellulose (40-60\%), hemicellulose (20-40\%), and lignin (10-25\%) (United States, Department of Energy 2006). Typical lignocellulosic content of some of the plant material is given in Table 7. Figure 20 shows the arrangement of cellulose, hemicellulose, and lignin in a biomass matrix.

Table 7. Typical lignocellulosic content of some plant materials (Mohan et al. 2006).

\begin{tabular}{lccc} 
& \multicolumn{3}{c}{ Lignocellulosic content (\%) } \\
\cline { 2 - 4 } \multicolumn{1}{c}{ Plant material } & Hemicellulose & Cellulose & Lignin \\
\hline Orchard grass (medium maturity) $^{\mathrm{a}}$ & 40.0 & 32 & 4.7 \\
Rice straw $^{\mathrm{b}}$ & 27.2 & 34.0 & 14.2 \\
Birch wood $^{\mathrm{b}}$ & 25.7 & 40.0 & 15.7 \\
\hline a. Data taken from Van Soest (1964) & & & \\
b. Data taken from Solo (1965) & & & \\
\hline
\end{tabular}




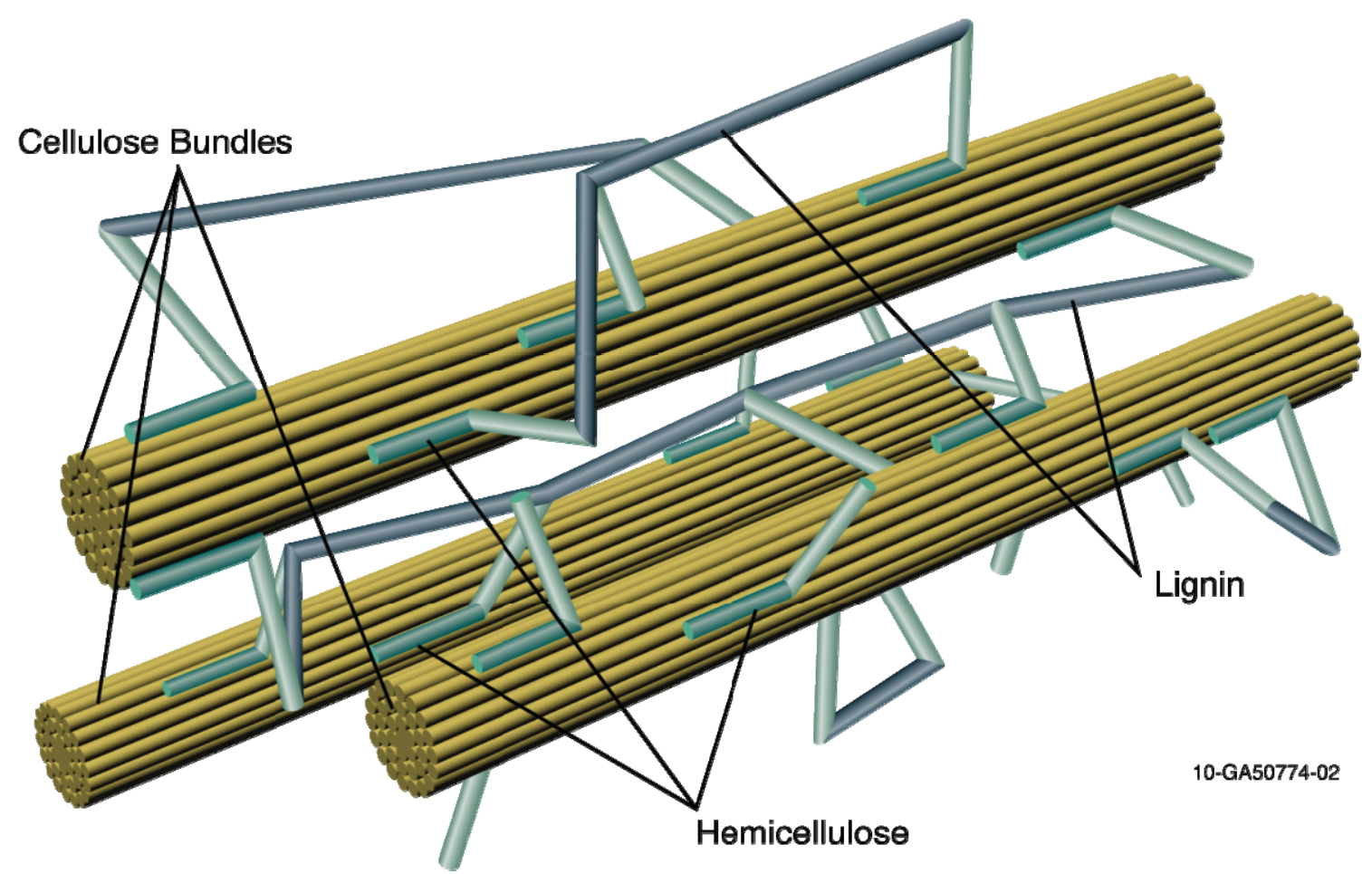

Figure 20. Arrangement of cellulose, hemicellulose, and lignin in biomass matrix (adapted from Murphy and McCarthy 2005; Shaw 2008).

\subsubsection{Cellulose}

Cellulose is a polymer of $\mathrm{D}$-glucose residues that are joined by $\beta 1 \rightarrow 4$ glycosidic bonds. Cellulose forms crystalline microfibrils that are surrounded by amorphous cellulose inside the cell (Chen et al. 2004). The structural integrity of cellulose is due to hydrogen bonding that occurs between glucose monomers (Goldstein 1981). According to Nelson and Cox (2005), cellulose is considered to be an abundant source of carbon in biomass. For hot pressing of wood material, Zandersons et al. (2004) conclude that the strength of binding in wood-based products mainly depends on converting cellulose to an amorphous state. Hon (1989) mentions that because cellulose is semi-crystalline in structure, the highly hydrogen-bonded cellulose cannot be dissolved easily in conventional solvents and is impossible to melt before it burns. Additionally, he finds that cellulose alone is not a suitable adhesive. To overcome this limitation, hydrogen bonds must be broken.

\subsubsection{Hemicellulose}

Hemicellulose contains $\beta 1 \rightarrow 4$-bonded $D$-xylan as the main chain, with branches made up of L-arabinose, D-glucose, D-galactose, 4-0-methyl-D-glucuronic acid, D-mannose, and L-rhamnose (Shambe and Kennedy 1985). Hemicellulose found in the cell wall is more of a heteropolysaccharide, which is a combination of many sugars other than simple glucose. The amorphous structure of hemicellulose is due to branching and is more easily hydrolyzed, or it can be dissolved in alkali solution. Some researchers believe that natural bonding may occur due to the adhesive degradation products of hemicellulose. 


\subsubsection{Lignin}

Lignin is a random-network polymer with a variety of linkages based on phenyl propane units (Zandersons et al. 2004). While the structure of lignin is complex, it is derived from two amino acids, phenylalanine and tyrosine (Nelson and Cox 2005), both of which contain aromatic rings. The lignin molecule in a plant provides many structural purposes, such as acting as glue to the cellulose fibers. The presence of lignin in the plant materials helps to form pellets without binders. Van Dam et al. (2004) report that lignin exhibits thermosetting properties at working temperatures of $>140^{\circ} \mathrm{C}$ and acts as intrinsic resin in binderless board production. Lignin is the component that permits adhesion in the wood structure and acts as a rigidifying and bulking agent (Anglès et al. 2001). Lehtikangas (1999) states that moisture of about $8-15 \%$ in biomass will reduce the softening temperature of lignin to $100-135^{\circ} \mathrm{C}$ by plasticizing molecule chains. The adhesive properties of thermally softened lignin are thought to contribute considerably to the strength characteristics of briquettes made of lignocellulosic materials (Granada et al. 2002).

\subsection{Common Binders Used in Biomass Densification}

Binders improve the binding characteristic of the biomass and produce a more durable product. Binders also help reduce wear in production equipment and increase abrasion-resistance of the fuel. In pellet production, binders are usually allowed, but must be specified on the final product. The addition of some binders can result in an increase in the sulfur content of densified biomass. The most commonly used binder in pellet making is lignosulphonates (Wafolin), or sulfonate salts made from the lignin in pulp mill liquors. The following subsections describe the different types of binders used for densification purposes (Tabil et al. 1997).

\subsubsection{Lignosulfonate}

Lignosulfonates are used in animal feeds and have been considered the most effective and popular binder (Anonymous 1983; MacMahon 1984). The composition includes sulfonate salts made from lignin of sulfite pulp mill liquors. The general levels of inclusions for effective binding are $1-3 \%$.

\subsubsection{Bentonite}

Bentonite, also referred to as colloidal clay, is commonly used as a binder in feed pelleting and is made up of aluminum silicate composed of montmorillonite.. During processing, binders form a gel with water to improve the binding characteristics. Pfost and Young (1973) report that the addition of bentonite at an inclusion rate of $100 \mathrm{~kg} /$ ton of feed mash significantly improves the durability of poultry feed consisting of ground yellow corn, ground sorghum grain, and soymeal ingredients.

\subsubsection{Starches}

Starches are popularly used in the food industry as a thickener or a binder. Wood (1987) reports that precooked starch works as a good binder during pelletization.

\subsubsection{Protein}

As mentioned previously, proteins are considered natural binders which are activated through the heat produced in the dies. Protein interacts with the other biomass compositions such as lipids and starches and results in formation of protein starch and lipid complexes which helps in producing more durable pellets. Some agricultural biomass, such as alfalfa, has high protein content and can be used as a binder to improve the durability of pellets made from lower protein biomass. 


\section{QUALITY OF DENSIFIED BIOMASS}

\subsection{Quality Attributes}

Quality attributes of the densified biomass play a major role in the end-user applications. Understanding the quality attributes of the densified biomass in terms of physical, chemical, and biochemical composition will help evaluate the quality changes of the biomass during the densification process. The quality of the densified biomass depends upon the feedstock composition, starch, protein, fiber, fat, lignin, and extractives; feed moisture content; feed particle size and distribution; feed conditioning, temperature/preheating of feed; added binders; and densification equipment variables (e.g., forming pressure, pellet mill, and roll press variables), which significantly affect the strength and durability of the densified products. The quality helps evaluate the effectiveness of the densification process and determine whether the pellets, cubes, or briquettes can withstand the compressive, impact, and water resistance during storage and transportation.

\subsubsection{Moisture Content (\%)}

The final moisture content of the pellets or briquettes from biomass is greatly dependent on process conditions like initial moisture content, temperature, and pressure. Higher moisture content in the final product results when the initial moisture content is greater than 15\%. Mani et al. (2006) observe that initial moisture content of $>15 \%$ and pressure $>15 \mathrm{MPa}$ has a negative effect on the final briquette quality where cracks were observed. Pellets with lower moisture content $(<5 \%)$ can result in revenue loss for the pellet manufacturer as they tend to break up, creating more fines during storage and transportation. Pellets with high moisture content can be subject to spoilage due to bacterial and fungal decomposition resulting in significant dry matter losses during storage and transportation (Tumuluru et al. 2010b).

\subsubsection{Unit Density $\left(\mathrm{kg} / \mathrm{m}^{3}\right)$}

Unit density and bulk density are important parameters for storage and transportation purposes. Several researchers have found that these parameters are greatly influenced by the material's moisture content and particle size, and the process pressure and temperature (Mani et al., 2006; Rhen et al., 2005; Shankar and Bandyopadhyay, 2005). Generally, they found that materials with higher moisture and larger particle sizes reduce the unit and bulk density of the product, while higher process temperatures and pressures increase the unit and bulk density. Rhen et al. (2005) also found a strong correlation between unit density and compression strength (i.e., high dry density corresponds to high compression strength). Tumuluru et al. (2010a), in their article on pelleting DDGS, supported the conclusions that both unit and bulk density greatly depends on feed moisture and die temperature where a maximum density of $1200 \mathrm{~kg} / \mathrm{m}^{3}$ is achievable at temperatures of about $100^{\circ} \mathrm{C}$ and feed moisture content of about $5-7 \%$.

\subsubsection{Bulk Density $\left(\mathrm{kg} / \mathrm{m}^{3}\right)$}

Bulk density is an important parameter for storage and transportation purposes. Pellets or briquettes with higher density are preferred as fuel because of their high energy content per unit volume and slow burning property (Kumar et al. 2009). Bulk density of pellets or briquettes greatly depends upon processing conditions, like temperature, moisture content, particle size, and pressure. High temperatures and lower moisture content favors high density products. Smaller particle size produces denser products. Tumuluru et al. (2010a), in their article on pelleting of Distillers' Dried Grains with Solubles (DDGS), indicate that lower moisture content and higher temperature result in denser DDGS pellets. Shankar and Bandyopadhyay (2004 and 2005) observe the same result for the fish feed pellets.

It is generally accepted that raw-material particle size influences the density of the pellets; e.g., small particles give a higher density for single pellets. This is true at least at low and medium densification 
pressures (Mani et al. 2006). On the other hand, Bergström et al. (2008), in their article on the effect of raw material particle-size distribution on the characteristics of Scots pine sawdust fuel pellets, indicate that the pellets produced show almost equal densities, indicating that the particle-size distribution of raw materials has only a minor influence on bulk density. They also reason that this could be a consequence of raw materials being ground during the pelletizing process, which results in a particle-size distribution different from the raw material. Bergström et al. (2008) also state that high pressure in the dies reduces the influence of the raw material particle-size distribution on the bulk density.

\subsubsection{Durability Index (\%)}

The durability index is a quality parameter defined as the ability of densified materials to remain intact when handled during storage and transportation. Thus, pellet durability is the pellet's physical strength and resistance to being broken up. This is measured by placing a quantity of pellets in a sealed metal box, which is spun round to abrade the pellets over one another. The amount of dust generated is then measured. Less dust generated means greater durability of the pellets (Kaliyan and Morey 2009). Durability or abrasive-resistance measurements help to simulate either mechanical or pneumatic handling forces, and control the feed quality. Different types of equipment (Holmen tester, tumbling can, Ligno tester, and Dural tester) are used to test durability (Kaliyan and Morey 2009). Feed moisture content acts a binding agent and as a lubricant, and it develops van der Waals forces by increasing the area of contact between the particles (Tabil and Sokhansanj 1996).

Moisture in the biomass helps to increase durability when water soluble compounds, such as sugar, starch, soda ash, sodium phosphate, potassium salt, and calcium chloride are present in the feed (Kaliyan and Morey 2009). High starch content in the feed acts as a binder; however, native starch has less binding capacity than gelatinized starch where the presence of moisture and heat accelerate the process (Wood 1987; Reece 1966; Israelsen 1981 and Thomas 1998). Protein present in the biomass feed will plasticize under heat and moisture and act as a binder, increasing the strength of the densified products (Winowiski 1988 and Briggs 1999). In addition, lignin, at elevated temperatures $\left(140^{\circ} \mathrm{C}\right)$, acts as a binder as the heat causes it to soften. However, Bradfield and Levi (1984) observe that when the content of lignin and other extractives increases to more than $35 \%$, the durability values decreased. They postulate that the auto-adhesive nature of lignin and other extractives decreases at higher concentrations due to their excessive mastic nature. Furthermore, high fat content in feeds will result in low durability as fat acts a lubricant between the feed particles and feed mill die wall (Stark 1994; Cavalcanti 2004; Briggs 1999; Richardson 1976; Angulo et al. 1996). Particle size is another important parameter that influences durability (Mani et al. 2002; 2003). Finer particles accept more moisture and, therefore, undergo a higher degree of preconditioning (Kaliyan and Morey 2009). Preheating or steam conditioning of the feed normally increases the activity of inherent binders like starch. Lignin also helps to create plastic deformation at higher temperatures, thus producing more durable pellets. Preheating temperatures are usually restricted to $300^{\circ} \mathrm{C}$ to limit the decomposition of the biomass (Kaliyan and Morey 2009). Steam conditioning also helps to release and activate natural binders and lubricants in the feed, increase starch gelatinization and protein denaturation, and produce durable and hard pellets (Kaliyan and Morey 2009).

Pellet mill variables, such as die dimensions and die speeds also influence durability. Smaller die dimensions produce greater gelatinization and higher durability. Die speeds of about 126-268 rpm are optimal for smaller pellets, and lower die speeds of about $6-7 \mathrm{~m} / \mathrm{s}$ are good for large-size corn-based swine die pellets (Stevens 1987).

\subsubsection{Percent Fines (\%)}

The presence of fines in the densified product is not desirable, especially when cofiring with other fossils fuels. Fines are generated during transportation and storage by the breakdown of the densified product. Pellets processed under suboptimal conditions - for example, at lower temperature, lower 
moisture content, and with less desirable chemical compositions, or with insufficient die size and roller speed - are less durable and can result in more fines in the final product. Percent fines, once they cross the storage threshold value in silos, can aggravate dust explosion and spontaneous combustion problems. Shankar et al. (2008b), in their studies on the effect of storage temperature on the quality of wood pellet properties, found that higher storage temperatures $\left(30-50^{\circ} \mathrm{C}\right)$ increase the percent fines by more than $1 \%$ during storage of 60 days.

\subsubsection{Calorific Value (MJ/kg)}

In general, the calorific value of pellets and briquettes depends upon process conditions like temperature, particle size, and in feed pretreatment. Generally, pellets with higher density have higher calorific value. The typical calorific values of wood pellets ranges from 17 to $18 \mathrm{MJ} / \mathrm{kg}$ (Tumuluru et al. 2010b). Pretreatment processes such as torrefaction and steam explosion can have a significant effect on the calorific value of the final product. The typical calorific values of straw-based pellets range from 17$18 \mathrm{MJ} / \mathrm{kg}$ (Satyanarayana et al. 2010). Pretreatment processes such as torrefaction and steam explosion can have a significant effect on the calorific value of the final product and increase them from $20-22 \mathrm{MJ} / \mathrm{kg}$. Tumuluru et al. (2010c \& d), in their studies on pretreatment of corn stover and miscanthus biomass using the torrefaction method, found that the calorific value increases by about $20 \%$ to its original value when torrefied at temperature ranges of $200-300^{\circ} \mathrm{C}$.

\subsection{Pretreatment Technologies to Improve Quality Attributes}

Pretreatment of herbaceous and woody biomass increases both its physical and chemical properties, thereby making the material easy to densify and helping minimize the costs of transport, handling, and storage. Pretreatment using high temperatures makes the material more energy dense, opens up the cell-wall structure, and makes the material easy to densify and transport.

\subsubsection{Grinding}

Prior to densification, biomass is ground to a certain particle size. This grinding partially breaks down the lignin, increases the specific area of the materials, and contributes to better binding. Peleg (1977), Peleg and Mannheim (1973), and Mani et al. (2006) concluded that particle size has a significant effect on the binding characteristics and the mechanical properties of pellets. Fine powders have advantages in densification because they have a higher number of contact points, more exposed surface area, and greater surface energy per unit of weight regardless of their physical and chemical characteristics.

\subsubsection{Preheating}

Preheating the biomass before densification is widely used as it results in a higher quality product. Most commercial pellet or briquette producers use preheating to form more stable and dense pellets or briquettes (Bhattacharya et al. 1989; Bhattacharya 1993). Aqa and Bhattacharya (1992) indicate that preheating biomass could significantly increase the throughput of the pelletizing machine and reduce the energy requirement per kilogram of the biomass pellets formed.

\subsubsection{Steam Conditioning and Explosion}

Steam explosion is a technique that has been widely used and is found to be an efficient method of pretreatment for both herbaceous and woody biomass, either for densification or ethanol production. In general, compressed hot water or steam is commonly used in this process. During steam explosion, which is a high-temperature, short-time process, the material is introduced into a reactor and heated under pressure at elevated temperatures. This process produces significant physical, chemical, and structural changes in the biomass and makes more lignin sites available for binding during pelletization (Liu and 
Wyman 2005). Steam explosion breaks down the lignin into low-molecular weight products, which retain the basic lignin structure and are moderately reactive. Mosier et al. (2005) postulate that the compression and compaction characteristics of the biomass can be improved by disrupting lignocellulosic biomass materials via steam explosion pretreatment.

Steam explosion also has benefits in terms of enzymatic hydrolysis, which are: (1) lignin is extensively depolymerized by cleavage of the $\beta$-aryl-ether bonds and is soluble in alkaline solutions or certain organic solvents, and (2) hemicelluloses are partially broken down, are predominantly soluble in water, and apparently condense with lignin, thereby increasing the lignin content. The major effect of a steam explosion is the large increase in the accessibility of cellulose to enzymatic hydrolysis. (Marchessault et al. 1981a; 1981b; Marchessault 1961; DeLong 1981; Foody 1980; Nunes and Pourquie, 1996). According to Zandersons et al. (2004), the activation of lignin and changes in the cellulosic structure during steam explosion help in the formation of new bonds, which in turn create more durable pellets. Steam explosion brings about significant changes in the materials as the hemicelluloses become more water soluble, cellulose is slightly depolymerized, and the lignin melts and is depolymerized (Toussaint et al. 1991). Kaar et al. (1998) note that steam explosion requires little or no chemical input and thus is more environmentally friendly than chemical treatment methods.

\subsubsection{Torrefaction}

Torrefaction is a method of changing the properties of biomass materials by slowly heating it in an inter-environment to a maximum temperature of $300^{\circ} \mathrm{C}$ (Felfli et al. 1998). The process is also called a mild pyrolysis as most of the smoke-producing compounds and other volatiles are removed resulting in a final product that has approximately $70 \%$ of the initial weight and $80-90 \%$ of the original energy content (Arcate 2000 and 2002). Thus, treatment yields a solid uniform product with lower moisture content and higher energy content compared to the initial biomass.

During the initial heating process, biomass undergoes drying and heating until most of the water is removed due to chemical reactions through a thermo-condensation process. This happens at over $160^{\circ} \mathrm{C}$ and also results in the formation of $\mathrm{CO}_{2}$ (Zanzi et al. 2002). Between 180 and $270^{\circ} \mathrm{C}$, the reaction is more exothermal, and the degradation of hemicellulose continues. At this point, the biomass begins to brown and give off additional moisture, carbon dioxide, and large amounts of acetic acid with some phenols that have low energy values (Zanzi et al. 2002). The major reactions of decomposition affect the hemicelluloses, and to a lesser degree, the lignin and cellulose (Shafizedeh 1985; Williams and Besler 1996). The biomass retains most of its energy and simultaneously loses its hygroscopic properties. At about $280^{\circ} \mathrm{C}$, the reaction is entirely exothermic and gas production increases, resulting in the formation of carbon monoxide, hydrocarbons like phenols and cresols, and other, heavier products. Temperatures over $300^{\circ} \mathrm{C}$ are not recommended as these initiate the pyrolysis process (Bourgeois and Doat 1985). There are many advantages in the pretreatment of biomass using torrefaction before densification. Torrefaction reduces variability in the feedstock caused by differences in types and species of raw materials, climatic and seasonal variations, storage conditions, and time (Lehtikangas 1999). It also helps develop a uniform feedstock. Furthermore, torrefaction affects biomass physical characteristics like grindability, hydrophobicity and pelletability.

Lignin in the biomass is considered to be the basic binding agent, and the pelletability of any biomass is evaluated based on the amount of lignin present. In general, it is believed that the higher the amount of lignin, the better the binding and milder the process conditions. Woody biomass has more lignin than lignocellulosic biomass (Table 7). The torrefaction process opens up a number of lignin-active sites by breaking down the hemicellulose matrix and forming fatty unsaturated structures that help create better binding. Bulk densities of the torrefied pellets are in the range of $750-50 \mathrm{~kg} / \mathrm{m}^{3}$ (Bergman and Kiel 2005). The flow diagram for torrefaction and pelletization (TOP) process proposed by Bergman (2005) is shown in Figure 21. 


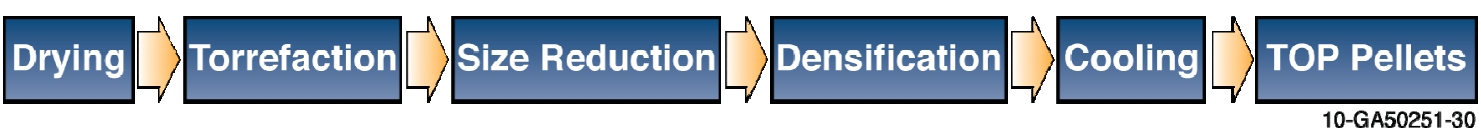

Figure 21. Flow diagram for production of torrefied wood pellets.

Furthermore, torrefaction affects biomass physical characteristics like grindability, hydrophobicity, pelletability, and calorific value. For example, during torrefaction, biomass loses the tenacious nature that is coupled to the breakdown of the hemicellulose matrix and depolymerization of the cellulose, resulting in a decrease in fiber length (Bergman et al. 2005; Bergman and Kiel 2005; Hakkou et al. 2006). Torrefaction also results in the shrinking of the biomass structure, making it light-weight, flaky, and fragile, improving the grinding and pulverizing process (Arias et al. 2008). Studies conducted on grinding-energy requirements of raw and torrefied biomass like willow, woodcuttings, demolition wood, and coal, indicate a significant reduction in power consumed (by about 70-90\%) for torrefied biomass (Bergman and Kiel 2005). Also, mill capacities increase from about 7.5 to 15 ton/hr.

Torrefaction causes biomass to become hydrophobic mainly due to the destruction of the hydroxyl group $(\mathrm{OH})$ and does not support the formation of hydrogen bonds (Pastorova et al. 1993). The chemical rearrangement reactions from torrefaction result in the formation of non-polar unsaturated structures that help preserve the biomass by reducing biological degradation, which is similar to coal (Bergman and Kiel 2005; Wooten et al. 2000). Torrefaction also improves binding during pelletization by increasing the number of available lignin sites, breaking down the hemicellulose matrix, and forming fatty unsaturated structures, resulting in bulk densities $750-850 \mathrm{~kg} / \mathrm{m}^{3}$ (Bergman and Kiel 2005). The torrefaction process drives off more oxygen and hydrogen compared to carbon, which in turn increases calorific value of the product (Uslu et al. 2008). The net caloric value of torrefied biomass ranges from 18 to $23 \mathrm{MJ} / \mathrm{kg}$ (LHV, dry) or 20 to $24 \mathrm{MJ} / \mathrm{kg}$ (HHV, dry) (Bergman et al. 2005; Prins 2005).

Torrefaction not only improves the physical properties of biomass, but also significantly changes its proximate and ultimate composition, making it more suitable for fuel applications. In general, an increase in torrefaction temperature results in an increase in carbon content and a decrease in hydrogen and oxygen content due to the formation of water, carbon monoxide, and carbon dioxide. This process also causes the hydrogen to carbon ratio $(\mathrm{H} / \mathrm{C})$ and oxygen to carbon ratio $(\mathrm{O} / \mathrm{C})$ to decrease with increasing torrefaction temperature and time, which results in less smoke and less water-vapor formation, and reduces energy losses during the combustion and gasification processes. Sadaka and Negi (2009) carried out a wide range of torrefaction studies showing a significant decrease in moisture content $(70.5,49.4$, and $48.6 \%)$ and corresponding increase in heating value $(15.3,16.9$, and 6.3\%). Zanzi et al. (2002) made similar observations where increasing the torrefaction temperature from 230 to $280^{\circ} \mathrm{C}$ and time from 1 to 3 hours increased the carbon content and decreased the hydrogen, nitrogen, and oxygen content due to the formation of water, carbon monoxide, and carbon dioxide.

A study of reed canary grass and wheat straw torrefaction at $230,250,270$, and $290^{\circ} \mathrm{C}$ for 30 minute residence times found that the moisture content decreases from an initial value of 4.7 to $0.8 \%$ and the carbon content values increase from 48.6 to $54.3 \%$, hydrogen content decreases from 6.8 to $6.1 \%$, and nitrogen content decreases from 0.3 to $0.1 \%$, respectively (Bridgeman et al. 2008). Table 8 and Table 9 present the physical properties and ultimate composition of the torrefied woody and lignocellulosic biomass properties compared to the original raw materials. 
Table 8. Physical properties of wood chips, regular and torrefied pellets (Mitchell et al. [2007]).

\begin{tabular}{lccc}
\hline \multicolumn{1}{c}{ Physical Property } & Wood Chips & Wood Pellets & Torrefied Wood pellets \\
\hline Moisture content $(\%)$ & 35 & $6-10$ & $1-5$ \\
Caloric value $(\mathrm{MJ} / \mathrm{kg})$ & 10.5 & 16 & 21 \\
Bulk density $(\mathrm{kg} / \mathrm{m} 3)$ & $300-500$ & $600-650$ & $750-800$ \\
Energy bulk density & 5.8 & 9 & 16.7 \\
Hygroscopic nature & Wets & Wets & Hydrophobic \\
Behavior in storage & Gets moldy & Deteriorates and & Stable \\
& Dry matter loss & gets moldy & \\
\hline
\end{tabular}

Table 9. Ultimate analysis, HHV (dry ash free basis), and moisture content of untreated and torrefied biomass (Bridgeman et al. [2007]).

\begin{tabular}{llllll}
\hline & Raw & \multicolumn{4}{c}{ Torrefaction temperature $\left({ }^{\circ} \mathrm{K}\right)$} \\
\hline Reed Canary Grass & & 503 & 523 & 543 & 563 \\
\hline C (\%) & 48.6 & 49.3 & 50.3 & 52.2 & 54.3 \\
H (\%) & 6.8 & 6.5 & 6.3 & 6.0 & 6.1 \\
N (\%) & 0.3 & 0.1 & 0.0 & 0.1 & 0.1 \\
O (\%) & 37.3 & & 37.0 & 37.3 & 36.3 \\
Moisture (\%) & 4.7 & 2.5 & 1.9 & 1.3 & 1.2 \\
CV (kJ/kg) & 19,500 & & 20,000 & 20,800 & 21,800 \\
\hline Wheat straw & & & & & \\
\hline C (\%) & 47.3 & 48.7 & 49.6 & 51.9 & 56.4 \\
H (\%) & 6.8 & 6.3 & 6.1 & 5.9 & 1.0 \\
N (\%) & 0.8 & 0.7 & 0.9 & 0.8 & 27.6 \\
O (\%) & 37.7 & & 35.6 & 33.2 & 27.6 \\
Moisture (\%) & 4.1 & 1.5 & 0.9 & 0.3 & 0.8 \\
CV (kJ/kg) & 18,900 & 19,400 & 19,800 & 20,700 & 22,600 \\
\hline Willow & & & & & \\
\hline C (\%) & 49.9 & 50.7 & 51.7 & 53.4 & 54.7 \\
H (\%) & 6.5 & 6.2 & 6.1 & 6.1 & 6.0 \\
N (\%) & 0.2 & 0.2 & 0.2 & 0.2 & 0.1 \\
O (\%) & 39.9 & 39.5 & 38.7 & 37.2 & 36.4 \\
Moisture (\%) & 2.8 & 0.5 & 0.1 & 0.1 & 0.0 \\
CV (kJ/kg) & 20,000 & 20,600 & 20,600 & 21,400 & 21,900 \\
\hline
\end{tabular}

\subsubsection{AFEX Pretreatment}

AFEX (ammonia fiber explosion) is a pretreatment method that uses aqueous ammonia at elevated temperatures and pressures (Tey-mouri et al., 2005). This process reduces lignin and removes some hemicellulose while decrystallizing cellulose in the biomass. A flow diagram of the AFEX process is 
shown in Figure 22. The important process variables in AFEX pretreatment are ammonia loading, water loading, reaction temperature, and residence time. The feedstock variables include moisture content, particle size, and feedstock composition. The typical ranges of the process conditions commonly used in AFEX process are (a) pressure, $20-30 \mathrm{~atm}$; (b) temperature, $70-140^{\circ} \mathrm{C}$; (c) residence time, $5-10$ minutes; (d) ammonia: dry biomass loading, $0.3-2.0$ to $1(\mathrm{w} / \mathrm{w})$; and (e) water: dry biomass content, $0.2-2.5$ to 1 (w/w) (Dale, 2009).

Compared to other pretreatment methods, AFEX retains most of the hemicellulose and cellulose sugars in their polymeric forms after pretreatment. The major advantage of this process is little biomass degradation (Dale 2009). Even though AFEX causes physical and chemical changes in the biomass, it does not result in prehydrolysis of hemicellulose to monomeric sugars. Consequently, AFEX-treated biomass may be considered a stable intermediate that can be stored, transported, and integrated with subsequent processing steps. During AFEX pretreatment, 99\% of the ammonia is recovered and reused, while the remainder serves as a nitrogen source for downstream fermentation.

AFEX pretreatment of biomass offers significant advantages for densification, storage, and transportation. Because AFEX-treated biomass is relatively dry and inert, it is more easily stored, transported, and densified to further improve bulk handling properties. These unique features allow biomass to be preprocessed and treated at a site close to the biomass source and then shipped to a centralized biorefinery location. AFEX treatment transfers some lignin and hemicellulose oligomers to the surface of biomass fibers where it can act as a binding agent. Initial trials at MSU have shown that the density and other properties of pellets of AFEX-treated biomass are better than pellets of untreated biomass (Dale 2009). A collaborative project between North Dakota State University, South Dakota State University, and Michigan State University on densifying and handling of AFEX biomass has indicated that pelleting and briquetting of AFEX-treated corn stover offers higher densities of 3-5 times compared to baled biomass. Also the pellets produced were hard and durable with a specific gravity of up to 1.16 without using any binders, whereas untreated corn stover pellets are much less dense and are not durable at all (Dale 2009).

Integrating this pretreatment with a densification process can help reduce many logistics problems (Dale 2009). Eranki et al. (2011), in their study on advanced biomass processing depots, evaluated densifying AFEX products to solve storage and transportation logistics. 


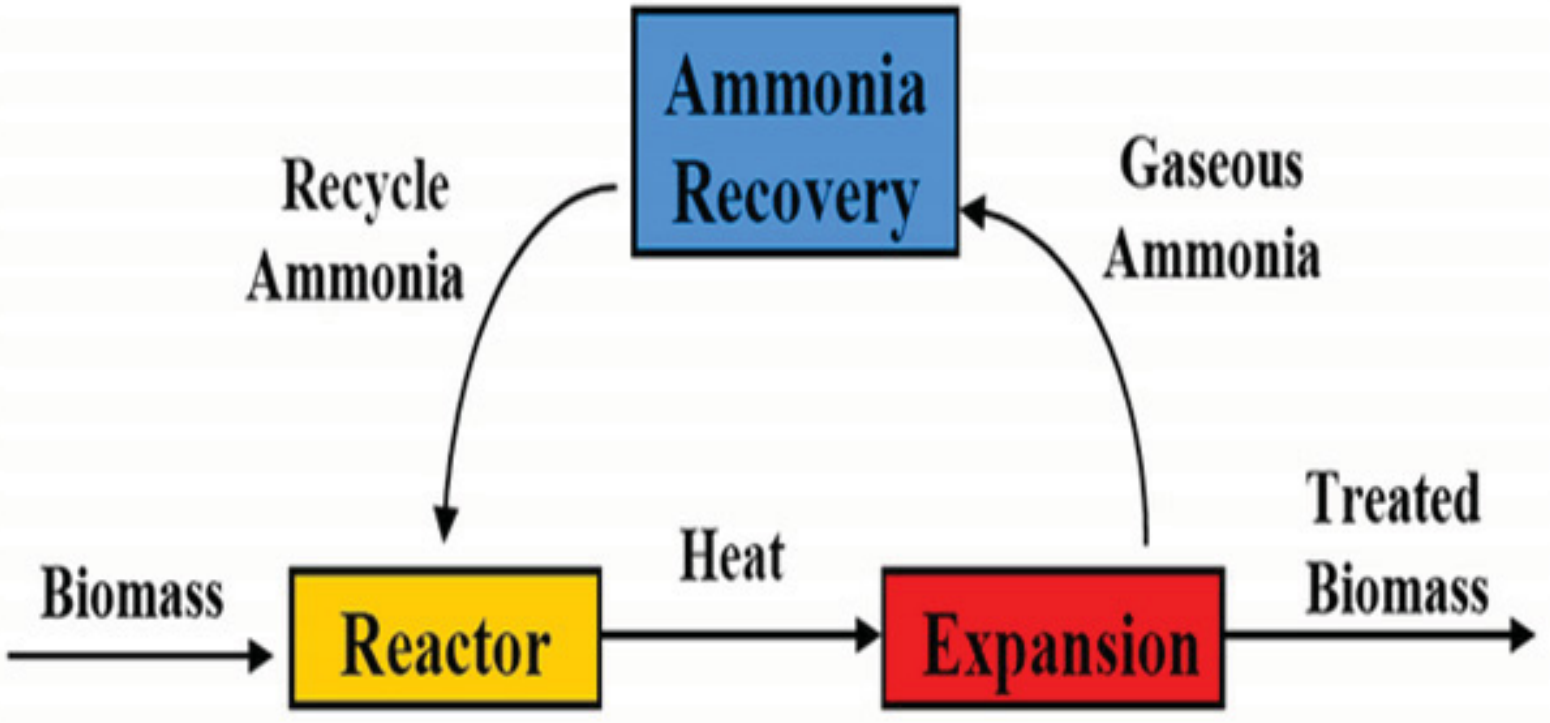

Figure 22. APEX process (Dale 2009). 


\section{MODELING AND OPTIMIZATION}

\subsection{Compression Models}

Compression models help reveal the behavior of the biomass grinds or particles during pelleting and can help optimize the pressures required to obtain a quality pellet. Pellets can be formed either by using pressure agglomeration or compaction in which the particles are bound together with or without binders. Compression tests and models have been widely used for pelletization in the areas of metal, pharmaceuticals, agriculture, and food. Several equations expressing the relationship between pressure and time during compaction of different raw materials are available in literature.

The majority of the compression models used in pharmaceutical and biomass materials has been discussed and reviewed in detail by Tabil and Sokhansanj (1996), Adapa et al. (2002a), Denny (2002) and Mani et al. (2003). Among the different compression models, the Heckel (1961) and Cooper-Eaton models (1962) are widely used for understanding the compression behavior of pharmaceutical and cellulosic materials and for soft and fluffy materials (Kawakita and Ludde 1971; Mani et al. 2004). Tabil and Sokhansanj (1996a and b) and Adapa et al. (2002a) studied the applicability of the models for alfalfa pellets and concluded that Cooper-Eaton (1962), Heckel (1961), and Panelli-Filho models provided a better fit to the compression data. The compression models, which have been widely used in biomass densification, are described in the following subsections (Tabil and Sokhansanj 1996a and b; Tabil 1996; Mani et al. 2002 and Adapa et al. 2009).

\subsubsection{Spencer and Heckel Model}

The Spencer and Heckel (1961) model equation is used to express density in terms of packing fractions as a function of applied pressure:

$\ln \frac{1}{1-\rho_{f}}=m \rho+b$

where

$\rho_{f}=\frac{\rho}{\rho_{1} x_{1}+\rho_{2} x_{2}}$.

Equations (6) and (7) are used to describe the compression behavior of the powder materials. The constants $m$ and $b$ describe the two stages of compression: (1) pre-occupation and (2) the particle rearrangement due to densification.

Shivanand and Sprockel (1992) indicated that constant $b$ is related to relative density at particle rearrangement $\left(\rho_{f}\right)$ by the following equation:

$b=\ln \frac{1}{1-\rho_{f}}$.

Equation (8) indicates that higher $\rho_{f}$ will result in greater volume reduction due to more particle rearrangement, and $m$ is the reciprocal of the mean yield pressure required to induce elastic deformation. Higher $m$ values indicate the onset of plastic deformation due to low yield pressures, indicating the material is more compressible. 


\subsubsection{Walker Model}

Walker (1923) developed a model based on the experimental data on compressibility of powders and expressed the volume ratio $\left(V_{R}\right)$ as a function of applied pressure $(P P)$.

$V_{R}=m \ln P+b$

$V_{R}=\frac{V}{V_{S}}$

where

$$
\begin{aligned}
P & =\text { applied pressure }(\mathrm{MPa}) \\
V_{R} & =\text { volume ratio } \\
V & =\text { volume of compact at pressure } P\left(\mathrm{~m}^{3}\right) \\
V_{S} & =\text { void free solid material }\left(\mathrm{m}^{3}\right) .
\end{aligned}
$$

\subsubsection{Jones Model}

Jones (1960) developed a model for the density and pressure data of compacted metal powder.

$\ln \rho=m \ln P+b$

$b=\ln \left(\frac{1}{1-\rho_{0}}\right)$ and $\rho f=\frac{\rho}{\rho_{1} x_{1}+\rho_{2} x_{2}}$

where

$\rho f=$ packing fraction or relative density of the material after particle rearrangement

$\rho_{0}=$ relative density of the powder mixture $\left(\mathrm{kg} / \mathrm{m}^{3}\right)$

$\rho_{1}$ and $\rho_{2}=$ the particle density of component of the mixture $\left(\mathrm{kg} / \mathrm{m}^{3}\right)$

$x_{1}$ and $x_{2}=$ mass fraction of the component of the mixture.

Constants $b$ and $m$ are determined based on the intercept and slope of the extrapolated linear region of the plot $\ln \left(\frac{1}{1-\rho f}\right)$ vs. $P$.

Higher values of $\rho f$ will indicate increased volume reduction of the samples due to particle rearrangement.

Constant $m$ is shown as reciprocal to the mean yield pressure required to induce the elastic deformation (York and Pilpel 1973). A large $m$ value will indicate that yield pressure is low and plastic deformation onsets at relatively low pressures, showing that the material is more compressible.

\subsubsection{Cooper-Eaton Model}

The Cooper-Eaton model (1962) assumes compression as nearly two independent probabilistic processes: (1) filling of voids of the same size as the particles and (2) filling of voids smaller than particles. 
$\frac{V_{0}-V}{V_{0}-V_{S}}=a_{1} e^{-\frac{k_{1}}{P}}+a_{2} e^{-\frac{k_{2}}{P}}$

where

$$
\begin{aligned}
& V_{0}=\text { volume of compact at zero pressure }\left(\mathrm{m}^{3}\right), a_{1}, a_{2} \\
& k_{1}, k_{2}=\text { Cooper-Eaton model constants. }
\end{aligned}
$$

The practical difficulty in the application of the Cooper-Eaton model (1962) is understanding the physical significance of the constants in the equation (Comoglu 2007). It is, therefore, more suitable to single-component systems (Comoglu 2007).

\subsubsection{Kawakita and Ludde Model}

The Kawakita and Ludde model includes the pressure and volume factors.

$\frac{P}{C}=\frac{1}{a b}+\frac{P}{a}$

$C=\frac{V_{0}-V}{V_{0}}$

where

$C=$ degree of volume reduction or engineering strain

$a$ and $b=$ Kawakita-Ludde model constants related to characteristics of the powder.

The linear relationship between $\frac{P}{C}$ and $P$ allows the constants to be evaluated graphically. This compression equation holds true for soft and fluffy powders (Denny 2002; Kawakita and Ludde 1971). Any deviations from this expression are sometimes due to fluctuations in the measured value of $\mathrm{V}_{0}$. Mani et al. (2004) indicated that constant $a$ is equal to the initial porosity of the sample, while constant $\frac{1}{b}$ is related to the failure stress in the case of piston compression.

\subsubsection{Sonnergaard Model (Log-Exp-Equation)}

Sonnergaard (2001) model is a log-exp equation that considers two processes simultaneously: (1) a logarithmic decrease in volume by fragmentation, and (2) an exponential decay representing plastic deformation of powders.

$V=V_{1}-w \log P+V_{0} \exp \left(-P / P_{m}\right)$

where

$$
\begin{aligned}
& V_{1}=\text { volume at pressure } 1(\mathrm{MPa}) \\
& P_{m}=\text { mean pressure }(\mathrm{MPa}) \\
& w=\text { constant. }
\end{aligned}
$$

Sonnergaard (2001) suggests that his model provides better regression values than either the Cooper-Eaton (1962) or the Kawakita and Ludde models. This model is suitable for medium-pressure applications (approximately $50 \mathrm{MPa}$ ). 


\subsubsection{Panelli-Filho Model}

Panelli-Filho model is given by the following expression:

$\ln \frac{1}{1-\rho_{r}}=A \sqrt{P}+B$

where

$\rho_{r}=$ relative density of the compact

$A=$ parameter related to densification of the compact by particle deformation

$B=$ parameter related to powder density at the start of compression.

\subsection{Response Surface Models and Optimization}

\subsubsection{Experimental Designs}

Experimental designs are widely used for product development with a minimum number of experimental runs. These designs will help explain the effect of process variables on the quality of the product. Different experimental designs, like factorial, central composite, Box-Behnken, and rotatable, can be used to carry out the densification experiments in an economical way. Rotatable experiments are the best for product development (Mullen and Ennis 1979). The main advantage of the rotatable design over the others is that it minimizes the number of experiments for a given set of process variables tested. In general, the objective of the researchers or commercial processers is to find the optimal conditions easily using a small number of level combinations and experiments.

These experimental designs help the researcher carry out the experiments for each variable at different levels. In general, each variable will have a number of levels (this is a range of values over which the variable will vary), and when these levels are combined for all the variables, this will give the total number of level combinations. In rotatable experimental designs, the range should be scanned to see that experimental limits do not go to extremes. The levels of the variables are generally divided into a lower average value, center value, and higher average value. In between lower and center level, other levels are also possible. In rotatable and other experimental designs, all the variables are coded; calculations are performed using these coded variables, which are converted to the original variables at the conclusion of the analysis.

Many researchers have successfully used these designs for developing response surface models (RSM) to understand the effect of process variables on product characteristics (Shankar and Bandyopadhyay 2004; Shankar and Bandyopadhyay 2005; Shankar et al. 2008a; Rout and Bandyopadhyay 1999; and Bandyopadhyay and Rout 2001). They have also used these models for optimization. Harper (1981), in his studies on extrusion, indicate that RSM is a good approach to work on optimization of extrusion process variables when all the independent variables and their levels and responses are not clearly understood. Many researchers have used RSM for process and product development and optimization (Khuri and Cornell 1987; Frazier et al. 1983; Bhattacharya and Prakash 1994; Rout and Bandyopadhyay 1999; Giri and Bandyopadhyay 2000; Sacchetti et al. 2004; Shankar and Bandyopadhyay 2004 and 2005).

\subsubsection{Response Surface Models (RSM)}

Response surface methodology (RSM) is a collection of mathematical and statistical techniques that is useful for modeling and analysis of problems in which the response of interest is influenced by several variables and the objective is to optimize this response (Montgomery 1976). 
Response surfaces are represented mathematically by equations (called models), which are similar to the regression equations. These models can be for $n$ number of variables. The general form of the response surface model is in Equation (18) (Montgomery 1976).

$y=f\left(x_{1}, x_{2}, x_{3}, x_{n}\right)+\varepsilon$

where

$y=$ response or dependent variable

$x_{1}, x_{2}, x_{3}, x_{n}=$ process or independent variables

$\varepsilon=$ noise or error observed in the response variable $y$.

In general the first step in RSM modeling is to find a suitable approximation for the true functional relationship between $y$ and the set of independent variables. Usually a low-order polynomial in some region of the independent variables is considered. If the response is well modeled by a linear function of the independent variables, then the approximate function is a first-order model.

The general form of first order model is:

$y=\beta_{0}+\beta_{1} x_{1}+\beta_{2} x_{2}+\beta_{3} x_{3}+\beta_{k} x_{k}+\varepsilon$

If the process involves curvature in the system, then a polynomial of higher degree must be used, such as second-order model.

$y=\beta_{0}+\sum_{i=1}^{k} \beta_{i} x_{i}+\sum_{i=1}^{k} \beta_{i i} x_{i}^{2}+\sum \sum_{i<j} \beta_{i j} x_{i} x_{j}+\varepsilon$

In general, all the RSMs utilize one or more of these models. It is unlikely that a polynomial model will be a reasonable approximation of the true functional relationship over the entire space of the independent variables, but for a relatively small region, they usually work quite well. The objectives of these models are to find the optimum operating conditions for a system to determine the region in which the requirements are most satisfied (Montgomery 1976).

\subsubsection{First-Order Models Analysis-Steepest Ascent or Descent Method}

The method of the steepest ascent is a procedure for moving sequentially along the path of the steepest ascent in the direction of maximum increase on the response. In the case of minimization, it is called steepest descent method. The direction of the steepest ascent is the direction in which the response increases steeply, whereas the opposite is true for minimization. Usually, the path of steepest ascent is the line through the center of the region of interest and normally to the fitted surface, indicating that the steps along the path are proportional to the regression coefficients. Experiments will be conducted along the path of steepest ascent until no further increase in response is observed. This procedure is continued until the experimenter reaches the vicinity of the optimum (Montgomery 1976).

\subsubsection{Second-Order Models Analysis}

In second-order model analysis, the experimenter wants to find the optimum set of operating conditions for the $x s$ and to characterize the nature of the response surface (Montgomery 1976). To find the levels of the process variables $x_{1}, x_{2}, x_{3} \ldots x_{k}$, or to find the optimized predicted response, there exists a set of variables of $x_{1}, x_{2}, x_{3} \ldots x_{k}$ for which the partial derivatives

$\frac{\partial \hat{y}}{\partial x_{1}}=\frac{\partial \hat{y}}{\partial x_{2}}=\cdots \frac{\partial \hat{y}}{\partial x_{k}}=0$. 
This point $x_{1}, x_{2}, x_{3}, x_{k s}$ is called stationary point, which can be a representation of (1) a maximum response, (2) minimum response, or (3) a saddle point. The mathematical solution for the second order models is given by the following (Montgomery 1976):

$\hat{y}=\hat{\beta}_{0}+x^{\prime} b+x^{\prime} B x$

where

$x=\left[\begin{array}{c}x_{1} \\ x_{2} \\ x_{3} \\ \cdot \\ \cdot \\ \cdot \\ x_{k}\end{array}\right] b=\left[\begin{array}{c}\hat{\beta}_{1} \\ \hat{\beta}_{2} \\ \hat{\beta}_{3} \\ \cdot \\ \cdot \\ \hat{\beta}_{k}\end{array}\right]$ and $B=\left[\begin{array}{c}\widehat{\beta_{11}}, \widehat{\beta_{12}} / 2, \ldots \widehat{\beta_{1 k}} / 2 \\ \widehat{\beta_{22}}, \ldots \widehat{\beta_{2 k}} / 2 \\ s y m ., \ldots \widehat{\beta_{k k}}\end{array}\right]$

$b=(k \times 1)$ vector of the first-order regression coefficients and $B$ is a $(k \times k)$ symmetric matrix whose main diagonal elements are pure quadratic coefficients $\left(\hat{\beta}_{i i}\right)$ and whose half-diagonal elements are one-half of the mixed quadratic coefficients $\beta_{i i}, i \neq j$.

The derivative of $\hat{y}_{w}$ with respect to the elements of the vector $x$ equated to 0 is:

$\partial \frac{\hat{y}}{\partial x}=b+2 B x=0$

where the stationary point is the solution to Equation (25):

$x_{s}=-\frac{1}{2} B^{-1} b$

\subsubsection{Characterizing the Response Surface}

The stationary point found should be used to characterize the response surface in the vicinity of this point. Characterization of the stationary point requires determining whether the stationary point is a point of maximum or minimum response or a saddle point. The response can be predicted at a stationary point using Equation (26):

$\hat{y}=\hat{\beta} 0+\frac{1}{2} x_{s}{ }^{\prime} b$

\subsubsection{Contour Map and Canonical Analysis}

Contour-map analysis is a more or less straightforward method if the number of variables is less than two or three. Construction and interpretation of the contour plots are relatively easy. Also, when there are few variables, a more formal analysis, called the canonical analysis, may be more useful (Montgomery 1976).

Canonical analysis helps to transform the model to a new coordinate system with the origin at the stationary point $x_{s}$ and then to rotate the axes of this system until they are parallel to the principal axes of the fitted response surface, which results in a new fitted model:

$\hat{y}=\hat{y}_{s}+\lambda_{1} w_{1}^{2}+\lambda_{2} w_{2}^{2}+\cdots \lambda_{k} w_{k}^{2}$.

where $\left\{w_{1}\right\}$ are the transformed independent variables and $\left\{\lambda_{1}\right\}$ are constants and the above model is the canonical form of the model. Furthermore, $\left\{\lambda_{1}\right\}$ are just the eigenvalues or the characteristic roots of the Matrix B. The nature of the response surface can be determined from the stationary point and the sign and 
magnitude of the $\left\{\lambda_{1}\right\}$. If $\left\{\lambda_{1}\right\}$ are all positive, then $x_{S}$ is a point of minimum response; if $\left\{\lambda_{1}\right\}$ are all negative, then the $x_{S} \mathrm{x}$ is a point of maximum response and if $\left\{\lambda_{1}\right\}$ is a mixture of positive and negative points, then $x_{s}$ is a saddle point. Further, the surface is steepest in the $w_{i}$ direction for which $\left|\lambda_{i}\right|$ is the greatest (Montgomery 1976).

Even though RSM, which is a combination of mathematical and statistical techniques, is widely used to study the effect of process variables on product properties, to get a model that is a true representation of the surface is very difficult when the number of process variables is greater than three (Khuri and Cornell 1987). RSM is considered an intuitively simple method, but precise interpretation is tedious when optimizing a function with more than three independent variables at wider experimental range. Also, solving the RSM equations using canonical analysis involves orthogonal rotation of canonical variables where the interpretation is considered very difficult (Hotelling 1935 and 1936). In using canonical analysis, the user must examine two sets of coefficients simultaneously, which may often be complex and difficult to interpret (Nie et al. 1970). To overcome these practical problems, advanced computational methods, which are based on evolutionary operations, are now commonly used for optimization of multivariate or complex problems.

\subsubsection{Optimization using Evolutionary Algorithms}

Living organisms are consummate problem solvers. Organisms come by their abilities through the apparently undirected mechanism of evolution and natural selection. Researchers who search for solutions to complex problems see evolution as a remarkable power that can be emulated. The process of natural selection helps eliminate one of the greatest hurdles in software design-specifying, in advance, all features of a problem and the actions necessary to deal with them. By harnessing the mechanisms of evolution, researchers should be able to "breed" programs that solve problems even when no person can fully understand their structure (Holland 1992).

The process of natural selection, which is a typical feature of genetic algorithms (GAs), makes it possible to explore a far greater range of potential solutions to a problem than do conventional programs (Holland 1992). Hill climbing is one of the conventional techniques that has been widely used for exploring complex landscapes to find possible solutions. In this process, finding a maximum or minimum starts at some random point, and if a slight modification improves the quality of the solution, the search is continued in that direction; otherwise, the search is performed in the opposite direction. Complex problems, however, have landscapes with many high and low points. With increases in the number of dimensions in the problem space, the resulting topography may include tunnels, bridges, and even more convoluted topological features that make it difficult to find a right solution (Holland 1992). In such problems, algorithms that work based on evolutions can help find globally optimum conditions. One such algorithm that has been widely used for optimization is the GA.

GAs are exhaustive search tools that have gained popularity in process engineering design, and new optimization techniques based on evolution have shown remarkable advantages for multiple process-parameters optimization. GAs are powerful stochastic optimization techniques that are based on the methods of evolution and find extensive application where process systems are highly complex and nonlinear (Holland 1992; Gen and Cheng 1997; Goldberg 2001; Deb 2000; Chen and Ramaswamy 2002, Shankar et al. 2008a; Shankar and Bandyopadhyay 2004). By harnessing the mechanisms of evolution, GAs make it possible to explore a greater number of potential solutions to a problem than do conventional programs and will help generate new solutions to complex nonlinear problems (Holland 1992).

Various operations used in GAs include the generation of possible solutions, application of selection procedures, crossover and mutation operations to generate new sets of populations, and evaluation of each solution at the end of each iteration over an objective function until the stopping criteria are met. If the search termination criterion is not met, the GA applies the selection, crossover, and mutation operations 
repeatedly to the current population, evaluates the fitness of each possible solution, and reproduces a new population (Koc et al. 2007). The main advantages of a GA compared to other gradient-based approaches are that (1) it explores the search space more thoroughly with fewer performance evaluations than those based on local searches, such as simulated annealing, and (2) it is less dependent on the good selection of the starting points, and they do not require neighborhood definition (April et al. 2003). The flow diagram for GA-based algorithm is given in Figure 23.

Crossover can look like this ( $\mid$ is the crossover point):

Chromosome $1=11011 \mid 00100110110$ Chromosome $2=11011 \mid 11000011110$

\section{After crossover:}

Chromosome $1=1101111000011110$

Chromosome $2=1101100100110110$

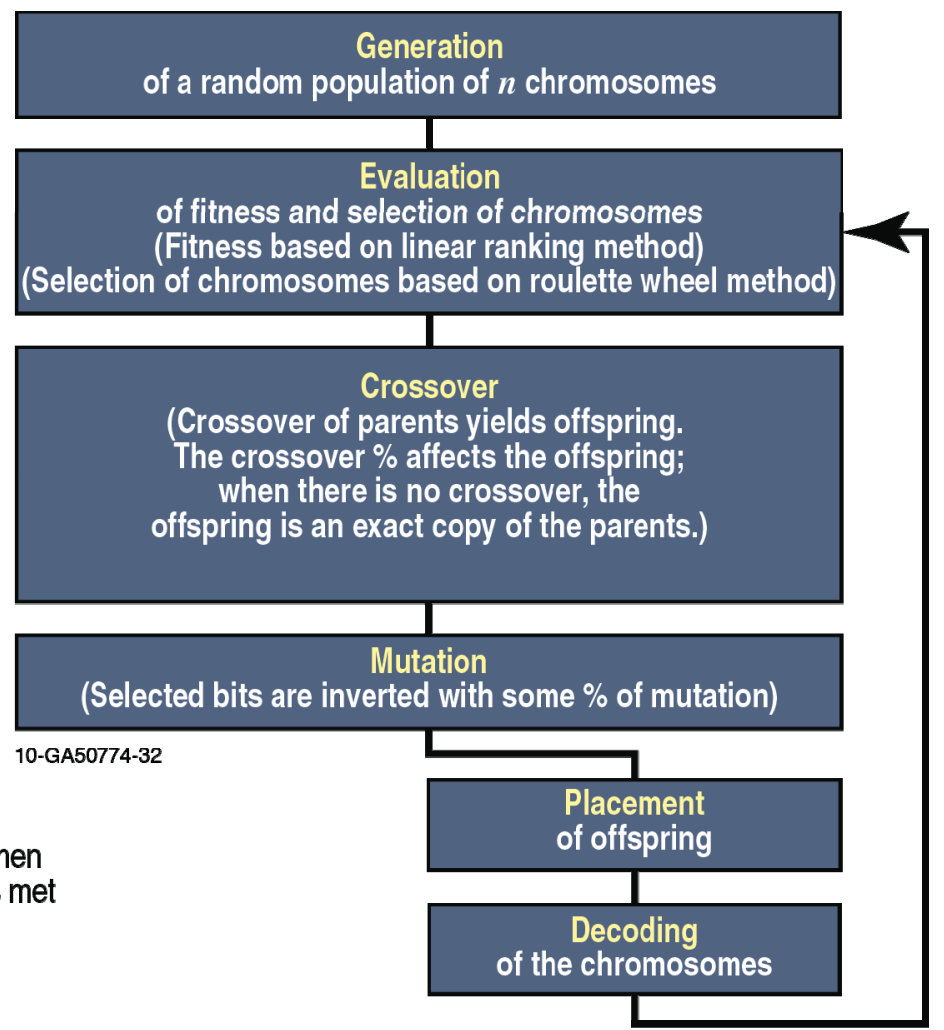

Figure 23. Flow diagram for GA-based algorithm for function optimization (adapted from Tumuluru et al. [2010c]).

As the process of densification using an extruder, briquette press, or pellet mill is complex and involves many process and feedstock variables, optimization using evolutionary algorithms will be a great advantage to precisely optimize for the best quality attributes and, also, for better understanding of the complex densification process. Shankar and Bandyopadhyay (2004 and 2007) and Shankar et al. (2008a) successfully used genetic algorithms and artificial neural networks to understand and optimize real-life time problems like extrusion processes. In their studies, they have used a combination of RSM and GA for a better understanding of the pelletization process using an extruder. Their studies were aimed at understanding how process variables like barrel temperature, screw speed, L/D ratio, and feedstock variables such as feed moisture content and feed content of the biomass mix affect the flow behavior and quality attributes like expansion ratio, bulk density, and hardness.

There are other optimization algorithms - ant colony, simulated annealing, tabu search, and particle swarm - that work extremely well in finding real-time solutions to complex systems. The ant colony algorithm (ACO) is an optimization algorithm, a probabilistic technique for solving computational problems. Simulated annealing (SA) is related to the global optimization technique, which traverses the search space by generating neighboring solutions of the current solution. Tabu search (TS) is similar to simulated annealing in that both traverse the solution space by testing mutations of an individual solution. 
While SA generates only one mutated solution, TS generates many mutated solutions and moves to the solution with the lowest fitness of those generated (Holland 1992; Deb 2000). The particle swarm optimization algorithm (PSO) belongs to the class of direct search methods used to find an optimal solution to an objective function in a search space. The advantages of the PSO algorithm include: (1) it is simple in the sense that even the basic form of the algorithm yields results and can be implemented quickly by a programmer, and (2) it can be used by anyone with an understanding of objective functions and the problem at hand without needing an extensive background in mathematical optimization theory.

Figure 24 shows the flow diagram for design of the experiments and further analysis of the data using statistical and evolutionary algorithms in order to understand the complex densification process that includes process, feedstock, and chemical composition variables.

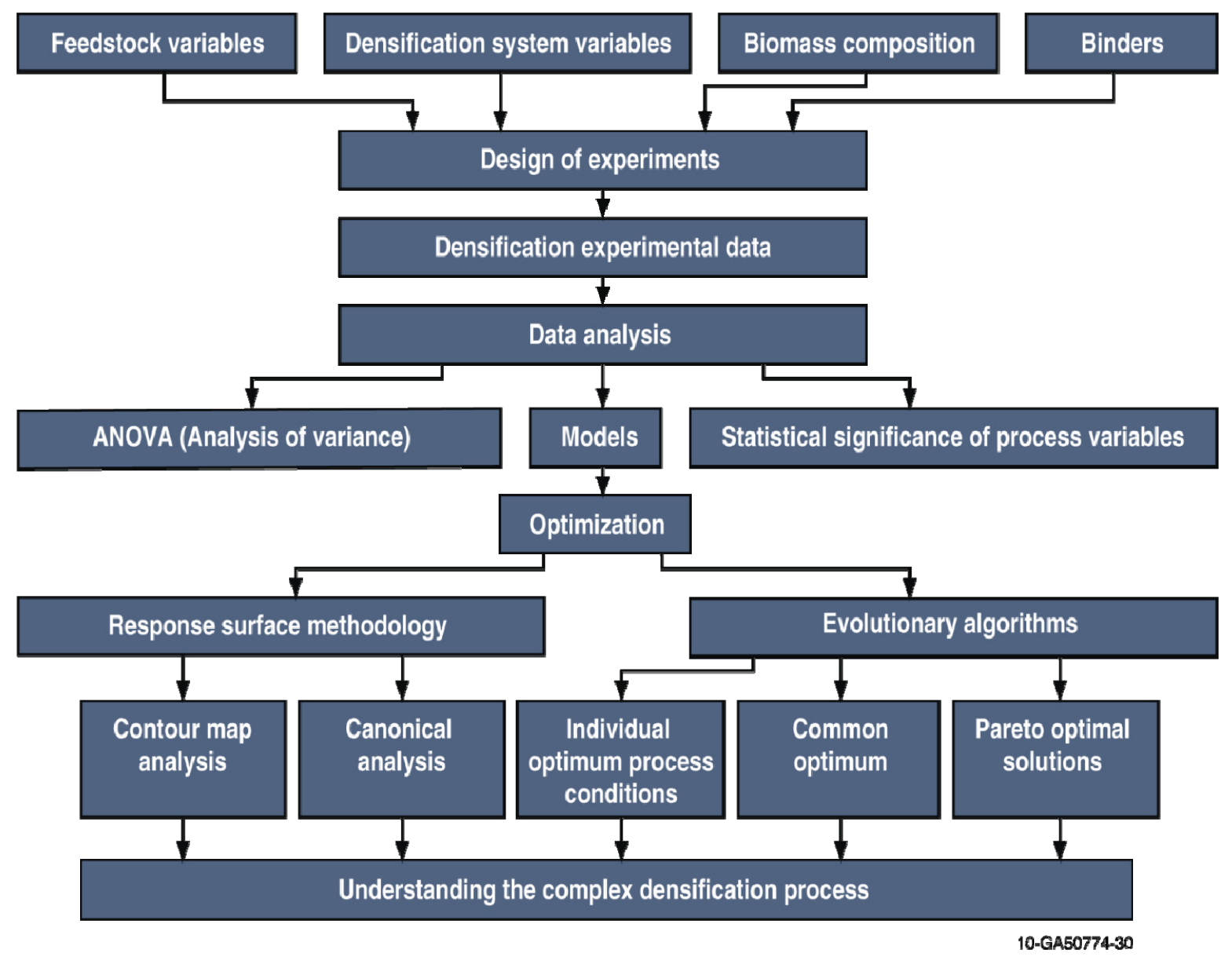

Figure 24. Flow diagram for the densification data analysis using a combination of RSM and evolutionary algorithms. 


\section{INTERNATIONAL SOLID FUEL STANDARDS}

\subsection{Pellets Fuel Institute, USA}

The important solid fuel standards that exist are the Pellet Fuel Institute (PFI) standards in the U.S.A. (see Table 10) and the combined standards from various European countries such as Austria, Sweden, United Kingdom, France, and Denmark, known as the European Common Standard for Solid Fuel (CEN). The European Committee for Standardization (CEN/TC 335) prepared technical specifications and testing methods for solid biofuels. CEN/TS 14961 gives the standards for the densified solid fuels like pellets and briquettes

Table 10. Pellet Fuel Institute (PFI) standard specification for residential/commercial densified fuel (August 2010). (http://www.pelletheat.org/2/StandardSpecificationWithCopyright\%20.pdf)

\begin{tabular}{lccc}
\hline FUEL PROPERTY & PFI PREMIUM & PFI STANDARD & PFI UTILITY \\
\hline Normative information - mandatory & & & \\
Bulk density (lb/ $\mathrm{ft}^{3}$ ) & $40.0-46.0$ & $38.0-46.0$ & $38.0-46.0$ \\
Diameter (in.) & $0.230-0.285$ & $0.230-0.285$ & $0.230-0.285$ \\
Diameter (mm) & $5.84-7.25$ & $5.84-7.25$ & $5.84-7.25$ \\
Pellet Durability Index (PDI) & $\geq 96.5$ & $\geq 95.0$ & $\geq 95.0$ \\
Percent Fines (at the mill gate) & $\leq 0.50$ & $\leq 1.0$ & $\leq 1.0$ \\
Inorganic ash (\%) & $\leq 1.0$ & $\leq 2.0$ & $\leq 6.0$ \\
Length (\% greater than 1.50 in.) & $\leq 1.0$ & $\leq 1.0$ & $\leq 1.0$ \\
Moisture (\%) & $\leq 8.0$ & $\leq 10.0$ & $\leq 10.0$ \\
Chloride (ppm) & $\leq 300$ & $\leq 300$ & $\leq 300$ \\
Informative only - not mandatory & & & \\
Ash Fusion & NA & NA & NA \\
Heating value & NA & NA & NA \\
\hline
\end{tabular}

\subsection{European Standards}

This section discusses the individual standards for solid fuels followed by different countries such as Austria, Sweden, the United Kingdom, France, and Denmark. These individual standards are now replaced with a common standard called the European Common Standard for Solid Fuel (CEN).

\subsubsection{National Standards for Different Countries in Europe}

\subsubsection{Austria}

The Austrian Federal Ministry for the Environment devised a special environment label for biomass fuels. Only raw material from natural wood is allowed (sawdust, shavings, etc.). Use of materials such as packaging, coatings, glues, chipboard, or fiberboard residues is forbidden. Chemical parameters, testing methods, and limit values are similar to those in ÖNORM 7135.

\subsubsection{Sweden}

Pellsam, the Swedish wood pellet trade body, was set up by manufacturers and suppliers of pellet heating equipment to establish standards for wood pellets for heating purposes. 


\subsubsection{United Kingdom}

The United Kingdom (UK) pellet market started with a project to introduce wood pellets to the UK with the Department of Trade and Industry (DTI). In the framework of this project, British BioGen have produced codes of good practice for biofuel pellets and pellet-burning room heaters $<15 \mathrm{~kW}$. The codes of good practice were developed as an interim measure and will be superseded by the European Standards for Solid Biofuels once they are published.

\subsubsection{France}

The French-based International Association for Bioenergy Professionals, ITEBE, created a Pellet Club. Its aim is to promote the quality of fuels and it has established a quality label. The ITEBE quality charter for pellet manufacturers (BIG, French Pellet Club, Charte Qualité) does more than simply outline the various wood pellet standards that exist in Europe; it offers specific advice on determining a quality pellet for various uses.

\subsubsection{Denmark}

In Denmark the general environment labels, such as Svanenmärket (the Scandinavian Blue Angel) or Die Blumme, are used for pellets. Table 11 shows the comparison of various pellet standards used in Europe by different countries prior to CEN. 
Table 11. General survey of limit values existing national standards for fuel pellets (Austria, Sweden, Germany and Italy) as well as national codes of good practice (UK) (Source: Hahn [2004]).

\begin{tabular}{|c|c|c|c|c|c|c|c|c|c|c|c|c|c|}
\hline \multirow[t]{3}{*}{ Specification } & \multicolumn{2}{|c|}{$\begin{array}{c}\text { Austria } \\
\text { ÖNORM M7135 }\end{array}$} & \multicolumn{3}{|c|}{$\begin{array}{c}\text { Sweden } \\
\text { SS } 187120\end{array}$} & \multirow{2}{*}{\multicolumn{2}{|c|}{$\begin{array}{l}\text { Germany } \\
\text { DIN } 51731 / \text { DIN } \\
\text { plus } \\
\begin{array}{l}5 \text { Längenklassen sonst } \\
\text { gleich [cm] }\end{array}\end{array}$}} & \multirow{2}{*}{\multicolumn{4}{|c|}{$\begin{array}{l}\text { Italy } \\
\text { CTI - R 04/5 } \\
4 \text { categories according origin and with or without } \\
\text { pressing aids A, no additives A, with additives B } \\
\text { C }\end{array}$}} & \multicolumn{2}{|c|}{$\begin{array}{l}\text { British BioGen/UK } \\
\text { Code of Good Practice }\end{array}$} \\
\hline & \multirow{2}{*}{$\begin{array}{l}\text { Holzpresslinge } \\
\text { Pellets } \\
\end{array}$} & \multirow{2}{*}{$\begin{array}{l}\text { Rindenpresslinge } \\
\text { Briketts: } \\
\end{array}$} & \multirow[t]{2}{*}{ Group 1} & \multirow[t]{2}{*}{ Group 2} & \multirow[t]{2}{*}{ Group 3} & & & & & & & & \\
\hline & & & & & & & & & & & & & \\
\hline Size & $\begin{array}{l}4-20 \mathrm{~mm} \mathrm{dia} \text {, } \\
\text { max. } 100 \mathrm{~mm} \\
\text { length }\end{array}$ & $\begin{array}{l}20-120 \mathrm{~mm} \text { dia, } \\
\text { max. } 400 \mathrm{~mm} \\
\text { length }\end{array}$ & max. $4 \mathrm{~mm}$ dia & $\begin{array}{l}\max _{\text {dia }} 5 \mathrm{~mm} \\
\end{array}$ & $\begin{array}{l}\max _{\text {dia }} 6 \mathrm{~mm} \\
\end{array}$ & $\begin{array}{l}\text { HP1 } \\
\text { HP2 } \\
\text { HP3 } \\
\text { HP4 } \\
\text { HP5 }\end{array}$ & $\begin{array}{l}\text { Length Dia } \\
>30>10 \\
15-306-10 \\
10-153-7 \\
<101-4 \\
<50.4-1\end{array}$ & $\begin{array}{l}6 \mathrm{~mm} \\
8 \mathrm{~mm}\end{array}$ & $\begin{array}{l}6 \mathrm{~mm} \\
8 \mathrm{~mm}\end{array}$ & $\begin{array}{l}6 \mathrm{~mm} \\
8 \mathrm{~mm}\end{array}$ & $\begin{array}{l}10- \\
25 \mathrm{~mm}\end{array}$ & $\begin{array}{l}<4 \mathrm{~mm}- \\
20 \mathrm{~mm}\end{array}$ & $\begin{array}{l}>10 \mathrm{~mm}- \\
<20 \mathrm{~mm}\end{array}$ \\
\hline Bulk density & & & $\geq 600 \mathrm{~kg} / \mathrm{m}^{3 b}$ & $\geq 500 \mathrm{~kg} / \mathrm{m}^{3}$ & $\geq 500 \mathrm{~kg} / \mathrm{m}^{3}$ & & & $\begin{array}{l}620- \\
720 \mathrm{~kg} / \mathrm{m}^{3}\end{array}$ & $\begin{array}{l}620-720 \\
\mathrm{~kg} / \mathrm{m}^{3}\end{array}$ & $\begin{array}{l}620-720 \\
\mathrm{~kg} / \mathrm{m}^{3}\end{array}$ & $\begin{array}{l}\geq 550 \\
\mathrm{~kg} / \mathrm{m}^{3}\end{array}$ & $\begin{array}{l}>600 \\
\mathrm{~kg} / \mathrm{m}^{3 \mathrm{~b}}\end{array}$ & $>500 \mathrm{~kg} / \mathrm{m}^{3 \mathrm{~b}}$ \\
\hline Fines in $\%<3 \mathrm{~mm}$ & & & $\leq 0.8$ & $\leq 1.5$ & $\leq 1.5$ & & & & & & & $<0.5 \%$ & $<0.5 \%$ \\
\hline Unit density & $\geq 1.0 \mathrm{~kg} / \mathrm{dm}^{3}$ & $\geq 1.0 \mathrm{~kg} / \mathrm{dm}^{3}$ & & & & $1-1.4 \mathrm{~g}$ & & & & & & & $\begin{array}{l}>40 \\
\text { pounds/cubic } \\
\text { ft. }+ \text { ) }\end{array}$ \\
\hline Moisture content & $\leq 12 \%$ & $\leq 18 \%$ & $\leq 10 \%$ & $\leq 10 \%$ & $\leq 12 \%$ & $<12 \%$ & & $\leq 10 \%$ & $\leq 10 \%$ & $\leq 10 \%$ & $\leq 15 \%$ & $\leq 10 \%$ & $\leq 10 \%$ \\
\hline Ash content & $\leq 0.5 \%^{\mathrm{a}}$ & $\leq 6.0 \%{ }^{\mathrm{a}}$ & $\leq 0.7 \%$ & $\leq 1.5 \%$ & $>1.5 \%$ & $>1.5 \%$ & & $\leq 0.7 \%$ & $\leq 0.7 \%$ & $\leq 1.5 \%$ & $\begin{array}{l}\text { to be } \\
\text { stated }\end{array}$ & $\begin{array}{l}<1 \%,<3 \% \\
\text { or } 6\end{array}$ & $\begin{array}{l}<1 \%,<3 \% \text { or } \\
6\end{array}$ \\
\hline Caloric value & $\geq 18.0 \mathrm{MJ} / \mathrm{kg}^{\mathrm{a}}$ & $\geq 18.0 \mathrm{MJ} / \mathrm{kg}^{\mathrm{a}}$ & $\begin{array}{l}\geq 16.9 \mathrm{MJ} / \mathrm{kg} \\
\geq 4.7 \mathrm{kWh} / \mathrm{kg}\end{array}$ & $\begin{array}{l}\geq 16.9 \mathrm{MJ} / \mathrm{kg} \\
\geq 4,7 \mathrm{kWh} / \mathrm{kg}\end{array}$ & $\begin{array}{l}\geq 16.9 \\
\mathrm{MJ} / \mathrm{kg} \\
\geq 4.7 \\
\mathrm{kWh} / \mathrm{kg} \\
\end{array}$ & $\begin{array}{l}17.5-19 \\
\mathrm{MJ} / \mathrm{kg}^{\mathrm{c}}\end{array}$ & & $\begin{array}{l}\geq 16.9 \\
\mathrm{MJ} / \mathrm{kg}\end{array}$ & $\begin{array}{l}\geq 16.9 \\
\mathrm{MJ} / \mathrm{kg}\end{array}$ & $\begin{array}{l}\geq 16.2 \\
\mathrm{MJ} / \mathrm{kg}\end{array}$ & $\begin{array}{l}\text { To be } \\
\text { stated }\end{array}$ & $\begin{array}{l}>4.7 \\
\mathrm{kWh} / \mathrm{kg}\end{array}$ & $>4.2 \mathrm{kWh} / \mathrm{kg}$ \\
\hline Sulphur & $\leq 0.04 \%{ }^{a}$ & $\leq 0.08 \%^{\mathrm{a}}$ & $\leq 0.08 \%$ & $\leq 0.08 \%$ & anges & $<0.08$ & & $\leq 0.05 \%$ & $\leq 0.05 \%$ & $\leq 0.05 \%$ & $\begin{array}{l}\text { To be } \\
\text { stated }\end{array}$ & $<300 \mathrm{ppm}$ & $<300 \mathrm{ppm}$ \\
\hline Nitrogen & $\leq 0.3 \%^{\mathrm{a}}$ & $\leq 0.6 \%^{\mathrm{a}}$ & & & & $<0.3$ & & $\leq 0.3 \%$ & $\leq 0.3 \%$ & $\leq 0.3 \%$ & $\begin{array}{l}\text { To be } \\
\text { stated }\end{array}$ & & \\
\hline Chlorine & $\leq 0.02 \%{ }^{a}$ & $\leq 0.04 \%{ }^{\mathrm{a}}$ & $\leq 0.03 \%$ & $\leq 0.03 \%$ & anges & $<0.03$ & & $\leq 0.03 \%$ & $\leq 0.03 \%$ & To be stat & & $<800 \mathrm{ppm}$ & $<800 \mathrm{ppm}$ \\
\hline Arsenic & & & & & & $<0.8 \mathrm{mg}$ & & & & & & & \\
\hline Cadmium & & & & & & $<0.5 \mathrm{mg}$ & & & & & & & \\
\hline Chromium & & & & & & $<8 \mathrm{mg} / \mathrm{l}$ & & & & & & & \\
\hline Copper & & & & & & $<5 \mathrm{mg} / \mathrm{l}$ & & & & & & & \\
\hline Mercury & & & & & & $<0.05 \mathrm{n}$ & & & & & & & \\
\hline Lead & & & & & & $<10 \mathrm{mg}$ & & & & & & & \\
\hline Zinc & & & & & & $<100 \mathrm{~m}$ & & & & & & & \\
\hline $\begin{array}{l}\text { EOX, } \\
\text { extractabl.org, } \\
\text { halogens }\end{array}$ & & & & & & $<3 \mathrm{mg} / 1$ & & $\leq 1.0 \%$ & $\leq 1.0 \%$ & $\leq 1.0 \%$ & $\begin{array}{l}\text { To be } \\
\text { stated }\end{array}$ & & \\
\hline
\end{tabular}


Table 11. (continued).

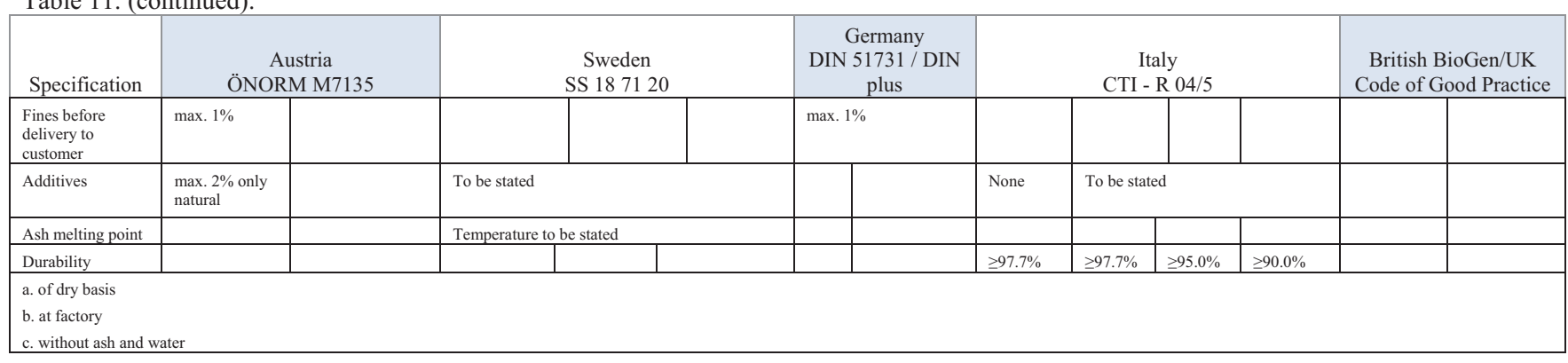




\subsubsection{European Common Standard (CEN)}

Common European solid biofuels standards were established to avoid ambiguity; previously, many European countries had their own standards. The European Committee for Standardization (CEN/TC 335) prepared technical specifications and testing methods for solid biofuels. The following are some of the standards developed for classifying properties of solid biofuels based on CEN:

1. Classification of biomass based on origin. Based on CEN/TS 14961, the biomass is classified based on its origin and divided into these subcategories: woody, herbaceous, fruit, and blends and mixtures (Table 12.).

2. Major traded forms of solid biofuels (Table 13).

3. Technical specifications for pellets and briquettes according to CEN (Table 14 and Table 15).

Table 12. Classification of origin and sources of woody biomass according CEN (Hahn 2004).

\begin{tabular}{|c|c|}
\hline \multicolumn{2}{|l|}{ Forest and plantation wood } \\
\hline \multirow[t]{5}{*}{ 1.1.1 Whole trees } & 1.1.1.1 Deciduous wood \\
\hline & 1.1.1.2 Coniferous wood \\
\hline & 1.1.1.3 Short rotation coppice \\
\hline & 1.1.1.4 Bushes \\
\hline & 1.1.1.5 Blends and mixtures \\
\hline \multirow[t]{3}{*}{ 1.1.2 Stem wood } & 1.1.2.1 Deciduous \\
\hline & 1.1.2.2 Coniferous \\
\hline & 1.1.2.3 Blends and mixtures \\
\hline \multirow[t]{3}{*}{ 1.1.3 Logging residues } & 1.1.3.1 Fresh/green (including leaves/needles) \\
\hline & 1.1.3.2 Dry \\
\hline & 1.1.3.1 Blends and mixtures \\
\hline \multirow[t]{5}{*}{ 1.1.4 Stumps } & 1.1.4.1 Deciduous wood \\
\hline & 1.1.4.2 Coniferous wood \\
\hline & 1.1.4.3 Short rotation coppice \\
\hline & 1.1.4.4 Bushes \\
\hline & 1.1.4.5 Blends and mixtures \\
\hline \multicolumn{2}{|l|}{ 1.1.5 Bark (from forestry operations)* } \\
\hline \multicolumn{2}{|l|}{ 1.1.6 Landscape management woody biomass } \\
\hline \multicolumn{2}{|l|}{1.2 Wood processing industry, by-products, and residues } \\
\hline \multirow[t]{4}{*}{ 1.2.1 Chemically untreated wood residues } & 1.2.1.1 Wood without bark \\
\hline & 1.2.1.2 Wood with bark* \\
\hline & 1.2.1.3 Bark (from industry operations)* \\
\hline & 1.2.1.4 Blends and mixtures \\
\hline \multirow[t]{4}{*}{ 1.2.2 Chemically treated wood residues } & 1.2.2.1 Wood without bark \\
\hline & 1.2.2.2 Wood with bark* \\
\hline & 1.2.2.3 Bark (from industry operations)* \\
\hline & 1.2.2.4 Blends and mixtures \\
\hline \multirow[t]{2}{*}{ 1.2.3 Fibrous waste from the pulp and paper industry } & 1.2.3.1 Chemically untreated fibrous waste \\
\hline & 1.2.3.2 Chemically treated fibrous waste \\
\hline \multicolumn{2}{|l|}{1.3 Used wood } \\
\hline \multirow[t]{3}{*}{ 1.3.1 Chemically untreated wood } & 1.3.1.1 Wood without bark \\
\hline & 1.3.1.2 Bark* \\
\hline & 1.3.1.3 Blends and mixtures \\
\hline \multirow[t]{3}{*}{ 1.3.2 Chemically treated wood } & 1.3.2.1 Wood without bark \\
\hline & 1.3.2.2 Bark* \\
\hline & 1.3.2.3 Blends and mixtures \\
\hline
\end{tabular}


Table 13. Major traded forms of solid biofuels according to European Standard (CEN) (Swedish Standards Institute, SIS-CEN/TS 14961:2005).

\begin{tabular}{|c|c|c|}
\hline FUEL & TYPICAL PARTICLE SIZE & COMMON PREPARATION METHOD \\
\hline Briquettes & $\varnothing>25 \mathrm{~mm}$ & Mechanical compression \\
\hline Pellets & $\varnothing<25 \mathrm{~mm}$ & Mechanical compression \\
\hline Fuel powder & $<1 \mathrm{~mm}$ & Milling \\
\hline Saw dust & $1-5 \mathrm{~mm}$ & Cutting with sharp tools \\
\hline Wood chips & $5-100 \mathrm{~mm}$ & Cutting with sharp tools \\
\hline Hog fuel & Varying & Cutting with sharp tools \\
\hline Logs & $100-1000 \mathrm{~mm}$ & Cutting with sharp tools \\
\hline Whole wood & $>500 \mathrm{~mm}$ & Cutting with sharp tools \\
\hline Small straw bales & $\mathrm{m}^{3}$ & Compressed and bound to squares \\
\hline Big straw bales & $3.7 \mathrm{~m}^{3}$ & Compressed and bound to squares \\
\hline Round straw bales & $2.1 \mathrm{~m}^{3}$ & Compressed and bound to cylinders \\
\hline Bundle & Varying & Lengthways oriented and bound \\
\hline Bark & Varying & $\begin{array}{l}\text { Debarking residue from trees } \\
\text { Can be shredded or unshredded }\end{array}$ \\
\hline Chopped straw & $10-200 \mathrm{~mm}$ & Chopped during harvesting \\
\hline Grain or seed & Varying & No preparation or drying \\
\hline Shells and fruit stones & $5-15 \mathrm{~mm}$ & No preparation \\
\hline Fiber cake $\varnothing$ & Varying & Prepared from fibrous waste by dewatering \\
\hline
\end{tabular}


Table 14. Technical specifications for pellets according to European Standard (CEN) (E. Alakangas, VTT Processes, Secretary of CENT C 335 Cited by Hahn [2004], http://www.pelletsatlas.info/resources/1020.pdf).

\begin{tabular}{|c|c|}
\hline $\begin{array}{l}\text { Origin: According to Table } 1 \text { in } \\
\text { previous CEN/TS 14961:2004 }\end{array}$ & $\begin{array}{l}\text { Woody biomass (1), herbaceous biomass (2), fruit biomass (3), } \\
\text { blends and mixtures (4) }\end{array}$ \\
\hline Traded Form & Pellets \\
\hline \multicolumn{2}{|l|}{ NORMATIVE SPECIFICATIONS } \\
\hline $\begin{array}{l}\text { Dimensions }(\mathrm{mm}) \\
\text { Diameter and length }(\mathrm{L})^{\mathrm{a}}\end{array}$ & $\begin{array}{l}\mathrm{D} 06 \leq 6 \mathrm{~mm} \pm 0,5 \mathrm{~mm} \text { and } \mathrm{L} \leq 5 \times \text { Diameter } \\
\mathrm{D} 08 \leq 8 \mathrm{~mm} \pm 0,5 \mathrm{~mm} \text { and } \mathrm{L} \leq 4 \times \text { Diameter } \\
\mathrm{D} 10 \leq 10 \mathrm{~mm} \pm 0,5 \mathrm{~mm} \text { and } \mathrm{L} \leq 4 \times \text { Diameter } \\
\mathrm{D} 12 \leq 12 \mathrm{~mm} \pm 1 \mathrm{~mm} \text { and } \mathrm{L} \leq 4 \times \text { Diameter } \\
\mathrm{D} 25 \leq 25 \mathrm{~mm} \pm 1 \mathrm{~mm} \text { and } \mathrm{L} \leq 4 \times \text { Diameter }\end{array}$ \\
\hline Moisture (w- $\%$ as received ) & $\begin{array}{l}\text { M10 } \leq 10 \% \\
\text { M15 } \leq 15 \% \\
\text { M20 } \leq 20 \%\end{array}$ \\
\hline Ash (w- $\%$ of dry basis) & $\begin{array}{l}\text { A } 0.7 \leq 0.7 \% \\
\text { A } 1.5 \leq 1.5 \% \\
\text { A } 3.0 \leq 3.0 \% \\
\text { A } 6.0 \leq 6.0 \% \\
\text { A6.0+ }>6.0 \% \text { (actual value to be stated) }\end{array}$ \\
\hline Sulphur (w- $\%$ of dry basis) ${ }^{b}$ & $\begin{array}{l}\text { S0.05 } \leq 0.05 \% \\
\text { S } 0.08 \leq 0.08 \% \\
\text { S0.10 } \leq 0.10 \% \\
\text { S0.20+ > } 0.20 \% \text { (actual value to be stated) }\end{array}$ \\
\hline $\begin{array}{l}\text { Mechanical durability ( } \mathrm{w}-\% \text { of } \\
\text { pellets after testing) }\end{array}$ & $\begin{array}{l}\text { DU97.5 } \geq 97.5 \\
\text { DU95.0 } \geq 95.0 \\
\text { DU90.0 } \geq 90.0\end{array}$ \\
\hline Amount of fines $(\mathrm{w}-\%<3.15 \mathrm{~mm})^{\mathrm{c}}$ & $\begin{array}{l}\text { F1.0 } \leq 1.0 \% \\
\text { F2.0 } \leq 2.0 \% \\
\text { F2.0+ }>2.0 \% \text { (actual value to be stated) }\end{array}$ \\
\hline Additives ( $\mathrm{w}-\%$ of pressing mass) & $\begin{array}{l}\text { Type and content of pressing aids, slagging inhibitors or any other } \\
\text { additives have to be stated }\end{array}$ \\
\hline Nitrogen (w- $\%$ of dry basis) & $\begin{array}{l}\text { N0.3 } \leq 0.3 \% \\
\text { N0.5 } \leq 0.5 \% \\
\text { N } 1.0 \leq 1.0 \% \\
\text { N3.0 } \leq 3.0 \% \\
\text { N } 3.0+>3.0 \% \text { (actual value to be stated) }\end{array}$ \\
\hline \multicolumn{2}{|l|}{ INFORMATIVE SPECIFICATIONS } \\
\hline $\begin{array}{l}\text { Net caloric value }(\mathrm{MJ} / \mathrm{kg} \text { as } \\
\text { received) or energy } \\
\text { density }\left(\mathrm{kWh} / \mathrm{m}^{3} \text { loose }\right)\end{array}$ & Recommended to be informed by retailer \\
\hline $\begin{array}{l}\text { Bulk density as received }\left(\mathrm{kg} / \mathrm{m}^{3}\right. \\
\text { loose) }\end{array}$ & $\begin{array}{l}\text { Recommended to be stated if traded by volume } \\
\text { basis }\end{array}$ \\
\hline $\begin{array}{l}\text { Chlorine, } \mathrm{Cl} \text { (weight of dry basis } \\
\mathrm{w}-\% \text { ) }\end{array}$ & $\begin{array}{l}\text { Recommended to be stated in category } \mathrm{Cl} 0.03, \mathrm{Cl} 0.07, \mathrm{Cl} 0.10 \text {, und } \\
\mathrm{Cl} 0.10+(\text { if } \mathrm{Cl}>0.10 \% \text { the actual value to be stated) }\end{array}$ \\
\hline \multicolumn{2}{|c|}{$\begin{array}{l}\text { a. Maximum } 20 \mathrm{w}-\% \text { of the pellets may have a length of } 7.5 \times \text { diameter. } \\
\text { b. Sulphur is normative only for chemically treated biomass and if sulphur-containing additives have been used. } \\
\text { c. After production at factory gate, at last possible place in the production site. }\end{array}$} \\
\hline
\end{tabular}


Table 15. Technical specifications of properties for briquettes according to European Standard (CEN) (Swedish Standards Institute, SIS-CEN/TS 14961:2005).

\begin{tabular}{|c|c|c|}
\hline $\begin{array}{l}\text { Origin: } \\
\text { According to Table } 1\end{array}$ & \multicolumn{2}{|c|}{$\begin{array}{l}\text { Woody biomass (1), herbaceous biomass (2), blends and mixtures } \\
\text { (4) }\end{array}$} \\
\hline Traded form (See Table 2) & \multicolumn{2}{|c|}{ Briquette } \\
\hline \multicolumn{3}{|l|}{ NORMATIVE SPECIFICATIONS } \\
\hline $\begin{array}{l}\text { Dimensions (mm) Diameter (D) or } \\
\text { equivalent (diagonal or cross cut), } \\
\mathrm{mm}\end{array}$ & $\begin{array}{l}\text { D40 } \\
\text { D50 } \\
\text { D60 } \\
\text { D80 } \\
\text { D100 } \\
\text { D125 } \\
\text { D125+ }\end{array}$ & $\begin{array}{l}25 \leq \mathrm{D} \leq 40 \\
\leq 50 \\
\leq 60 \\
\leq 80 \\
\leq 100 \\
\leq 125 \\
\geq 125 \text { actual value to be stated }\end{array}$ \\
\hline Length (L) & $\begin{array}{l}\text { L50 } \\
\text { L100 } \\
\text { L200 } \\
\text { L300 } \\
\text { L400 } \\
\text { L400+ }\end{array}$ & $\begin{array}{l}\leq 50 \\
\leq 100 \\
\leq 200 \\
\leq 300 \\
\leq 400 \\
\geq 400 \text { actual value to be stated }\end{array}$ \\
\hline Moisture ( $\mathrm{w}-\%$ as received ) & $\begin{array}{l}\text { M10 } \\
\text { M15 } \\
\text { M20 }\end{array}$ & $\begin{array}{l}\leq 10 \% \\
\leq 15 \% \\
\leq 20 \%\end{array}$ \\
\hline Ash (w-\% of dry basis) & $\begin{array}{l}\text { A } 0.7 \\
\text { A } 1.5 \\
\text { A } 3.0 \\
\text { A6.0 } \\
\text { A } 10.0 \\
\end{array}$ & $\begin{array}{l}\leq 0.7 \% \\
\leq 1.5 \% \\
\leq 3.0 \% \\
\leq 6.0 \% \\
\leq 10.0 \%\end{array}$ \\
\hline Sulphur (w- $\%$ of dry basis) ${ }^{\mathrm{a}}$ & $\begin{array}{l}\text { S0.05 } \\
\text { S0.08 } \\
\text { S0.10 } \\
\text { S0.20 } \\
\text { S0.20+ }\end{array}$ & $\begin{array}{l}\leq 0.05 \% \\
\leq 0.08 \% \\
\leq 0.10 \% \\
\leq 0.20 \% \\
>0.20 \% \text { (actual value to be stated) }\end{array}$ \\
\hline Particle density $\left(\mathrm{kg} / \mathrm{dm}^{3}\right)$ & $\begin{array}{l}\text { DE0.8 } \\
\text { DE1.0 } \\
\text { DE1.1 } \\
\text { DE1.2 }\end{array}$ & $\begin{array}{l}0.8 \text { to } 0.99 \\
1.00 \text { to } 1.09 \\
1.10 \text { to } 1.19 \\
\geq 1.20\end{array}$ \\
\hline Additives (w-\% of pressing mass) & \multicolumn{2}{|c|}{$\begin{array}{l}\text { Type and content of pressing aids, slagging inhibitors, or any other } \\
\text { additives have to be stated }\end{array}$} \\
\hline Nitrogen, $\mathrm{N}$ (w-\% dry basis) & $\begin{array}{l}\text { N0.3 } \\
\text { N0.5 } \\
\text { N1.0 } \\
\text { N3.0 } \\
\text { M3.0+ }\end{array}$ & $\begin{array}{l}\leq 0.3 \% \\
\leq 0.5 \% \\
\leq 1.0 \% \\
\leq 3.0 \% \\
>3.0 \% \text { (actual value to be stated) }\end{array}$ \\
\hline \multicolumn{3}{|l|}{ INFORMATIVE SPECIFICATIONS } \\
\hline $\begin{array}{l}\text { Net caloric value }(\mathrm{MJ} / \mathrm{kg} \text { as } \\
\text { received) or energy density }\left(\mathrm{kWh} / \mathrm{m}^{3}\right. \\
\text { loose) }\end{array}$ & \multicolumn{2}{|c|}{ Recommended to be stated at the retail level } \\
\hline $\begin{array}{l}\text { Bulk density as received }\left(\mathrm{kg} / \mathrm{m}^{3}\right. \\
\text { loose) }\end{array}$ & \multicolumn{2}{|c|}{ Recommended to be stated if traded by volume basis } \\
\hline Chlorine, $\mathrm{Cl}(\mathrm{w}-\%$ of dry basis, $\%)$ & \multicolumn{2}{|c|}{$\begin{array}{l}\text { Recommended categories: } \mathrm{Cl} 0.03, \mathrm{Cl} 0.07, \mathrm{Cl} 0.10 \text { and } \mathrm{Cl} 0.10+ \\
\text { (if } \mathrm{Cl} \text { is }>0.10 \% \text { the actual value to be stated) }\end{array}$} \\
\hline
\end{tabular}




\section{CONCLUSIONS}

Densification is critical for producing a dense, bulk-flowable, uniform commodity material with (a) improved handling and conveying efficiencies throughout the feedstock assembly system and biorefinery in-feed, (b) controlled particle-size distribution for improved feedstock uniformity and density, (c) fractionated structural components for improved compositional quality, (d) conformity to predetermined specifications based on specific supply-system constraints and conversion technologies, and (e) reduced storage, handling, and transportation logistics costs.

During densification, the material initially undergoes rearrangement of the particles to form a packed mass followed by elastic and plastic deformation. At the end of the compaction process, the densified material reaches the true density of the component ingredients.

The commonly used technologies for densification are pellet mills, briquette and roller presses, and extruders. Densification using briquette presses offers advantages like the ability to handle a wide moisture range and biomass particle sizes, whereas an extruder is good in making homogenous briquettes that are more suitable for combustion applications. A pelletizer is similar to briquetting but uses smaller dies and smaller particles sizes. In a pelletizer the die size restricts the particle size of the biomass material, but the capacity is not restricted by the density of the raw material as in the case of screw and piston presses. Agglomeration, which is widely used in the pharmaceutical industry for densifying powders, can be adapted to biomass if material properties like particle size, distribution and shape, porosity, and surface chemistry are modified.

The densification process, which involves more compression and pushing, consumes more energy because it depends on the dimensions of the pressing channel. About $40 \%$ of the energy is required for compressing the material and the remaining for overcoming friction during compression. Among the different densification systems, the screw press consumes the most energy because it not only compresses but also shears and mixes the material, whereas a pellet mill or cubing consumes the least, depending the on the material processed.

Preheating biomass to temperatures of $100-130^{\circ} \mathrm{C}$ improves its binding characteristics. Having a moisture content of 10-12\% and a certain percentage of fine to medium particle sizes in the biomass mix also helps improve pelleting efficiency and reduce costs. Lignocellulosic biomass, which does not bind easily, can be improved by adding either natural or commercial binders like protein or lignosulphonates. Pretreating biomass using steam conditioning, steam explosion, torrefaction, and ammonia will help improve its physical, chemical, and binding characteristics. Pretreating the biomass before densification also significantly reduces the specific energy consumption. Moisture content, durability, bulk density, and calorific value are important quality attributes of densified biomass because they have a significant impact on storage, handling, transportation, and conversion characteristics.

Among the different densification models available on compaction, the Kawakita-Ludde model best describes the compression characteristics of agricultural biomass samples.

Experimental data analysis using both statistical methods (such as ANOVA) and response surface methods and evolutionary algorithms (such as genetics, simulated annealing, or particle swarm algorithms) can help to better explain the complex densification process.

The quality of densified biomass is evaluated with international standards established by the Pellet Fuel Institute (PFI) and European Common Standard (CEN) for solid fuel. 
Even though densification of biomass has been in practice for a long time, some research gaps still need to be addressed in order to understand the interaction of feedstock, process variables, and pretreatment methods on the quality of the densified biomass. The following research areas can help to advance the science of densification:

1. Understanding the mechanisms of densification using SEM and TEM techniques

2. Densifying biomass using the agglomeration technique by modifying material properties

3. Understanding the effect of torrefaction, steam explosion, and AFEX pretreatment methods on material properties, densification behavior, and specific energy consumption

4. Studying glass transition temperature of biomass components in relation to densification. 


\section{REFERENCES}

Adapa P. K., L. G. Tabil, and G. Schoenau, 2009, "Compression Characteristics of Selected Ground Agricultural Biomass," Agricultural Engineering International: CIGR Ejournal, Manuscript 1347, 11, June 2009.

Adapa, P. K., G. J. Schoenau, L. G. Tabil, S. Sokhansanj, and B. Crerar, 2003, "Pelleting of Fractionated Alfalfa Products," 2003 ASAE Annual International Meeting, Las Vegas, Nevada, July 27-30, 2003.

Adapa, P. K., J. Bucko, L. Tabil, Jr., G. Schoenau, and S. Sokhansanj, 2002, "Pelleting Characteristics of Fractionated Suncure and Dehydrated Alfalfa Grinds," ASAE/CSAE North-Central Intersectional Meeting, Saskatoon, Saskatchewan, Canada, September 27-28, 2002.

Adapa, P. K., L. G. Tabil, G. J. Schoenau, B. Crerar, and S. Sokhansanj, 2002a, “Compression Characteristics of Fractionated Alfalfa Grinds," Powder Handling and Processing, 14(4), 252-259, 2002.

Alebiowu, G. and O. A. Itiola, 2002, "Compression Characteristics of Native and Pregelatinized Forms of Sorghum, Plantain, and Corn Starches and the Mechanical Properties of their Tablets," Drug Development and Industrial Pharmacy, 28(6), 663-672, 2002.

Al-Widyan, M. I., H. F. Al-Jalil, M. M. Abu-Zreig, and N. H. Abu-Handeh, 2002, "Physical Durability and Stability of Olive Cake Briquettes," Canadian Biosystems Engineering, 44, 341-345, 2002.

Anglès, M. N., F. Ferrando, X. Farriol, and J. Salvadó, 2001, "Suitability of Steam Exploded Residual Softwood for the Production of Binderless Panels: Effect of the Pre-treatment Severity and Lignin Addition," Biomass and Bioenergy, 21, 211-224, 2001.

Angulo E., J. Brufau, and E. Esteve-Garcia, 1996, "Effect of a Sepiolite Product on Pellet Durability in Pig Diets Differing Particle Size and in Broiler Starter and Finisher Diets," Animal Feed Science and Technology, 63, 25-34, 1996.

Anonymous, 1983, “Special Report: Binders,” Milling, 166(2), 31-33, 1983.

April, J. F., G. J. Kelly, and M. Laguna, 2003, "Practical Introduction to Simulation Optimization,” in S. Chick, T. Sanchez, D. Ferrin, and D. Morrice (Eds.), Proceedings of the 2003 Winter Simulation Conference, Piscataway, New Jersey: Institute of Electrical and Electronics Engineers, 71-78, 2003.

Aqa, S. and S. C. Bhattacharya, 1992, "Densification of Preheated Sawdust for Energy Conservation," Energy, 17(6), 575-578, 1992.

Arcate, J. R., 2000, "New Process for Torrefied Wood Manufacturing," Bioenergy Update, 2, 2002, https://www.bioenergyupdate.com/magazine/security/NL0400/bioenergy_update_april_2000.htm, accessed April 2010.

Arcate, J. R., 2002, "Global Markets and Technologies for Torrefied Wood in 2002," Wood Energy, 5, 26-28, 2002.

Arias, B., C. Pedida, J. Fermoso, M. G. Plaza, F. Rubiera, and J. J. Pis, 2008, "Influence of Torrefaction on the Grindability and Reactivity of Woody Biomass," Fuel Processing Technology, 89, 169-175, 2008.

Austin, A., 2010, "Packing Heat and Power," Biomass Power \&Thermal, 2010, http://biomassmagazine.com/articles/5085/packing-heat-and-power, accessed December 22, 2010.

Balk, W. A., 1964, "Energy requirements for dehydrating and pelleting coastal Bermuda grass," Transactions of ASAE, 7, 349-351, 355, 1964. 
Bandyopadhyay, S. and R. K. Rout, 2001, “Aquafeed Extrudate Flow Rate and Pellet Characteristics from Low-cost Single-Screw Extruder," Journal of Aquatic Food Product Technology, 10(2), 3-15. 2001.

Bapat, D. W., S. V. Kulkarni, V. P. Bhandarkar, 1997, "Design and Operating Experience on Fluidized Bed Boiler Burning Biomass Fuels with High Alkali Ash,” in F. D. S. Preto (Ed.), Proceedings of the 14th International Conference on Fluidized Bed Combustion, New York: Vancouver ASME 1997, 165-174, 1997.

Beaudequin, F. et al., 1985, “Agglomeration of Charcoal,” in H. Egneus et al. (Eds.), Bioenergy, 84, Barking, 1985.

Bergman, P. C. A. (2005). Combined torrefaction and pelletisation: The TOP process, ECN-C--05-073.

Bergman, P. C. A. and J. H. A. Kiel, 2005, "Torrefaction for Biomass Upgrading," Published at 14th European Biomass Conference and Exhibition, Paris, France, October 17-21, 2005.

Bergman, P. C. A., A. R. Boersma, J. H. A. Kiel, and R. W. H. Zwart, 2005, "Development of Torrefaction for Biomass Co-firing in Existing Coal-fired Power Stations," BIOCOAL Concept Version, ECN Report, 2005.

Bhattacharya, S. C. and M. Prakash, 1994, "Extrusion Blends of Rice and Chickpea Flours: A Response Surface Analysis," Journal of Food Engineering, 21(3), 315-330, 1994.

Bhattacharya, S. C., 1993, "State-of-the-Art of Utilizing Residues and other Types of Biomass as an Energy Source," RERIC International Energy Journal, 15(1), 1-21, 1993.

Bhattacharya, S. C., S. Sett, and R. M. Shrestha, 1989, "State of the Art for Biomass Densification," Energy Sources, 11, 161-182, 1989.

Bilanski, W. K. and V. A. Graham, 1984, “A Viscoelastic Model for Forage Wafering," Transactions of the CSME, Canadian Society for Mechanical Engineers, 8(2), 70-76, 1984.

Björheden R, Driers Behind the Development of Forest Energy in Sweden. Biomass Bioenergy, 30, pp 289-295 (2006).

Bourgeois, J. and J. Doat, 1985, Proceedings Conference on Bioenergy, Göteborg, 3, 153, 1985.

Bradfield, J. and M. P. Levi, 1984, "Effect of Species and Wood to Bark Ratio on Pelleting of Southern Woods," Forest Products Journal, 34, 61-63, 1984.

Bridgeman, T. G., J. M. Jones, I. Shiel, and P. T. Williams, 2008, "Torrefaction of Reed Canary Grass, Wheat Straw and Willow to Enhance Solid Fuel Qualities and Combustion Properties," Fuel, 87, 844-856, 2008.

Briggs, J. L., D. E. Maier, B. A. Watkins, and K. C. Behnke, 1999, "Effects of Ingredients and Processing Parameters on Pellet Quality," Poultry Science, 78, 1464-1471, 1999.

Butler, J. L. and H. F. McColly, 1959, "Factors Affecting the Pelleting of Hay," Agricultural Engineering, 40, 442-446, 1959.

Carre, J., L. Hebert, L. Lacrosse, and Y. Schenkel, 1987, "Briquetting agricultural and wood residues: experience gained with a heated die cylindrical screw press," Paper presented at the First FAO/CNRE Workshop on Handling and Processing of Biomass for Energy, Hamburg, FRG, 14-15, 1987.

Cavalcanti, W. B., 2004, "The Effect of Ingredient Composition on the Physical Quality of Pelleted Feeds: a Mixture Experimental Approach,” Ph.D. Dissertation, Manhattan, KS: Kansas State University, 2004. 
Chen, C. R. and H. S. Ramaswamy, 2002, "Modeling and Optimization of Variable Retort Temperature (VRT) Thermal Processing using coupled Neural Networks and Genetic Algorithms," Journal of Food Engineering, 53(3), 209-220, 2002.

Chen, W., G. C. Lickfield, and C. Q. Yang, 2004, "Molecular Modeling of Cellulose in Amorphous State Part I: Model Building and Plastic Deformation Study,” Polymer, 45, 1063-1071, 2004.

Collado, L. S. and H. Corke, 2003, "Starch Properties and Functionalities" in G. Kaletunç and K.J. Breslauer (Eds.), Characterization of Cereals and Flours, New York, NY: Marcel Dekker, Inc., 473506, 2003.

Comoglu, T., 2007, “An Overview of Compaction Equations," Journal of Faculty of Pharmacy, Ankara, 36(2), 123-133, 2007.

Cooper, A. R. and L. E. Eaton, 1962, "Compaction Behavior of Several Ceramic Powders," Journal of the American Ceramic Society, 45(3), 97-101, 1962.

Datta, R., 1981,. "Energy requirement for lignocellulose pretreatment processes," Process Biochemistry, 16 (June/July), 16-19, 42, 1981.

Deb, S., 2000, Optimization for Engineering Design: Algorithms and Examples, New Delhi: Prentice-Hall of India Private Ltd.,2000.

DeLong, E. A., Canadian Patent 1096374, 1981.

Demirbas, A., A. Şahin-Demirbaş, and A. Hilal Demirbaş, 2004, "Briquetting Properties of Biomass Waste Materials," Energy Sources, 26, 83-91, 2004.

Denny, P. J., 2002, "Compaction Equations: A Comparison of the Heckel and Kawakita Equations," Powder Technology, 127, 162-172, 2002.

Dobie, J. B., 1959, “Engineering Appraisal of Hay Pelleting," Agricultural Engineering, 40(2), 76-77, 1959.

Ellis, R. P., M. P. Cochrane, M. F. B. Dale, C. M. Duffus, A. Lynn, I. M. Morrison, R. D. M. Prentice, J. S. Swanston, and S. A. Tiller, 1998, "Starch production and its use," Journal of the Science of Food and Agriculture, 77, 289-311, 1998. Faborode, M. O and J. R. O. Callaghan, 1987, "Optimizing the compression/briquetting of fibrous agricultural materials," Journal of Agricultural Engineering Research, 38, 245-262.

FAO, 1996, "Biomass briquetting: Technology and Practices. In Regional Wood Energy Development Program in Asia," Report prepared by P. D. Grover and S. K. Mishra, GCP/RAS/154/NET, f40_97.html, October 29, 2007.

Felfli, F. F., C.A. Luengo, and P.A. Beaton, 1998, "Bench Unit for Biomass Residues Torrefaction," in H. Kopetz, (Ed.), Biomass for Energy and Industry, Proceedings in International Conference, Wurzburg, Germany, 1593-1595, 1998.

Foody, P., 1980, "Optimization of Steam Explosion Pretreatment," Final Report to DOE, Contract AC02-79ET23050. 1 B80, 1980.

Frazier, P. H., A. Crawshaw, N. W. R. Daniels, and P. W. R. Eggitt, 1983, "Optimization of Process Variables in Extrusion Cooking of Soya," in R. Jowitt (Ed.), Extrusion Cooking Technology, London and New York: Elsevier Applied Science Publishers, 1-26, 1983.

Gen, M. and R. Cheng, 1997, Genetic Algorithms and Engineering Design, NY, USA: John Wiley and Sons, Inc., 1997.

Ghebre-Sellassie, I., 1989, "Mechanism of Pellet Formation and Growth," I. Ghebre-Sellassie (Ed.), Pharmaceutical Pelletization Technology, New York, NY: Marcel Dekker, Inc., 123-143, 1989. 
Ghorbani, Z., A. A. Masoumi, and A. Hemmat, 2010, "Specific energy consumption for reducing the size of alfalfa chops using a hammer mill," Biosystems Engineering, 105(1), 34-40.

Gibson, L., 2010, “Energy Tablets,” Biomass Power \& Thermal, http://biomassmagazine.com/articles/5086/energy-tablets, accessed December 21, 2010.

Giri, S. K. and S. Bandyopadhyay, 2000, "Effect of Extrusion Variables on Extrudate Characteristics of Fish Muscle-Rice Flour Blend in Single Screw Extruder," Journal of Food Processing and Preservation, 24, 177-190, 2000.

Goldberg, D. E., 2001, “Genetic Algorithms in Search, Optimization, and Machine Learning," Singapore: Pearson Education, 2001.

Goldstein, I. S., 1981, “Composition of Biomass,” in I. S. Goldstein (Ed.), Organic Chemicals from Biomass, Boca Raton, FL: CRC Press Inc., 9-18, 1981.

Granada, E., L. M. López González, J. L. Míguez, and J. Moran, 2002, "Fuel Lignocellulosic Briquettes, Die Design, and Products Study," Renewable Energy, 27, 561-573, 2002.

Gray, W. A., 1968, "Compaction after Deposition," in The Packing of Solid Particles, New York, NY: Barnes \& Noble, 89-107, 1968.

Grover, P. D. and S. K. Mishra, 1996, "Biomass Briquetting: Technology and Practices," Regional Wood Energy Development Programme in Asia, GCP/RAS/154/NET, Food and Agricultural Organization of the United Nations, Bangkok, 1996.

Hahn, B., 2004, Existing Guidelines and Quality Assurance for Fuel Pellets-Pellets for Europe Project. UMBERA, Umweltorientierte Betriebsberatungs-, Forschungs- und Entsorgungs-Gesellschaft m.b.H., Schießstattring 25/4, A-3100 St. Pölten, AUSTRIA (www: umbra.at), 2004.

Hakkou, M., M. Pétrissans, P. Gérargin, and A. Zoulalian, 2006, "Investigation of the Reasons for Fungal Durability of Heat-treated Beech Wood," Polymer Degradation and Stability, 91, 393-397, 2006.

Hall, D., O. F. Rosillo-Calle, and P. de Groot, 1992, "Biomass Energy: Lessons from Case Studies in Developing Countries," Energy Policy, 20, 62-73, 1992.

Hall, G. E. and C. W. Hall, 1968, "Heated-die Wafer Formation of Alfalfa and Bermudagrass," Transactions of the ASAE, 11, 578-581, 1968.

Harper, J. M., 1981, Extrusion of Foods, Boca Raton, Florida: CRC Press, 1 and 2, 203-212, 1981.

Heckel, R. W., 1961, “An Analysis of Powder Compaction Phenomena," Transactions of the Metallurgical Society of AIME, 221, 1001-1008, 1961.

Heffiner, L. E. and H. B. Pfost, 1973, “Gelatinization during Pelleting,” Feedstuff, 45(23), 33, 1973.

Hill, B. and D. A. Pulkinen, 1988, "A Study of Factors Affecting Pellet Durability and Pelleting Efficiency in the Production of Dehydrated Alfalfa Pellets. A special Report," Saskatchewan Dehydrators Association, Tisdale, SK, Canada, 25, 1988.

Holland, J. H., 1992, “Genetic Algorithms,” Scientific American, 66-72, July 1992.

Holm, J. K., U. B. Henriksen, J. E. Hustad, and L. H. Sorensen, 2006, “Toward an Understanding of Controlling Parameters in Softwood and Hardwood Pellet Production," Energy and Fuels, 20, 26862694, 2006.

Hon, D. N. S., 1989, "Cellulosic Adhesives," in R.W. Hemmingway and A.H. Conner (Eds.), Adhesives from Renewable Resources, Washington, DC: American Chemical Society, 289-304, 1989.

Hotelling, H., 1935, “The Most Predictable Criterion,” Journal of Educational Psychology, 26, 139-142, 1935. 
Hotelling, H., 1936, “Relations between Two Sets of Variates,” Biometrika, 28, 321-377, 1936.

Israelsen, M., J. Busk, and J. Jensen, 1981, "Pelleting Properties of Dairy Compounds with Molasses, Alkali-treated Straw and Other Byproducts," Feedstuffs, 7, 26-28, 1981.

Jannasch, R., Y. Quan, and R. Samson, 2001, “A process energy analysis of pelletizing switchgrass, Final report," http://www.reap-canada.com/online_library/feedstock_biomass/11\%20A\%20Process.pdf, accessed June 2010.

Johanson, J. R., 1965, “A Rolling Theory for Granular Solids,” Transactions of the ASME, Journal of Applied Mechanics (December 1965), 842-848, 1965.

Jones, W. D., 1960, Fundamental Principles of Powder Metallurgy, Edward Arnold Publishers Ltd., London, 242-370, 1960.

Kaar, W. E., C. V. Gutierrez, and C. M. Kinoshita, 1998, "Steam Explosion of Sugarcane Bagasse as a Pretreatment for Conversion to Ethanol," Biomass and Bioenergy, 14(3), 277-287, 1998.

Kaliyan, N. and R. Morey, 2006, "Densification Characteristics of Corn Stover and Switchgrass," Presented at the ASABE Annual International Meeting, July 9-12, 2006, Portland, OR, ASABE Paper No. 066174, ASAE, 2950 Niles Road, St. Joseph, MI 49085-9659, USA.

Kawakita, K. and K. H. Ludde, 1971, "Some Considerations on Powder Compression Equations," Powder Technology, 4, 61-68, 1971.

Khuri, A. Z. and J. A. Cornell, 1987, "Response Surface Designs and Analysis,” New York: Marcel Dekker, 149, 1987.

Koc, A. B., P. H. Heinemann, and G. R. Ziegler, 2007, "Optimization of Whole Milk Powder Processing Variables with Neural Networks and Genetic Algorithms," Food Bioproducts Process, 85(C4), 336343, 2007.

Kumar, R., N. Chandrashekar, and K. K. Pandey, 2009, Fuel Properties and Combustion Characteristics of Lantana Camara and Eupatorium Spp., Current Science, 97 (6), 930-935, 2009.

Lampart-Szczapa, E., P. Konieczny, M. Nogala-Kalucka, S. Walczak, I. Kossowska, and M. Malinowska, 2006, "Some Functional Properties of Lupin Proteins Modified by Lactic Fermentation and Extrusion," Food Chemistry, 96, 290-296, 2006.

Lehtikangas, P., 1999, “Quality Properties of Fuel Pellets from Forest Biomass," Licentiate Thesis, Department of Forest Management and Products, Report 4, Uppsala, 1999.

Li, J. F. and R. Q. Hu, 2003, "Sustainable Biomass Production for Energy in China," Biomass Bioenergy, 25, 483-499, 2003.

Li, Y. and H. Liu, 2000, "High Pressure Densification of Wood Residues to Form an Upgraded Fuel," Biomass and Bioenergy, 19, 177-186, 2000.

Liu, C. and C. E. Wyman, 2005, "Partial Flow of Compressed-Hot Water Through Corn Stover to Enhance Hemicellulose Sugar Recovery and Enzymatic Digestibility of Cellulose," Bioresource Technology, 96, 1978-1985, 2005.

MacBain, R., 1966, "Pelleting Animal Feed,” Arlington, VA: American Feed Manufactures Association, 1966.

MacMahon, M. J., 1984, “Additives for Physical Quality of Animal Feed,” in D. A. Beaven (Ed.), Manufacturing of Animal Feed, Herts, England: Turret- Wheatland Ltd., 69-70, 1984.

Mani, S. 2005. System analysis of biomass densification process. PhD thesis submitted to Department of Chemical and Biological Engineering, University of British Columbia, Vancouver, Canada. 
Mani, S., 2008, "Recent Development in Biomass Densification Technology," Annual Conference, Institute of Biological Engineering, Biological and Agricultural Engineering Department, University of Georgia, 2008.

Mani, S., L. G. Tabil, and S. Sokhansanj, 2002, "Compaction Characteristics of Some Biomass Grinds," AIC 2002 Meeting, CSAE/SCGR Program, Saskatoon, Saskatchewan, July 14-17, 2002.

Mani, S., L. G. Tabil, and S. Sokhansanj, 2004, "Evaluation of Compaction Equations Applied to Four Biomass Species," Canadian Biosystems Engineering, 46, 3.55-3.61, 2004.

Mani, S., L. G. Tabil, and S. Sokhansanj, 2006, "Specific Energy Requirement for Compacting Corn Stover," Bioresource Technology, 97, 1420-1426, 2006.

Mani, S., L.G. Tabil, and S. Sokhansanj, 2003, "An Overview of Compaction of Biomass Grinds," Powder Handling \& Processing, 15(3), 160-168, 2003.

Marchessault, R. H., 1961, "Carbohydrate Polymers: From Cellulose to DNA," Milton Harris 75th Birthday Symposium, Washington, D.C., April 27-26, 1961.

Marchessault, R. H., S. Coulombe, H. Morikawa, D. Robert, 1981a, Canadian Journal of Chemistry, 1082 (60), 2372, $1981 \mathrm{a}$.

Marchessault, R. H., S. Coulombe, T. Hanai, and H. Morikawa, 1981b, "Vinylic Monomers from Bioconversion of Wood," 181st National Meeting of the American Chemical Society, Atlanta, GA, 1981.

Mewes, E., 1959, "Berechung der druckverteilung an stroh-und heupressen (Calculation of the pressure distribution in straw and hay balers)," Landtechnische Forschung, 9(6), 160-170.

Miles, T. R. and T. R. Miles Jr., 1980, "Densification systems for agricultural residues," in Thermal conversion of solid wastes and biomass, American Chemical Society, Washington, DC, 179-191.

Mitchell, P., J. Kiel, B. Livingston, and G. Dupont-Roc, 2007, “Torrefied Biomass: A Foresighting Study into the Business Case for Pellets from Torrefied Biomass as a New Solid Fuel," All Energy, May 24, 2007.

Mohan, D., C. U. Pittman, and P. H. Steele, 2006, Pyrolysis of Wood/Biomass for Bio-oil: A Critical Review, Energy \& Fuels. 20, 848-889, 2006.

Mohsenin, N. and J. Zaske, 1975, "Stree relaxation and energy requirements in compaction of unconsolidated materials," Journal of Agricultural Engineering Research, 11, 193-205.

Montgomery, D. C., 1976, Design and Analysis of Experiments, New York: John Wiley, Edition 4, 1976.

Mort, P. R., 2009, "Scale-up and control of binder agglomeration process-flow and stress fields," Powder Technology, 189, 313-317.

Moshenin, N. and J. Zaske, 1976, "Stress Relaxation and Energy Requirements in Compaction of Unconsolidated Materials," Journal of Agricultural Engineering Research, 21, 193-205, 1976.

Mosier, N., R. Henderson, N. Ho, M. Sedlak, and M. R. Ladisch, 2005, "Optimization of pH Controlled Liquid Hot Water Pretreatment of Corn Stover," Bioresource Technology, 96, 1986-1993, 2005.

Mullen, K. and D. M. Ennis, 1979, "Rotatable Design in Product Development," Food Technology, 78, 1979.

Murphy, J. D. and K. McCarthy, 2005, "Ethanol Production from Energy Crops and Wastes for Use as a Transport Fuel in Ireland," Applied Energy, 82, 148-166, 2005.

Ndiema, C. K. W., P. N. Manga, and C. R. Ruttoh, 2002, "Influence of Die Pressure on Relaxation Characteristics of Briquetted Biomass," Energy Conversion and Management, 43, 2157-2161, 2002. 
Neale, M. A., 1986, "Straw compaction research,” Agricultural Engineer, 4(4), 126-130.

Nelson, D. L. and M. M. Cox, 2005, Lehninger Principles of Biochemistry, New York, NY: W. H. Freeman and Company, 2005.

Nie, N., D. H. Brent, and C. H. Hull, 1970, Statistical Package for Social Sciences, New York: McGraw-Hill, 1970.

Nunes, A. P. and J. Pourquie, 1996, "Steam Explosion Pretreatment and Enzymatic Hydrolysis of Eucalyptus Wood,” Bioresource Technology, 57, 107-110, 1996.

Nyanzi, F. A. and J. A. Maga, 1992, "Effect of Processing Temperature on Detergent-solubilized Protein in Extrusion-cooked Cornstarch/Soy Protein Subunit Blends," Journal of Agricultural and Food Chemistry, 40, 131-133, 1992.

O’Dogherty, M. J. and J. A. Wheeler, 1984, “Compression of Straw to High Densities in Closed Cylindrical Dies,” Journal of Agricultural Engineering Research, 29(29), 61-72, 1984.

Ollett, A. L., A. R. Kirby, R. Parker, and A. C. Smith, 1993, "A Comparative Study of the Effects of Water Content on the Compaction Behavior of Some Food Materials," Powder Technology, 75, 59$65,1993$.

Panelli, R. and F. A. Filho, 2001, “A Study of a New Phenomenological Compacting Equation," Powder Technology, 114, 255-261, 2001.

Pastorova, I., P. W. Arisz, and J. J. Boon, 1993, "Preservation of D-glucose Oligosaccharides in Cellulose Chars.," Carbohydrates Research, 248, 151-165, 1993.

Payne J. D., 1996, “Troubleshooting the Pelleting Process,” http://www.asasea.com/, accessed November 2009

Payne, J. D., 1978, “Improving Quality of Pellet Feeds,” Milling Feed and Fertilizer, 161, 34-41, 1978.

Peleg, M. and R. Moreyra, 1979, "Effect of Moisture on the Stress Relaxation Pattern of Compacted Powders," Powder Technology, 23, 277-279, 1979.

Peleg, M., 1977, "Flowability of Food Powders and Methods for its Evaluation-A Review," Journal of Food Process Engineering, 1, 303-328, 1977.

Peleg, M., and C. H. Mannheim, 1973, "Effect of Conditioners on the Flow Properties of Powdered Sucrose," Powder Technology, 7, 45-50, 1973.

Pfost, H. B. and L. R. Young, 1973, "Effect of Colloidal Binder and Other Factors on Pelleting," Feedstuffs, 45(49), 21-22, 1973.

Pietsch, W. B., 1984, "Size Enlargement Methods and Equipments-Part 2: Agglomerate Bonding and Strength," in M. E. Fayed and L. Otten (Eds.), Handbook of Powder Science and Technology, New York, USA: Van Nostrand Reinhold Co., 231-252, 1984.

Pietsch, W., 1991, Size Enlargement by Agglomeration, John Wiley \& Sons, New York, 1991.

Prins M. J., 2005, “Thermodynamic Analysis of Biomass Gasification and Torrefaction,” Ph.D. Thesis, Eindhoven Technical University, The Netherlands, 2005.

Purohit P., A. K. Tripathi, and T. C. Kandpal, 2006, "Energetics of Coal Substitution by Briquettes of Agricultural Residues," Energy, 31, 1321-1331, 2006.

Reece, F. N., 1966, "Temperature, Pressure, and Time Relationships in Forming Dense Hay Wafers," Transactions of the ASAE 9, 749-751, 1966. 
Reed, T. B. and Bryant, B., 1978, "Densified biomass: A new form of solid fuel," SERI-35, Solar Energy Research Institute, Golden, CO, 30, 1978.

Reed, T. B., G. Trezek, and L. Diaz, 1980, "Biomass densification energy requirements," iIn Thermal conversion of solid wastes and biomass, Washington DC: American chemical Society, 167-177, 1980.

Reynieix, M., et al., 1987, "Pelletization of Vegetable Charcoal Smalls," in G. Grassi, et al. (Eds.), Biomass for Energy and Industry, 4th E. C. Conference, New York, 1987.

Rhen, C., R. Gref, M. Sjöström, and I. Wästerlund, 2005, "Effects of Raw Material Moisture Content, Densification Pressure and Temperature on Some Properties of Norway Spruce Pellets," Fuel Processing Technology, 87(1), 11-16, 2005.

Richardson, W. and E. J. Day, 1976, "Effect of Varying Levels of Added Fat in Broiler Diets on Pellet Quality," Feedstuffs, 48, 24, 1976.

Robinson, R., 1984, "Pelleting," in D. A. Beaven (Ed.), Manufacturing of Animal Feed, 50-53, Herts, England: Turret-Wheatland Ltd., 1984.

Rout, R. K. (1997). Studies on extrusion cooking in relation to shrimp feed processing. Ph.D. Thesis, Indian Institute of Technology, Kharagpur, India.

Rout, R. K. and S. Bandyopadhyay, 1999, "A Comparative Study of Shrimp Feed Pellets Processed through Cooking Extruder and Meat Mincer," Aquaculture Engineering, 19, 71-79, 1999.

Rumpf, H., 1962, "The Strength of Granules and Agglomerates," in W. A. Knepper (Ed.), Agglomeration, New York, USA: Interscience Publishers, 379-418, 1962.

Sacchetti, G., G. G. Pinnavaia, E. Guidolin, and M. Dalla Rosa, 2004, "Effects of Extrusion Temperature and Feed Composition on the Functional, Physical and Sensory Properties of Chestnut and Rice Flour-based Snack-like Products," Food Research International, 37, 527-534, 2004.

Sadaka, S. and S. Negi, 2009, "Improvements of Biomass Physical and Thermochemical Characteristics via Torrefaction Process," Environmental Progress \& Sustainable Energy, 28(3), 427-434, 2009.

Sastry, K. V. S. and D. W. Fuerstenau, 1973, Mechanisms of Agglomerate Growth in green Pellitization, Powder Technology, 7, 97-105, 1973.

Satyanarayana N., Y. Tao, C. Glaser, G. Hans-J€org and P. Ay. 2010. Increasing the Calorific Value of Rye Straw Pellets with Biogenous and Fossil Fuel Additives. Energy Fuels, 24, 5228-5234 (2010).

Schaich, K. M. and C. A. Rebello, 1999, "Extrusion of Wheat Flour Proteins: I. Free Radical Formation,” Cereal Chemistry, 76(5), 748-755, 1999.

Schell, D. J. and C. Harwood, 1994, "Milling of lignocellulosic biomass: results of pilot-scale testing," Applied Biochemistry and Biotechnology, 45/46, 159-68.

Schineberger, G. L., 1971, Understanding Adhesives, Hitchcock Publishing Co., Wheaton, Il, USA, 3.6$3.7,1971$.

Shafizedeh, F., 1985, "Pyrolytic Reactions and Products of Biomass," in R. P. Overend, T. A. Milne, and L. K. Mudge (Eds.), Fundamentals of Biomass Thermochemical Conversion, London: Elsevier, 183$217,1985$.

Shambe T. and J. F. Kennedy, 1985, "Acid and Enzymatic Hydrolysis of Chaotropically Pretreated Millet Stalk, Acha and Rice Straws, and Conversion of the Products to ethanol," Enzyme and Microbial Technology, 7, 115-120, 1985.

Shankar, T. J and S. Bandyopadhyay, 2004, "Optimization of Extrusion Process Variables using a Genetic Algorithm," Food and Bioproducts Processing, 82(C2), 143-150, 2004. 
Shankar, T. J. and S. Bandyopadhyay, 2005, "Process Variables during Single Screw Extrusion of Fish and Rice Flour Blends," Journal of Food Processing and Preservation, 29, 151-164, 2005.

Shankar, T. J. and S. Bandyopadhyay, 2006, "Scanning Electron Microscope Study of Fish and Rice Flour Coextrudates," in A. Mendez-Vilas (Ed.), Proceedings of modern multidisciplinary applied microbiology, Exploiting microbes and their interactions, Wiley-VCH, 791-795, 2006.

Shankar, T. J. and S. Bandyopadhyay, 2007, "Prediction of Extrudates Properties using Artificial Neural Networks," Food and Bioproducts Processing, 85(1), 29-33, 2007.

Shankar, T. J., S. Sokhansanj, S. Bandyopadhyay, and A. S. Bawa, 2008a, “A Case Study on Optimization of Biomass Flow During Single Screw Extrusion Cooking Using Genetic Algorithm (GA) and Response Surface Method (RSM)," Food and Bioprocess Technology, (In press), 2008.

Shankar, T. J., X. Kuang, S. Sokhansanj, J. Lim, Tony Bi, and S. Melin, 2008b, "Effect of Storage Temperature on Off-gassing and Physical Properties of Wood Pellets," An ASABE Meeting Presentation, Paper Number: 084248, Providence, Rhode Island, June 29-July 2, 2008.

Shaw, M., 2008, "Feedstock and Process Variables Influencing Biomass Densification," Ph.D. thesis submitted to Department of Agricultural and Bioresource Engineering, University of Saskatchewan, Saskatoon, Saskatchewan, Canada, 2008.

Shepperson, G. and W. T. B. Marchant, 1978, "Production of grass and alfalfa cubes using experimental ring die press," Proceedings $2^{\text {nd }}$ International Green Crop Drying Conference, Saskatoon, SK, pp. 264-270.

Sherrington, P. J. and R. Oliver, 1981, "Fundamentals of Particle Size Enlargement by Granulation,” in Granulation, London, England: Heyden and Sons Ltd., 7-54, 1981.

Shivanand, P. and O. L. Sprockel, 1992, “Compaction Behavior of Cellulose Polymers," Powder Technology, 69, 177-184, 1992.

Shrivastava, M. et al., 1990, "Briquetting of Rice Husks Under Hot Compression," Proceedings of the International Agricultural Engineering Conference and Exhibition, Bangkok, Thailand, 666-672, 1990.

Siemons, R. V., Dr. Ahmed, and H. Hood, 1989, “Cotton Stalk Charcoal Agglomeration in the Sudan," Boiling Point, Issue SE 1989, http://www.hedon.info, accessed April, 2010.

Singh, N., J. Singh, and N. S. Sodhi, 2002, "Morphological, Thermal, Rheological, and Noodle-Making Properties of Potato and Corn Starch," Journal of the Science of Food and Agriculture, 82, 13761383, 2002.

Smith, I. E., S. D. Probert, R. E. Stokes, and R. J. Hansford, 1977, “The Briquetting of Wheat Straw," Journal of Agricultural Engineering Research, 22, 105-111, 1977.

Smith, William, 1880, U.S. Patent No. 233,887, November 2, 1880.

Snow, R. H., et al., "Size Reduction and Size Enlargement," in D. W. Green, et al. (Ed.), Perry's Chemical Engineers Handbook, 6th Ed., Singapore, 1984.

Sokhansanj, S., S. Mani, X. Bi, P. Zaini, and L. Tabil, 2005, "Binderless Pelletization of Biomass," Presented at the ASAE Annual International Meeting, Tampa, FL, ASAE Paper No. 056061. ASAE, 2950 Niles Road, St. Joseph, MI 49085-9659 USA, July 17-20, 2005.

Solo, M. L., 1965, "Mattalorest,” Aikakawsh, 37, 127, 1965.

Sonnergaard, J. M., 2001, "Investigation of a New Mathematical Model for Compression of Pharmaceutical Powders,” European Journal of Pharmaceutical Sciences, 14, 149-157, 2001. 
Stark, C. R., 1994, "I. Pellet Quality and Its Effect on Swine Performance. II. Functional Characteristics of Ingredients in the Formation of Quality Pellets," Ph.D. dissertation, Manhattan, KS: Kansas State University, 1994.

Stevens, C. A., 1987, "Starch Gelatinization and the Influence of Particle Size, Steam Pressure and Die Speed on the Pelleting Process," Ph.D. dissertation, Manhattan, KS: Kansas State University, 1987.

Tabil, Jr., L. G., 1996, "Binding and Pelleting Characteristics of Alfalfa," Unpublished Ph.D. Thesis, Saskatoon, Saskatchewan: Department of Agricultural and Bioresource Engineering, University of Saskatchewan, 1996.

Tabil, L. G. and S. Sokhansanj, 1996, "Process Conditions Affecting the Physical Quality of Alfalfa Pellets," American Society of Agricultural Engineers, 12(3), 345-350, 1996.

Tabil, L. G. and S. Sokhansanj, 1996a, "Compression and Compaction Behavior of Alfalfa Grind: Part 2: Compaction Behavior,” Powder Handling \& Processing, 8(2), 1996.

Tabil, L. G. and S. Sokhansanj, 1996b, "Compression and Compaction Behavior of Alfalfa Grinds: Part 1: Compression Behavior," Powder Handling \& Processing, 8(1), 17-23, January/March 1996.

Tabil, L. G., S. Sokhansanj, and R. T. Tyler, 1997, "Performance of Different Binders during Alfalfa Pelleting," Canadian Agricultural Engineering, 39(1), 17-23, 1997.

Technical Specification DS DS/CEN/TS 14588, 2004, "Solid Biofuels-Terminology, Definitions and Descriptions," April 23, 2004.

Technical Specifications SIS-CEN/TS 14961, 2005, "Solid Biofuels-Fuel Specifications and Classes," 2005.

Thomas, M., D. J. van Zuilichem, and A. F. B. van der Poel, 1997, "Quality of Pelleted Animal Feed 2. Contribution of Processes and its Conditions," Animal Feed Science Technology, 64, 173-192, 1997.

Thomas, M., P. T. H. J. Huijnen, T. van Vliet, D. J. van Zuilichem, and A. F. B. van der Poel, 1999, "Effects of Process Conditions during Expander Processing and Pelleting on Starch Modification and Pellet Quality of Tapioca," Journal of the Science of Food and Agriculture, 79, 1481-1494, 1999.

Thomas, M., T van Vliet, and A. F. B. van der Poel, 1998, "Physical Quality of Pelleted animal Feed 3. Contribution of Feedstuff Components," Animal Feed Science Technology, 70, 59-78, 1998.

Toussaint, B., G. Excoffier, and M. R. Vignon, 1991, "Effect of Steam Explosion Treatment on the Physico-Chemical Characteristics and Enzymic Hydrolysis of Poplar Cell Wall Components," Animal Feed Science and Technology, 32, 235-242, 1991.

Tumuluru, J. S., C. T. Wright, K. L. Kevin, and J. R. Hess. 2011. "A review on biomass densification technologies to develop uniform feedstock commodities for bioenergy application," BioFPR (Under review), 2011.

Tumuluru, J. S., L. Tabil, A. Opoku, M. R. Mosqueda, and O. Fadeyi, 2010a, "Effect of Process Variables on the Quality Characteristics of Pelleted Wheat Distiller's Dried Grains with Soluble," Biosystems Engineering, 105(4), 466-475, 2010.

Tumuluru, J. S., S. Sokhansanj, C. J. Lim, X. Bi, L. Anthony, M. Staffan, T. Sowlati, and O. Ehsan, 2010b, "Quality of Wood Pellets Produced in British Columbia," Applied Engineering in Agriculture 26(6): 1013-1020, 2010.

Tumuluru, J. S., S. Sokhansanj, L. Tabil, M. Kashaninejad, and S. Bandyopadhyay, 2010c, "Effect of Extrusion Process Conditions on the Quality Attributes of Multi-Component Biomass Pellets," Food and Bioprocess Technology (Under review), 2010. 
United States Department of Energy, 2006, "Energy Efficiency and Renewable Energy- Biomass Program,” http://www1.eere.energy.gov/biomass, January 24, 2006.

Uslu, A., P. C. Andrè, A. B. Faaij, and P. C. A. Bergman, 2008, "Pre-Treatment Technologies, and Their Effect on International Bioenergy Supply Chain Logistics. Techno-Economic Evaluation of Torrefaction, Fast Pyrolysis, and Pelletization," Energy, 33, 1206-1223, 2008.

van Dam, J. E. G., M. J. A. van den Oever, W. Teunissen, E. R. P. Keijsers, and A. G. Peralta, 2004, "Process for Production of High Density/High Performance Binderless Boards from Whole Coconut Husk-Part 1: Lignin as Intrinsic Thermosetting Binder Resin," Industrial Crops and Products, 19(3), 207-216, 2004.

Van Soest, P. J., 1964, "Symposium on Nutrition and Forage and Pastures: New Chemical Procedures for Evaluating Forages," Journal of Animal Science, 23, 838-845, 1964.

Von Bargen, K., M. Lamb, D.E. Neels, 1981, "Energy requirements for particle size reduction of crop residue," American Society of Agricultural Engineers, Paper no. 81-4062. St. Joseph, MI, USA.

Walker, E. E., 1923, "The Properties of Powders-Part VI: The Compressibility of Powders," Transactions of the Faraday Society, 19, 73-82, 1923.

Wamukonya L. and B. Jenkins, 1995, "Durability and Relaxation of Sawdust and Wheat-Straw Briquettes as Possible Fuels for Kenya," Biomass and Bioenergy, 8(3), 175-179, 1995.

WEC, 1994, "Biomass Energy," Chapter 5 in New Renewable Energy Resources-A Guide to the Future, London, UK: World Energy Council, 1994.

Werther J., M. Saenger, E. U. Hartge, T. Ogada, and Z. Siagi, 2000, "Combustion of Agricultural Residues," Progress in Engineering and Combustion Science, 26, 1-27, 2000.

Williams, P. T. and S. Besler, 1996, "The Influence of Temperature and Heating Rate on the Slow Pyrolysis of Biomass," Renewable Energy, 7, 233-250, 1996.

Winowiski T., 1988, “Wheat and Pellet Quality,” Feed Management, 39, 58-64, 1988.

Winter, E., 1981, "Fundamental considerations for preparing densified refuse-derived fuel," United States Environmental Protection Agency, Municipal Environmental Research Laboratory, Cincinnati OH, EPA-600/S2-81-180, Oct, 1981.

Wood, J. F., 1987, "The Functional Properties of Feed Raw Materials and the Effect on the Production and Quality of Feed Pellets," Animal Feed Science and Technology, 18, 1-17, 1987.

Wooten, J. B., B. Crosby, and M. R. Hajaligol, 2000, "Evaluation of Cellulose Char Structure Monitored by 13C CPMAS NMR," Fuel Chemistry Division, Preprints, 46, 191-193, 2000.

Yaman, S., M. Şahan, H. Haykiri-açma, K. Şeşen, and S. Küçükbayrak, 2000, "Production of Fuel Briquettes from Olive Refuse and Paper Mill Waste," Fuel Processing Technology, 68, 23-31, 2000.

Yehia, K. A., 2007, "Estimation of Roll Press Design Parameters Based on the Assessment of a Particular Nip Region," Powder Technology, 177, 148-153, 2007.

York, P. and N. Pilpel, 1972, "The Effect of Temperature on the Mechanical Properties of Some Pharmacuticals Powders in Relation to Tableting," Journal of Pharmacy and Pharmacology, 24, 47P-56P, 1972.

York, P. and N. Pilpel, 1973, "The Tensile Strength and Compression Behavior of Lactose, Four Fatty Acids and Their Mixture in Relation to Tableting," Journal of Pharmacy and Pharmacology, 25, $1-11,1973$. 
Zandersons, J., J. Gravitis, A. Zhurinsh, A. Kokorevics, U. Kallavus, and C. K. Suzuki, 2004, "Carbon Materials Obtained from Self-Binding Sugar Cane Bagasse and Deciduous Wood Residues Plastics," Biomass and Bioenergy, 26, 345-360, 2004.

Zanzi, R., D. T. Ferro, A. Torres, P. B. Soler, and E. Bjornbom, 2002, "Biomass Torrefaction," in the 6th Asia-Pacific International Symposium on Combustion and Energy Utilization, Kuala Lumpur, May 20-22, 2002.

Zeng, X. Y., Y. T. Ma, and L. R. Ma, 2007, "Utilization of Straw in Biomass Energy in China," Renewable and Sustainable Energy Revisions, 11, 976-987, 2007. 
Appendix A

\section{Biomass Densification Companies}




\section{Appendix A}

\section{Biomass Densification, Torrefaction, and Pyrolysis Companies}

\section{A-1. Densification Companies}

\section{Pellet Mill}

CPM Roskamp

1746 Canvasback Drive

Johnstown, CO 80534 U.S.A.

Office: +1 (720) 227-9338

Fax: +1 (720) 227-9351

Cell: +1 (720) 530-1058

Website: www.cpmroskamp.com

CPM - California Pellet Mills (Pellet Mills/Coolers/Crumblers)

CPM - Roskamp/Champion (Roller Mills/Flakers/Hammermills)

CPM - Beta-Raven (Automation)

Model: CL3 lab mill

Capacity: 20-25 lbs/hr

Data logging system: Available (Touch screen PLC that can store data)

Material that can be processed: Biomass and other waste

NOTE: Pellet mills available in commercial-scale production capacities.

Colorado Mill Equipment, LLC

1675 Fry Avenue

Colorado Springs, CO 81212 U.S.A.

Phone: +1 (719) 275-1081

Fax: +1 (866) 759-5894

E-mail: marcel@,coloradomillequipment.com

Website: www.coloradomillequipment.com

Model: ECO-3 pellet mill

Capacity: $15-50 \mathrm{lb} / \mathrm{hr}$

HP of motor: 3

Available die sizes: 3,4 , and 6 millimeters

Die diameter: 4 inch

Type of pellet mill: Flat die design

RPM: 450 (we can add VFD to change rpm)

Max particle size: $6 \mathrm{~mm}$

Material that can be processed: Biomass and other waste

Model: ECO-10 pellet mill

Capacity: $30-150 \mathrm{lb} / \mathrm{hr}$

HP of motor: 10

Available die sizes: 3, 4, 6, and 8 millimeters

Die diameter: 8 in. 
Type of pellet mill: Flat die design

RPM: 450

Max particle size: $8 \mathrm{~mm}$

Material that can be processed: Biomass and other waste

Model: ECO-R30 pellet mill

Capacity: $500-3500 \mathrm{lb} / \mathrm{hr}$

Die inner diameter: 10 in.

Die sizes: $1 / 16$ inch to $1 / 2$ in.

Discharge height: $30 \mathrm{in.}$

Type of pellet mill: Ring die design

Material that can be processed: Biomass and other waste

NOTE: Pellet mills are available with commercial-scale production capacities.

\section{Pellet Pros, Inc.}

4004 W. Kimberly Rd., Ste. C

Davenport, IA 52806 U.S.A.

Phone: +1 (563) 386-4300 or +1 (877) 386-4350

Fax: +1 (563) 386-4303

Website: http://www.pelletpros.com/index.html

Model: Pellet Pros Model PP65-Laboratory Mill

Capacity: 45-65 lbs/hour

Motor HP: 4

Model: Pellet Pros Model PP220

Capacity: 110-220 lbs/hour

Motor HP: 5

Model: Pellet Pros Model PP600A

Capacity: 350-600 lbs/hour

Motor HP: 10

Model: Pellet Pros Model PP600W

Capacity: 100-200 lbs/hour

Motor HP: 10

\section{Bliss Industries, Inc.}

P.O. Box 910

Ponca City, OK 74602 U.S.A.

Phone: +1 (580) 765-7787

Fax: +1 (580) 762-0111

E-mail: sales@bliss-industries.com

Website: www.bliss-industries.com

Product details: http://www.bliss-industries.com/pdfs/peltmill.pdf

Model: B-200B-280

Capacity: 5 ton/hr

Material that can be processed: Biomass, animal, and other waste.

NOTE: Available in different production capacities. 


\title{
Briquette Press
}

\section{Stiles Machinery, Inc.}

\author{
$396544^{\text {th }}$ St. SE
}

Grand Rapids, MI 49512 U.S.A.

Phone: +1 (616) 698-7500 ext. \#1299

Cell: +1 (616) 299-4973

Fax: +1 (616) 698-9411

E-mail: info@stilesmachinery.com

Website: www.stilesmachinery.com

Model No: BP-6000

Capacity: 2 tons/hr

Diameter of Briquettes: $90 \mathrm{~mm}$

Touch screen control panel features include:

- IP address - Ethernet or WiFi

- Data logging of operational data - motors, temperatures, etc.

- Alarm logging

- Maintenance system/manual

- Text message to be send to external operator

- External monitoring

- Possibility to hook up Web-cam

- Up to 16 languages.

\section{K. R. Komarek, Inc.}

\section{Clayton Court}

Wood Dale, IL 60191-1115 U.S.A.

Phone: +1 (847) 956-0060 ext. \#24

Fax: +1 (847) 956-0157

Website: http://www.komarek.com/

Model No: B400B

Capacity: $3-10$ ton $/ \mathrm{hr}$

Diameter of Briquettes: $90 \mathrm{~mm}$

Features include:

- Cantilevered roll design for easy roll replacement

- Horizontal feed design provides more versatile and precise feed into the rolls

- Pockets are available in different shapes and sizes

- Vacuum de-aeration available for fine powder applications

- Variable speed roll and screw feeder drives to maximize product quality

- Rolls and feed screws are available in wear- and corrosion-resistant alloys

- Rugged industrial frame construction

- Heavy-duty, long-lasting bearings and drive components

- Designed for ease of maintenance. 


Model B400B General Specifications
\begin{tabular}{|l|l|l|}
\hline Roll Diameter & $18 \mathrm{in}$. & $460 \mathrm{~mm}$ \\
\hline Roll Width & $6 \mathrm{in}$. & $150 \mathrm{~mm}$ \\
\hline Roll Separating Force & $120 \mathrm{ton}$ & $1067 \mathrm{kN}$ \\
\hline Roll Drive (typical) & $100 \mathrm{hp}$ & $75 \mathrm{~kW}$ \\
\hline Feeder Drive (typical) & $15 \mathrm{hp}$ & $11 \mathrm{~kW}$ \\
\hline Throughput Range & $3-10 \mathrm{tph}$ & $3-9 \mathrm{mtph}$ \\
\hline Machine Weight (typical) & $26,000 \mathrm{lb}$ & $12,000 \mathrm{~kg}$ \\
\hline
\end{tabular}

NOTE: The Model B400B is a rugged machine designed specifically for briquetting operations requiring high pressures combined with ease of roll change. Typical applications include inorganic chemicals such as quick lime $(\mathrm{CaO})$ and metal powders.

\section{Sunomi, LLC}

2279 Limehurst Dr. NE

Atlanta, GA 30319, U.S.A.

Phone: +1 (404) 467-8800

Website: http://www.sunomi-llc.com

Model No: BRIK MB 110

Capacity: $1.4-2.5$ ton/hr

Diameter of Briquettes: $110 \mathrm{~mm}$

Length of Briquette: $20-300 \mathrm{~mm}$

Main Motor power: $90 \mathrm{~kW}$

Approximate weight of machine: 8.2 ton

Applications include: compress wood, agricultural, and industrial waste material, as well as community garbage, and transform into fuel, which can then be used for both domestic and industrial purposes.

\section{Roller Press}

\section{K.R. Komarek, Inc.}

548 Clayton Ct.

Wood Dale, IL 60191 U.S.A.

Phone: +1 (847) 956-0060

Fax: +1 (847) 956-0157

Email: info@komarek.com

Website: http://www.komarek.com/

\section{K.R. Komarek Briquetting Research, Inc.}

20 Wm. F. Andrews Dr.

Anniston, AL 36207 U.S.A.

Phone: +1 (256) 831-5741

Fax: +1 (256) 831-1331

Email: info@komarek.com

Website: http://www.komarek.com/

Features:

- Separation of the process zone from the mechanical area of the equipment. 
- Product contact assemblies are all stainless steel and easily removable for quick setup changes, cleaning, and sterilization.

- Integrated mixing system allows small batch preparation followed by direct loading into the screw feeder.

- Continuous display of all important process parameters with output to data acquisition system.

- Multiple roll configurations available for briquetting or compacting applications.

\section{Bepex International LLC}

MS Series Roll Compactors

333 N.E. Taft Street

Minneapolis, MN 55413 U.S.A.

Phone: +1 (612) 331-4370

Fax: +1 (612) 627-1444

Website: http://www.bepex.com/companyinfo.htm

The Fitzpatrick Company

832 Industrial Drive

Elmhurst, IL 60126 U.S.A.

Phone: +1 (630) 433-3115 or +1 (630) 530-3333

Cell: +1 (708) 822-5709

Fax: +1 (630) 530-0832 


\title{
A-2. FOOD, FEED, AND BIOMASS EXTRUDERS
}

\author{
American LEISTRITZ Extruder Corp. USA \\ 169 Meister Avenue \\ Somerville, NJ 08876 U.S.A. \\ Phone: +1 (908) 685-2333 \\ Fax: +1 (908) 685-0247 \\ E-Mail: sales@alec-usa.com \\ Website: http://www.leistritz.com/extrusion/en/index.html \\ American Kuhne \\ 401 Main Street \\ Ashaway, RI 02804 U.S.A. \\ Phone: +1 (401) 326-6200 \\ Fax: +1 (401) 326-6201 \\ Email: sales@americankuhne.com/ \\ Website: http://www.americankuhne.com/index.html \\ Anderson International \\ 6200 Harvard Avenue \\ Cleveland, OH 44105-4896 U.S.A. \\ Phone: +1 (216) 641-1112 \\ Fax: +1 (216) 641-0709 \\ Website: http://www.andersonintl.net/Default.htm
}

B\&P Process Systems

1000 Hess Avenue

Saginaw, MI 48601 U.S.A.

Phone: +1 (989) 757-1300

Fax: +1 (989) 757-1301

Email: sales@bpprocess.com/

Website: http://www.bpprocess.com/

Bepex International LLC

333 N.E. Taft Street

Minneapolis, MN 55413, U.S.A.

Phone: +1 (612) 331-4370

Fax: +1 (612) 627-1444

Website: http://www.bepex.com/companyinfo.htm

C.W. Brabender Instruments, Inc.

50 East Wesley Street

P.O. Box 2127

South Hackensack, NJ 07606 U.S.A.

Phone: +1 (201) 343-8425

Fax: +1 (201) 343-0608

E mail: cwbi@cwbrabender.com; foodsales@cwbrabender.com

Website: http://www.cwbrabender.com/ 


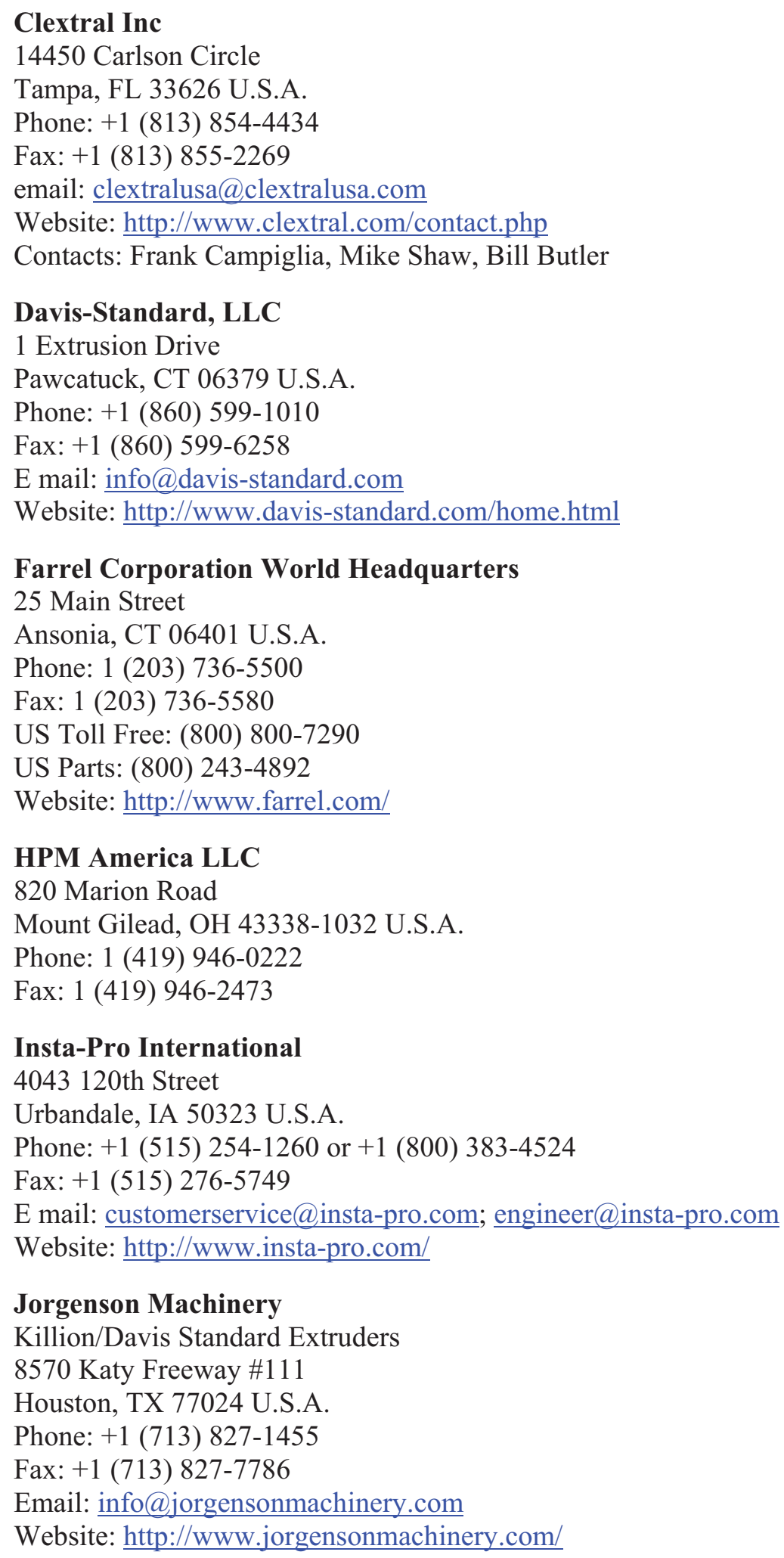




\author{
KraussMaffei Corporation, Division Berstorff \\ 7095 Industrial Road \\ Florence, KY 41022-6270 U.S.A. \\ Phone: +1 (859) 283-0200 \\ Fax: +1 (859) 283-1860 \\ E mail: info@Berstorff.com \\ Website: http://www.berstorff.com/
}

\title{
New Castle Industries
}

1399 Countyline Rd

New Castle, PA 16107 U.S.A.

Phone: 724-656-5600 ext. \#800-8

Fax: 724-656-5620

Sterling Extruders

2900 S. 160th Street

New Berlin, WI 53151 U.S.A.

Phone: +1 (262) 641-8610

Fax: +1 (262) 641-8653

Website: http://www.sterlco.com/

\section{Welex Incorporated}

1600 Union Meeting Road

Blue Bell, PA 19422 U.S.A.

Phone: +1 (215) 542-8000 or +1 (215) 542-8014

Fax: +1 (215) 542-9841

E mail:welex@welex.com

Website: http://www.welex.com/

\section{Wenger Plant and Corporate Offices}

714 Main Street

Sabetha, KS 66534-0130 U.S.A.

Phone: +1 (785) 284-2133

Fax: +1 (785) 284-3771

Website: http://www.wenger.com/contact-us.php

New Air Technical Services, Ltd.

Winchester Avenue

Blaby Industrial Park

Blaby, Leicester, LE8 4GZ, England

Phone: +44 (0) 116-277-8080

E mail: new-air@shimada.co.uk

Website: http://www.shimada.co.uk/

Single Screw Extruder

Type of machine: Laboratory single screw extruder (Shimada Extrusion Press)

Capacity: $30-40 \mathrm{~kg} / \mathrm{hr}$

Die sizes available: $4,6,8,10$, and 12

NOTE: Extruders are available with commercial-scale production capacities. 


\section{BIOMASS HEAT TREATMENT COMPANIES}

\section{Torrefaction}

\section{Agri-Tech Producers, LLC}

116 Wildewood Club Ct.

Columbia, SC 29223 U.S.A.

Phone: +1 (803) 462-0153

Fax: +1 (803) 462-9676

Website: http://www.agri-techproducers.com/

\section{Earth Care Products, Inc.}

P.O. Box 787, 800 N. 21 st Street

Independence, KS 67301 U.S.A.

Phone: +1 (620) 331-0090

Fax: +1 (620) 331-0095

Info: http://www.ecpisystems.com/wcms/index.php?Torrefaction

E-mail: ecpi@ecpisystems.com

Website: www.ecpisystems.com

\section{EcoTechnologies Group, LLC}

1125 Lancaster Avenue

Berwyn, PA 19312 U.S.A.

Phone: +1 (877) ECO-1909

Fax: +1 (610) 993-9938

E-mail: Info@EcoTechnologies.com

Website: http://www.ecotechnologies.com/technologies.html

\section{Integro Earth Fuels, LLC}

204 Charlotte Highway, Suite E

Asheville, NC 28803 U.S.A.

Phone: +1 (828) 651-8988

E-mail: wchilds@integrofuels.com

Website: http://www.integrofuels.com/

New Earth Renewable Energy Inc.

146 N. Canal Street

Seattle, WA 98103 U.S.A.

Phone: +1 (206) 310-1205

Fax: +1 (206) 577-3874

E-mail: info@newearth1.net

Website: http://www.newearth1.net/about.html

\section{Sea 2 Sky Corporation}

2287 Slater Road

Ferndale, WA 98227 U.S.A.

Phone: +1 (877) 732-2759

Info: info@sea2skyenergy.com

E-mail: ir@sea2skyenergy.com

Website: http://www.ecotechenergygroup.com/ 
Terradyne Energy Systems, Inc.

3732 SW 30th Ave.

Hollywood, FL, 33312, U.S.A.

Phone: +1 (506) 863-7135

Website: http://www.terradyneenergy.com/

Terra Green Energy, LLC

100 Four Falls Corporate Center, Suite 215

W. Conchohocken, PA 19428-2960 U.S.A.

Phone: +1 (610) 940-4420

Website: http://www.terragreenenergy.com/

Wyssmont

1470 Bergen Blvd.

Fort Lee, NJ 07024 U.S.A.

Phone: +1 (201) 947-4600

Fax: +1 (201) 947-0324

Info: http://www.wyssmont.com/lib/images/pdf/torrefaction-newsletter.pdf

E-mail: sales@wyssmont.com

Website: http://www.wyssmont.com/home.php

\section{Biochar and Pyrolysis}

\section{Biochar Engineering}

701 Pine Ridge Rd \#3

Golden, CO 80403 U.S.A.

Phone +1 (303) 279-3776

Fax: +1 (303) 279-3734

Website: http://www.biocharengineering.com/technology/index.html

\section{BioChar Products}

P.O. Box 811

38371 Sawmill Cutoff Lane

Halfway, OR 97834 U.S.A.

E-mail: eric@biocharproducts.com

Website: http://www.biocharproducts.com/

\section{Biochar Systems, LLC}

1125 Lancaster Avenue

Berwyn, PA 19312 U.S.A.

Phone: +1 (877) 326-1909

Website: http://www.biocharsystems.com/biochar/index.html

\section{Carbon Char Group}

865 Amwell Road

Hillsborough, NJ 08844-3902 U.S.A.

Phone: +1 (828) 254-7418

E-mail: sales@carbonchar.com

Website: http://www.carbonchar.com/ 


\author{
Genesis Industries \\ 212 Yacht Club Way A-12 \\ Redondo Beach, CA 90277 U.S.A. \\ Phone: +1 (310) 399-9775 \\ Fax: +1 (310) 697-3032 \\ E-mail: info@eGenIndustries.com \\ Website: http://www.egenindustries.com/technology.php \\ International Biochar Initiative \\ Thayer Tomlinson, Communications Director \\ 640 Brook Run Dr. \\ Westerville, $\mathrm{OH} 43081$ U.S.A. \\ Office Phone: +1 (914) 693-0496 \\ Mobile Phone. +1 (202)-247-5251 \\ E-mail: info@biochar-international.org \\ Website: http://www.biochar-international.org/ \\ Mantria Industries \\ 555 City Avenue, Suite 430 \\ Bala Cynwyd, PA 19004 U.S.A. \\ Phone: +1 (484) 483-1010 \\ Website: http://www.eternagreen.com/home

\section{R \& A Energy Solutions, LLC} \\ 3273 Fallhaven Circle \\ N. Ridgville, $\mathrm{OH} 44039$ U.S.A. \\ Phone: +1 (440) 3772387 \\ Website: http://randaenergysolutions.com/ \\ Vega Biofuels, Inc. \\ P.O. Box 922395 \\ Norcross, GA 30010 U.S.A. \\ Phone: +1 (800) 481-0186 \\ Fax: +1 (866) 421-1216 \\ Website: http://vegabiofuels.com/
}

